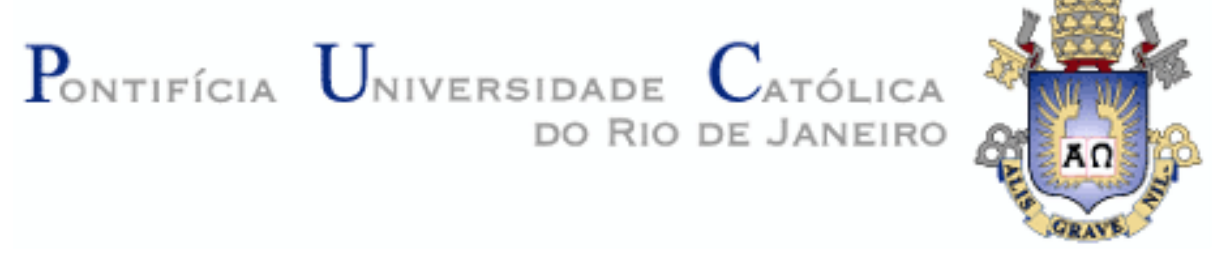

Antonyony Carlos Jordão Heitor

\title{
Estudo de um Sistema de Vigamento de Piso tipo "Stub-Girder" Modificado
}

\section{Dissertação de Mestrado}

Dissertação apresentada como requisito parcial para obtenção do grau de Mestre pelo Programa de PósGraduação em Engenharia Civil do Departamento de Engenharia Civil da PUC-Rio.

Orientador: Prof. Sebastião Arthur Lopes de Andrade 
Antonyony Carlos Jordão Heitor

\section{Estudo de um Sistema de Vigamento de Piso tipo "Stub-Girder" Modificado}

Dissertação apresentada como requisito parcial para obtenção do grau de Mestre pelo Programa de PósGraduação em Engenharia Civil do Departamento de Engenharia Civil da PUC-Rio do Centro Técnico Científico da PUC-Rio. Aprovada pela Comissão Examinadora abaixo assinada.

Prof. Sebastião Arthur Lopes de Andrade Orientador

Departamento de Engenharia Civil - PUC-Rio

Prof. Ney Augusto Dumont Departamento de Engenharia Civil - PUC-Rio

Prof. Luciano Rodrigues Ornelas de Lima Departamento de Engenharia Civil - UERJ

Prof. Márcio da Silveira Carvalho Coordenador Setorial do Centro Técnico Científico - PUC-Rio 
Todos os direitos reservados. É proibida a reprodução total ou parcial do trabalho sem autorização da universidade, do autor e do orientador.

\section{Antonyony Carlos Jordão Heitor}

Graduou-se em Engenharia Civil na Pontifícia Universidade Católica do Rio de Janeiro em 2014. Na PUC-Rio, desenvolveu pesquisas na área de estruturas, atuando na linha de estruturas metálicas e mistas.

Ficha Catalográfica

Heitor, Antonyony Carlos Jordão

Estudo de um sistema de vigamento de piso tipo "Stub-Girder" modificado / Antonyony Carlos Jordão Heitor ; orientador: Sebastião Arthur Lopes de Andrade. $-2017$.

94 f. ; $30 \mathrm{~cm}$

Dissertação (mestrado)-Pontifícia Universidade Católica do Rio de Janeiro, Departamento de Engenharia Civil, 2017.

Inclui bibliografia

1. Engenharia civil - Teses. 2. Estruturas de aço. 3. Vigamentos de piso. 4. Estruturas mistas. 5. Análise computacional de estruturas. I. Andrade, Sebastião Arthur Lopes de. II. Pontifícia Universidade Católica do Rio de Janeiro. Departamento de Engenharia Civil. III. Título.

CDD: 624 


\section{Agradecimentos}

A Deus por todas as oportunidades.

Ao meu orientador, Sebastião, por sua ajuda e orientação, além da amizade e confiança depositada em mim. O aprendizado com ele é constante e não se resume apenas à vida profissional, pois ele em diversas oportunidades mostrou ser uma pessoa ímpar.

A minha mãe e minha avó, por não medirem esforços para que eu tenha sucesso em todas as minhas empreitadas apesar de todas as dificuldades.

Aos professores da PUC-Rio, por todo o conhecimento transmitido, especialmente à professora Marta Velasco por toda a torcida e conselhos desde a época de graduação.

A minha família, especialmente meus tios Plínio, Marileide e Marinês.

Aos meus amigos, que estiveram comigo em todos os momentos de minha jornada.

A Cassiana por ter revisado o texto deste trabalho e ao Bruno pela ajuda com o ANSYS.

Ao CNPq pelo auxílio financeiro no desenvolvimento deste trabalho. 


\section{Resumo}

Heitor, Antonyony Carlos Jordão; Andrade, Sebastião Arthur Lopes de (Orientador); Estudo de um Sistema de Vigamento de Piso tipo "StubGirder" Modificado; Rio de Janeiro, 2017. 94 p. Dissertação de Mestrado Departamento de Engenharia Civil, Pontifícia Universidade Católica do Rio de Janeiro.

Este estudo tem por objetivo avaliar o comportamento estrutural de um sistema de vigamento de piso tipo stub-girder, modificado para melhor aproveitamento dos perfis em sua fabricação. O estudo é baseado em formulações não lineares a partir do método dos elementos finitos (MEF), com uso do software ANSYS. Através do software FTOOL foi criado um modelo simplificado para a análise estrutural e o cálculo das resistências nominais foi feito com base na norma canadense CAN-S16-10 da Canadian Standards Association. Além disso, foram avaliadas as cargas de máximas e de serviço do sistema, bem como os deslocamentos associados a estes carregamentos. Com base nos resultados obtidos, foram feitas recomendações de projeto do sistema e foram avaliadas as condições de economia de material e possibilidade de utilização na prática de construção de edificações de andares múltiplos. Com vistas à fase de construção, é feita a discussão sobre a possibilidade de obtenção de um método construtivo industrializado, já que o sistema de fabricação é caracterizado pela rapidez de produção e montagem, que são facilitadas pelo fato deste sistema permitir a reutilização de pequenos comprimentos de perfis que sobram no processo normal de fabricação.

\section{Palavras-chave}

Estruturas de Aço; Vigamentos de Piso; Estruturas Mistas; Análise Computacional de Estruturas 


\section{Abstract}

Heitor, Antonyony Carlos Jordão; Andrade, Sebastião Arthur Lopes de (Advisor); Study of a Modified Stub-Girder Floor System; Rio de Janeiro, 2017. 94 p. Dissertação de Mestrado - Departamento de Engenharia Civil, Pontifícia Universidade Católica do Rio de Janeiro.

This study's purpose was to evaluate the structural behavior of a stub-girder floor-system, which was modified to better utilize the steel profiles in its manufacturing process. The study is based on nonlinear analysis through the use of the finit element method (FEM), employing the software ANSYS. For the structural analysis, a simplified model was created through the use of the software FTOOL and the nominal resistances was obtained based on the canadian CAN-S16-10 Standard, by the Canadian Standards Association. Furthermore, the working and tensile loads were evaluated, as were the displacements associated to them. Based on the results, designs recommendations were made and the conditions of economy of material, as well the possibility of the system's practical use in multi-storey buildings were discussed. With regards to the construction phase, a discussion was made on the possibility of obtaining an industrialized construction method, since the manufacturing process is characterized by the fast production and assembly, which are facilitade by the fact that this system allows the reuse of small lenghts of remaining profiles from the normal manufacturing process.

\section{Keywords}

Steel Structures; Floor Systems; Composite Structures; Computacional Analisys 


\section{Sumário}

1 Introdução 14

1.1. Considerações Iniciais e Objetivos $\quad 14$

1.2. Revisão Bibliográfica 16

$\begin{array}{ll}\text { 1.3. Estrutura do documento } & 17\end{array}$

2 Sistema de vigamento de pisos Stub-Girder 19

2.1. Considerações gerais 19

2.2. Sistema Stub-Girder 21

2.3. Critérios de Projeto 22

2.4. Considerações a respeito da laje de concreto para Stub-Girder 23

2.5. Layout dos stubs e do banzo inferior $\quad 24$

2.6. Modelagem estrutural do Stub-Girder para análise computacional 25

2.7. Verificação da resistência dos elementos do Stub-Girder 26

2.8. Projeto dos conectores de cisalhamento 27

2.9. Projeto das soldas do Stub-Girder 27

2.10. Verificação dos deslocamentos 28

2.11. Verificações de escoramentos 28

2.12. Sistema Stub-Girder modificado: considerações iniciais e $\begin{array}{ll}\text { mudanças propostas } & 28\end{array}$

3 Análise computacional 30

3.1. Software de modelagem estrutural 30

3.2. Definição e geometria dos modelos estudados 30

3.3. Unidades 33

3.4. Modelo Geométrico 33

3.5. Propriedades dos materiais 34

3.6. Condições de contorno e aplicação de carregamentos 36

3.7. Tipo de Análise 37

3.8. Exemplo de modelo geométrico 37 
4 Análise e discussão dos resultados 41

4.1. Força versus deslocamento nos modelos 41

4.1.1. Cargas Máximas $\quad 47$

4.2. Critério de plastificação de Von Mises 48

4.3. Cargas de serviço 54

4.4. Relação entre carga de escoamento e carga de máxima 55

4.5. Deslocamentos

4.6. Discussão 56

5 Modelo de Análise Unifilar $\quad 63$

5.1. Introdução 63

5.2. Modelo Simplificado de Ritchie e Chien [2] 63

5.3. Modelagem do sistema modificado $\quad 65$

5.4. Comparação de resultados 66

5.4.1. Seção homogeneizada da viga mista (stub-misto) 68

$\begin{array}{ll}\text { 5.4.2. Corda Inferior } & 70\end{array}$

$\begin{array}{ll}\text { 5.4.3. Corda Superior } & 71\end{array}$

6 Projeto do sistema de vigamento modificado $\quad 74$

6.1. Método dos estados limites $\quad 74$

6.2. Resistências de projeto dos elementos segundo a CSA S16.1 [3] 75

6.2.1. Viga Mista (stub misto) 75

6.2.2. Stubs $\quad 78$

$\begin{array}{ll}\text { 6.2.3. Banzo Superior } & 79\end{array}$

6.2.4. Banzo Inferior $\quad 81$

6.3. Resistências nominais dos modelos $\quad 81$

6.4. Projeto de um pavimento de edifício de múltiplos andares 86

6.4.1. Stub-girder modificado (SGM) 87

6.4.2. Vigas mistas VM1 89

6.4.3. Vigas mistas tradicionais $\quad 89$

$\begin{array}{ll}\text { 6.4.4. Discussão de resultados } & 90\end{array}$

7 Considerações finais $\quad 92$ 
7.1. Conclusões

7.2. Sugestões para trabalhos futuros

Referências bibliográficas 


\section{Lista de figuras}

$\begin{array}{ll}\text { Figura 1.1. Sistema de pisos stub-girder } & 15\end{array}$

Figura 1.2. Sistema de pisos stub-girder modificado 15

Figura 2.1. Sistema de vigamentos de piso tipo Stub-Girder [2] 19

Figura 2.2. Integração estrutural e mecânica de um piso típico

de Stub-Girder [2] 22

Figura 2.3. Reforço longitudinal da laje de concreto [2] 24

Figura 2.4. Stub-Girders usuais [2] 25

Figura 2.5 Modelo estrutural Vierendeel para análise computacional [2] 26

$\begin{array}{lr}\text { Figura 2.6. Sistema modificado } & 29\end{array}$

Figura 2.7. Modelo simplificado proposto por Ritchie e Chien [2] 29

Figura 3.1. Sistema modificado longitudinalmente 32

Figura 3.2. Seção a $\quad 32$

Figura 3.3. Seção b $\quad 32$

Figura 3.4. Seção c $\quad 32$

Figura 3.5. Elemento SOLID185 33

Figura 3.6. Curva tensão versus deformação do concreto 35

Figura 3.7. Malha criada vista frontalmente 38

Figura 3.8. Malha criada vista lateralmente 39

Figura 3.9. Sistema após a criação de apoios e deslocamentos aplicados $\quad 40$

Figura 4.1. Força Aplicada versus Deslocamento dos modelos 1 a $7 \quad 42$

Figura 4.2. Força Aplicada versus Deslocamento dos modelos 8 a $14 \quad 43$

Figura 4.3. Comparativo entre SGM-1 e SGM-8 44

Figura 4.4. Comparativo entre SGM-2 e SGM-9 44

Figura 4.5. Comparativo entre SGM-3 e SGM-10 45

Figura 4.6. Comparativo entre SGM-4 e SGM-11 45

Figura 4.7. Comparativo entre SGM-5 e SGM-12 46

Figura 4.8. Comparativo entre SGM-6 e SGM-13 46

Figura 4.9. Comparativo entre SGM-7 e SGM-14 47

Figura 4.10. Tensões de von Mises no modelo SGM-1 49

Figura 4.11. Tensões de von Mises no modelo SGM-2 49 
Figura 4.12. Tensões de von Mises no modelo SGM-3 50

Figura 4.13. Tensões de von Mises no modelo SGM-12 50

Figura 4.14. Tensões de von Mises no modelo SGM-13 51

Figura 4.15. Tensões de Von Mises nas seções críticas do modelo SGM-2 52

Figura 4.16. Tensões de Von Mises nas seções críticas do modelo SGM-3 52

Figura 4.17. Tensões de Von Mises nas seções críticas do modelo SGM-4 52

Figura 4.18. Tensões de Von Mises nas seções críticas do modelo SGM-12 53

Figura 4.19. Tensões de Von Mises nas seções críticas do modelo SGM-13 53

Figura 4.20. Tensões de Von Mises nas seções críticas do modelo SGM-14 54

Figura 5.1. Modelo simplificado proposto por Ritchie e Chien [3] 64

Figura 5.2. Modelo Simplificado SG-EX no FTOOL. 65

Figura 5.3. Corte no sistema Stub-girder tradicional. 65

Figura 5.4. Modelo simplificado do sistema modificado. 66

Figura 5.5. Força aplicada versus deslocamento do modelo SGM-12 67

Figura 5.6. Tensão normal na seção transversal do stub misto. 68

Figura 5.7. Modelo SGM-12 simplificado. $\quad 69$

Figura 5.8. Diagrama de momentos fletores do modelo SGM-12 simplificado. 69

Figura 5.9. Diagrama de tensão normal no centro da corda inferior. $\quad 70$

Figura 5.10. Diagrama de tensão normal no centro da corda inferior. $\quad 70$

Figura 5.11. Diagrama de tensão normal no centro da corda superior. 72

Figura 6.1. Esforços solicitantes nos stubs 78

Figura 6.2. Planta baixa de um pavimento de edifício de múltiplos andares $\quad 86$

Figura 6.3. Pavimento calculado com uso de vigas mistas tradicionais $\quad 89$

Figura 6.4. Peso do pavimento em função do carregamento distribuído 91 


\section{Lista de tabelas}

Tabela 2.1. Lista parcial de estruturas construídas com Stub-Girder [2] 20

Tabela 2.2 Larguras adequadas para as aberturas do Stub-Girder [3] 25

Tabela 2.3. Verificações necessárias para os elementos do Stub-Girder 26

Tabela 3.1. Informações pertinentes aos modelos estudados 31

Tabela 3.2. Unidades utilizadas 33

Tabela 3.3. Propriedades dos materiais 36

Tabela 4.1. Cargas Máximas $\quad 47$

Tabela 4.2. Cargas de serviço dos modelos 1 a 14

Tabela 4.3. Relação entre $F_{u}$ e $F_{w}$

Tabela 4.4. Deslocamentos de escoamento e máximos 56

Tabela 4.5.a. Carga máxima com stubs W250 x 17,3 57

Tabela 4.5.b. Carga máxima com stubs W250 x 22,3 57

Tabela 4.5.c. Carga máxima com stubs W250 x 25,3 58

Tabela 4.5.d. Carga máxima com stubs W250 x 28,4 58

Tabela 4.5.e. Carga máxima com stubs W250 x 32,7 58

Tabela 4.5.f. Carga máxima com stubs W250 x 38,5 59

Tabela 4.5.g. Carga máxima com stubs W250 x 44,8 59

Tabela 4.6.a. Carga de serviço com stubs W250 x 17,3 60

Tabela 4.6.b. Carga de serviço com stubs W250 x 22,3 60

Tabela 4.6.c. Carga de serviço com stubs W250 x 25,3 60

Tabela 4.6.d. Carga de serviço com stubs W250 x 28,4 61

Tabela 4.6.e. Carga de serviço com stubs W250 x 32,7 61

Tabela 4.6.f. Carga de serviço com stubs W250 x 38,5 61

Tabela 4.6.g Carga de serviço com stubs W250 x 44,8 61

Tabela 5.1. Informações do Stub-girder SG-EX 64

Tabela 5.2. Comparativo entre resultados do ANSYS e FTOOL 69

Tabela 5.3. Comparativo entre resultados do ANSYS e FTOOL

para a corda inferior $\quad 71$

Tabela 5.4. Comparativo entre resultados do ANSYS e FTOOL

$\begin{array}{ll}\text { para a corda superior } & 72\end{array}$ 
Tabela 5.5. Esforços solicitantes atuantes nos elementos do $\begin{array}{ll}\text { sistema modificado } & 73\end{array}$

Tabela 6.1. Resistências nominais dos elementos do modelo SGM-1 82

Tabela 6.2. Resistências nominais dos elementos do modelo SGM-2 82

Tabela 6.3. Resistências nominais dos elementos do modelo SGM-3 82

Tabela 6.4. Resistências nominais dos elementos do modelo SGM-4 82

Tabela 6.5. Resistências nominais dos elementos do modelo SGM-5 82

Tabela 6.6. Resistências nominais dos elementos do modelo SGM-6 83

Tabela 6.7. Resistências nominais dos elementos do modelo SGM-7 83

Tabela 6.8. Resistências nominais dos elementos do modelo SGM-8 83

Tabela 6.9. Resistências nominais dos elementos do modelo SGM-9 83

Tabela 6.10. Resistências nominais dos elementos do modelo SGM-10 83

Tabela 6.11. Resistências nominais dos elementos do modelo SGM-11 84

Tabela 6.12. Resistências nominais dos elementos do modelo SGM-12 84

Tabela 6.13. Resistências nominais dos elementos do modelo SGM-13 84

Tabela 6.14. Resistências nominais dos elementos do modelo SGM-14 84

Tabela 6.15. Cargas máximas possíveis encontradas para os modelos 85

Tabela 6.16. Carregamentos distribuídos analisados $\quad 87$

Tabela 6.17. Seções escolhidas para o stub misto $\quad 87$

Tabela 6.18. Seções escolhidas para a corda inferior $\quad 88$

Tabela 6.19. Verificação da laje de concreto 88

Tabela 6.20. Verificação da resistência dos stubs $\quad 88$

Tabela 6.21. Seção das vigas mistas VM1 89

Tabela 6.22. Seção das vigas mistas VM2 90

Tabela 6.23. Taxa de consumo de aço com uso do sistema modificado 90

Tabela 6.24. Taxa de consumo de aço com vigas mistas tradicionais 91 


\section{Introdução}

\subsection{Considerações Iniciais e Objetivos}

Um dos maiores desenvolvimentos na área de projeto de estruturas metálicas do último século foi a capacidade de unir perfis de aço, sejam eles laminados ou soldados, a um sistema de lajes de concreto maciças ou formadas por formas metálicas (sistema Steel-deck). Desta maneira, o projeto e a construção de estruturas mistas consistem na utilização, de modo simultâneo das capacidades do aço e do concreto de modo a resistir a esforços de tração e compressão, respectivamente, de maneira que sejam aumentadas a resistência e a rigidez do sistema, com gasto otimizado de materiais.

Neste contexto, existem inúmeros sistemas que fazem uso das vantagens oferecidas pelo uso simultâneo de aço e concreto, sendo alguns exemplos os sistemas de vigas mistas, pilares mistos, lajes mistas, treliças mistas e o sistema de piso tipo stub-girder.

No Brasil, a construção mista ainda não é utilizada tão frequentemente quanto em países como Canadá e Estados Unidos. Este trabalho e a pesquisa associada a ele são mais um esforço no que tange a mostrar as vantagens dos sistemas mistos, marcadamente o sistema de pisos stub-girder, que foi modificado e deu origem a um novo sistema de vigamentos, que busca diminuir o peso da estrutura quando comparado às vigas mistas, além de possuir altura total menor que a dos stubgirders tradicionais sem perder a vantagem de possuir aberturas inerentes a si que facilitam a instalação de serviços.

Colaco [1] propôs o sistema misto de piso tipo stub-girder, o qual oferece a integração mecânica e estrutural através de aberturas de alma. Além disso, esse sistema gera economia de peso devido à combinação estrutural proposta entre os stub-girders e as vigas transversais a eles. Ele pode ser classificado como híbrido entre uma viga de seção I de alma cheia e uma viga tipo Vierendeel, sendo o banzo superior a laje de concreto armado, o banzo inferior um perfil laminado de seção $\mathrm{H}$, e os stubs, formados por perfis laminados de seção I que conectam os dois 
elementos (banzos superior e inferior) para garantir a transferência de esforço cortante entre eles. O sistema é mostrado na Figura 1.1.

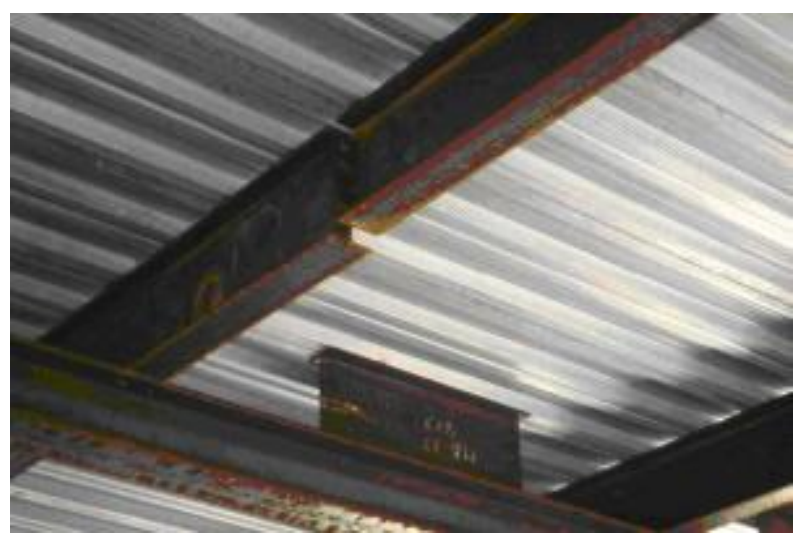

\section{Figura 1.1. Sistema de pisos stub-girder}

O novo sistema é composto por diferentes seções, explicadas no capítulo 3, que traz as modificações propostas, e cada uma delas resiste a um tipo de esforço diferente, que variam entre flexo-compressão, flexo-tração, momento fletor e esforço cortante. O sistema modificado é apresentado na Figura 1.2.

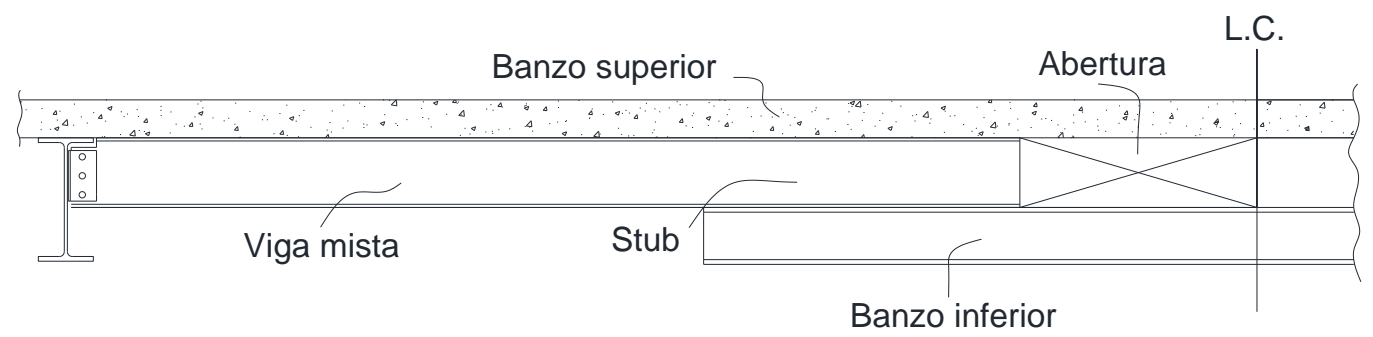

Figura 1.2. Sistema de pisos stub-girder modificado

Para que se possa considerar o comportamento do sistema, foram feitas análises computacionais utilizando o software ANSYS 15. Essas análises serão comparadas a esforços retirados do modelo simplificado proposto por Ritchie e Chien [2] e sua resistência será obtida a partir da norma canadense CAN S16.1 [3], da Canadian Standards Association..

Os objetivos principais deste trabalho são:

- A avaliação da carga e o modo de ruína da estrutura;

- A avaliação do modelo simplificado proposto por Ritchie e sua utilidade para o sistema modificado como forma de obtenção de esforços solicitantes; 
- A apresentação de um exemplo com o procedimento de projeto para o sistema de vigamentos proposto neste trabalho, seguindo parte do procedimento proposto por Ritchie e Chien [2];

- A verificação da viabilidade do sistema no que tange aos deslocamentos de serviço, quando comparados aos deslocamentos máximos permitidos pela norma NBR 8800/2008, que rege a construção metálica no Brasil.

\subsection{Revisão Bibliográfica}

O sistema de pisos stub-girder foi desenvolvido por Colaco [1], que utilizou um esquema estrutural do tipo Vierendeel, obtendo o conjunto de tensões atuantes e, consequentemente, os esforços solicitantes relacionados. A partir destas informações foram avaliadas diversas alturas possíveis para o sistema, de maneira que o mesmo fosse otimizado.

Ritchie e Chien [2] produziram um manual de projeto e construção de sistemas mistos em que a resistência é calculada de acordo com a norma canadense S.16 do CSA. No referido trabalho, são apresentadas orientações sobre o projeto e construção do sistema de pisos stub-girder em tópicos que incluem: considerações sobre a laje de concreto, esboço dos stubs e das vigas, stub-girders calculados como vigas gerber e controle da altura e verificações para os mesmos; propriedades estruturais da laje de concreto reforçadas, modelagem do sistema para análises preliminares, resistência dos componentes do sistema, conectores de cisalhamento, vibração de piso e deslocamentos.

Harbok e Hosain [4] desenvolveram um programa computacional baseado no método das subestruturas para calcular o deslocamento do sistema em que é assumida a interação completa entre os stubs e a laje de concreto.

Faria [5] concluiu que quando os stubs correspondem a $40 \%$ do comprimento total da viga, será encontrada a solução mais econômica para a utilização do sistema. Também foi verificado que o uso de tipos diferentes de perfis soldados resulta em um acréscimo de $2,0 \mathrm{~kg} / \mathrm{m}^{2}$ em relação aos resultados apresentados no manual supracitado.

Ritchie e Chien [6] conduziram novos estudos sobre sistemas de vigamentos de piso, incluindo os stub-girders, vigas mistas e treliças mistas. Cada um desses sistemas foi analisado e discutido, incluindo o sistema de laje mista steel-deck, além 
de reforços necessários nas lajes de concreto, qualidade do concreto, especialmente no que diz respeito à retração e fluência. Foi concluído que as características que tornam estes sistemas atrativos são a eficiência no que se refere a vãos maiores, a integração otimizada da estrutura com outros sistemas mecânicos, bem como menores deslocamentos sob a ação de cargas permanentes e variáveis.

Wang et al. [7] apresentou dois métodos para determinar a resistência última dos stub-girders, em que é assumida a interação completa entre os stubs e a laje de concreto. No primeiro modelo, o stub-girder é calculado como uma viga Vierendeel, de forma a ser derivada uma expressão explícita para a resistência última. O segundo método consistiu na análise computacional do sistema utilizando o software ABAQUS para a análise não linear do sistema.

Ismail et al. [8,9] investigou diferentes parâmetros, como o efeito do tipo de carregamento, localização e altura dos stubs, que podem influenciar a maneira como o sistema se comporta.

\subsection{Estrutura do documento}

O presente trabalho será dividido em sete capítulos, descritos nesta seção.

A dissertação começa com este capítulo, no qual é apresentada uma introdução a respeito do tema, bem como seus objetivos e uma revisão sobre alguns trabalhos pertinentes ao entendimento e estudo sobre o sistema de vigamentos de piso stub-girder.

O capítulo dois consiste em uma revisão teórica em torno do tema. Nele serão apresentados os métodos de análise utilizados para o sistema stub-girder e o sistema modificado, tema desta dissertação.

No capítulo três é apresentada a modelagem computacional realizada para obtenção das tensões, esforços solicitantes e curvas de carga versus deslocamento do sistema modificado. Esta análise, não-linear inelástica, foi executada através do método dos elementos finitos por meio do software ANSYS 15.

O capítulo quatro traz os resultados obtidos através da análise citada acima, apresentando a discussão a respeito dos mesmos.

O capítulo cinco trata do modelo simplificado do sistema modificado, similar ao proposto por Ritchie, do qual a análise será feita com uso software FTOOL. 
Nesta análise, linear elástica, foram obtidos os esforços solicitantes e comparados com os obtidos pelo método dos elementos finitos.

O capítulo seis apresenta exemplos do sistema modificado em que serão calculadas as previsões para resistências últimas por meio da norma S.16, do CSA. Estes resultados também foram comparados com os obtidos pelo método dos elementos finitos.

Por fim, o capítulo sete apresenta as considerações finais feitas na pesquisa e sugestões para trabalhos futuros. 


\section{2 \\ Sistema de vigamento de pisos Stub-Girder}

\subsection{Considerações gerais}

O sistema de vigamento de pisos Stub-Girder foi introduzido no mercado dos Estados Unidos a partir de 1970. O nome deste sistema misto foi proposto pelo seu principal desenvolvedor, Colaco [1]. O arranjo estrutural, que pode ser observado na Fig. 2.1, oferece integração mecânica e estrutural através de aberturas inerentes a si e, por isso, apresenta economia no peso do aço devido à eficiência do sistema misto bem como a combinação entre o projeto das vigas mistas e vigas gerber. Alguns ensaios foram realizados também nos Estados Unidos para complementar os resultados teóricos. A Figura 2.1 apresenta o sistema stub-girder.

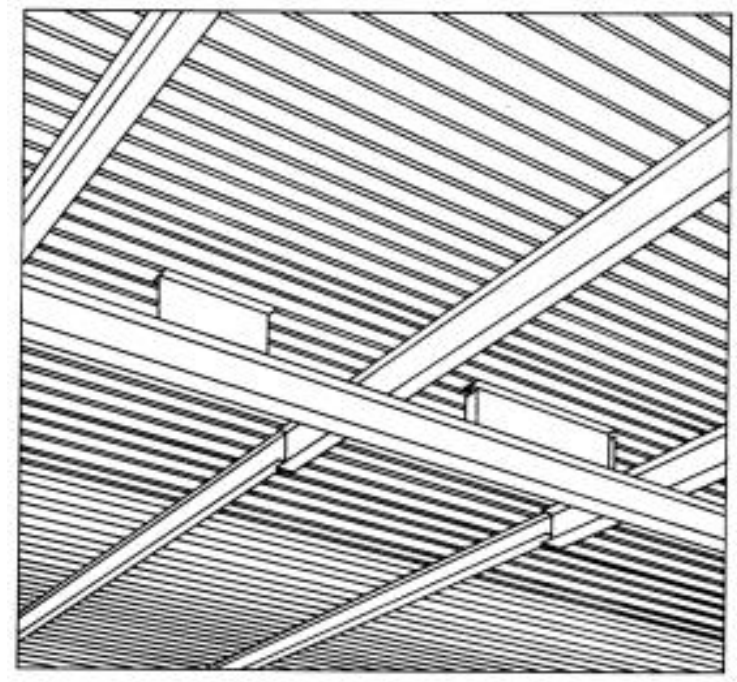

Figura 2.1. Sistema de vigamentos de piso tipo Stub-Girder [2]

No Canadá, este sistema foi tema de várias pesquisas, incluindo testes em escala real que resultaram em mudanças significativas em comparação ao conceito original. Essas mudanças incluíram a altura dos perfis, acréscimo de enrijecedores nos stubs e reforço na laje de concreto [6]. A Tabela 2.1 apresenta alguns exemplos de construções nas quais foi utilizado o sistema stub-girder. 
Tabela 2.1. Lista parcial de estruturas construídas com Stub-Girder [2]

\begin{tabular}{|c|c|c|}
\hline Nome & $\begin{array}{c}\text { № } \\
\text { de andares }\end{array}$ & $\begin{array}{l}\text { Área de piso } \\
\qquad\left(\mathrm{m}^{2}\right)\end{array}$ \\
\hline $\begin{array}{l}\text { First International Building } \\
\text { Dallas }\end{array}$ & 51 & 176.000 \\
\hline $\begin{array}{l}\text { Mercantil Center } \\
\text { St. Louis }\end{array}$ & 35 & 70.000 \\
\hline $\begin{array}{l}\text { X'Town Center Tower } \\
\text { Southfield }\end{array}$ & 32 & 48.000 \\
\hline $\begin{array}{l}\text { Cullen Center, Dresser Tower } \\
\text { Houston }\end{array}$ & 40 & 93.000 \\
\hline $\begin{array}{l}\text { One Allen Center Building } \\
\text { Houston }\end{array}$ & 34 & 88.000 \\
\hline $\begin{array}{l}\text { Penzoil Place (twin towers) } \\
\text { Houston }\end{array}$ & 37 & 167.000 \\
\hline $\begin{array}{c}\text { Georgia } \quad \text { Power } \quad \text { Company } \\
\text { Headquarters } \\
\text { Atlanta }\end{array}$ & 24 & 71.000 \\
\hline $\begin{array}{l}\text { One Houston Center } \\
\text { Houston }\end{array}$ & 48 & 100.000 \\
\hline $\begin{array}{l}\text { First City Bank Building } \\
\text { Houston }\end{array}$ & 50 & 130.000 \\
\hline $\begin{array}{l}\text { Nova Corporation Head Office } \\
\text { Calgary }\end{array}$ & 37 & 70.000 \\
\hline $\begin{array}{l}\text { Manulife Place } \\
\text { Edmonton }\end{array}$ & 33 & 112.000 \\
\hline $\begin{array}{l}\text { NRC Bulding } \\
\text { Boucherville, Quebec }\end{array}$ & 2 & 7.800 \\
\hline $\begin{array}{l}401 \text { West Georgia } \\
\text { Vancouver }\end{array}$ & 22 & 28.000 \\
\hline
\end{tabular}




\subsection{Sistema Stub-Girder}

O sistema de pisos Stub-Girder é basicamente um sistema de vigamento de pisos de transferência de cargas gravitacionais. Os Stub-Girder são conjuntos tipo Vierendeel, que consistem num banzo inferior composto por um perfil metálico de seção W e um banzo superior composto pela laje de concreto. As ligações intermitentes são compostas também por perfis metálicos de seção W (que são chamados de stubs) conectados a ambos os banzos com o objetivo de realizar a transferência de esforço cortante entre os dois elementos. Vigas secundárias passam pelas aberturas e são conectadas também a ambos os banzos. Idealmente, o sistema pode chegar a 12 metros de vão, com o sistema de vigas secundárias chegando a vãos de 9 metros. O sistema é muito versátil, particularmente no que diz respeito às vigas secundárias, com a altura das vigas variando de acordo com a configuração estrutural e arquitetônica. Tradicionalmente, as pesquisas e construções canadenses concentram-se na utilização de perfis de altura igual a $310 \mathrm{~mm}$ para o banzo inferior, enquanto a maior parte dos projetos estadunidenses usa altura do mesmo igual a $360 \mathrm{~mm}$. Para vãos maiores que 13,5 metros, os Stub-Girders tornam-se impraticáveis, uma vez que o modo de ruína da laje torna-se crítico.

As vigas de piso têm altura variando entre 310 e $460 \mathrm{~mm}$ e ficam localizadas acima do banzo inferior do stub-girder e entre os stubs, espaçados de 2,5 a 3,5 metros, dependendo do modelo estrutural e da capacidade de carga da laje de concreto. A laje geralmente é formada por uma laje mista composta por concreto e uma forma de aço galvanizado de formato trapezoidal (steel-deck) de altura $51 \mathrm{~mm}$ ou $75 \mathrm{~mm}$, coberta por aproximadamente $85 \mathrm{~mm}$ de concreto de semi-baixa densidade ou 65 a $75 \mathrm{~mm}$ de concreto de densidade normal, não sendo indicada resistência característica menor que $25 \mathrm{MPa}$.

Este sistema de pisos único tem sido usado principalmente para prédios de escritórios onde as cargas variáveis estão entre 2,4 a $4,8 \mathrm{kN} / \mathrm{m}^{2}$, excluindo divisórias. Também é utilizado em construções de uso especial, como laboratórios, e é uma boa alternativa para a construção de hospitais.

Estruturalmente, os stub-girders são projetados baseados em construções tipo gerber onde as vigas de piso são contínuas em relação a eles e rótulas são adicionadas próximas aos pontos de inflexão para receber os vãos em balanço. As 
regiões de momento positivo são projetadas como vigas mistas em conjunto com a laje de concreto, garantindo economia de material e aumento da rigidez.

O Stub-Girder é analisado como uma viga Vierendeel, com a laje de concreto trabalhando como um banzo superior comprimido, o perfil metálico inferior trabalhando como um banzo inferior tracionado, e os stubs como painéis de cisalhamento. É importante ressaltar que, ao usar este sistema, é necessário o uso de escoramentos ao longo do stub-girder na fase de concretagem, já que o banzo superior não apresenta nenhuma resistência nesta fase. Este arranjo estrutural permite o uso do aço e do concreto em suas resistências ótimas, resultando numa grande eficiência. As aberturas do sistema permitem interação com as instalações mecânicas e estrutural nas duas direções, concedendo a redução da altura total do piso quando comparado a outros sistemas estruturais. Na Figura 2.2 é apresentado o sistema stub-girder integrado às instalações e vigas gerber.

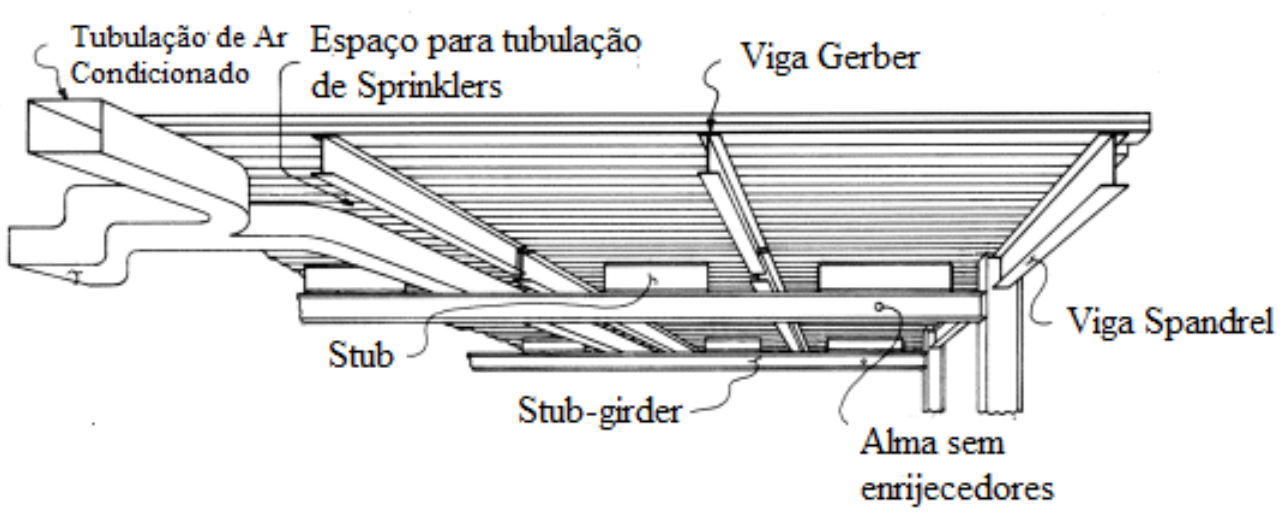

Figura 2.2. Integração estrutural e mecânica de um piso típico de StubGirder [2]

\subsection{Critérios de Projeto}

Os critérios de projeto apresentados nesta seção foram preparados por Ritchie e Chien [2] baseados num estudo detalhado deste sistema estrutural por muitos anos.

As orientações para o projeto e construção do sistema Stub-Girder cobrem os seguintes tópicos:

- considerações sobre a laje de concreto;

- layout dos stubs e do banzo inferior;

- construção Gerber; 
- controle de altura e verificações para as vigas Gerber;

- propriedades estruturais do banzo superior (laje de concreto reforçada);

- modelagem estrutural dos Stub-Girders para análise computacional;

- verificações das resistências dos elementos do Stub-Girder;

- projeto de conectores de cisalhamento;

- verificações referentes à vibração de pisos;

- verificações para os escoramentos na fase de concretagem;

- considerações especiais de projeto e construção.

\subsection{Considerações a respeito da laje de concreto para Stub-Girder}

A seleção de um sistema steel-deck para Stub-Girders envolve mais que apenas considerar a capacidade de carga do mesmo. Alguns pontos devem ser considerados no início do processo de seleção.

a) steel decks de $50 \mathrm{~mm}$ ou mais são mais adequados. Um banzo superior mais rígido pode fornecer uma ação Vierendeel mais eficiente, proporcionando economia no projeto da corda inferior;

b) uma espessura efetiva de $85 \mathrm{~mm}$ de concreto agregado leve com a parte inferior sem aplicação de nenhum produto antifogo é escolhida para fornecer uma resistência contra incêndio estimada em duas horas;

c) em locais onde agregados leves (cinasita) não são normalmente disponíveis ou não são econômicos, pode ser utilizado concreto com densidade normal $\mathrm{e}$ espessura efetiva de 65 a $75 \mathrm{~mm}$. Se nesses lugares for exigida resistência a fogo, devem ser aplicados materiais antifogo no steel-deck;

d) como a laje estará sujeita a altas tensões de compressão e cisalhamento, a resistência característica do concreto é sempre recomendada como superior a 25 Mpa;

e) os steel-decks trapezoidais são escolhidos para a forma a fim de fornecer a área adequada de concreto posicionada exatamente em cima dos stubs, além de largura suficiente para que os conectores de cisalhamento possam ser utilizados;

f) a localização das canaletas do steel-deck deve coincidir com os stubs e as vigas secundárias;

g) vergalhões de comprimento igual ao vão total do sistema, arranjadas dentro do tamanho da largura efetiva da laje, são necessárias nas partes superior e inferior 
da laje. Este sistema aumenta a resistência à flexão, resistência ao cisalhamento e ductilidade do banzo superior do stub-girder. A Figura 2.3 apresenta os diversos arranjos possíveis para o reforço longitudinal.

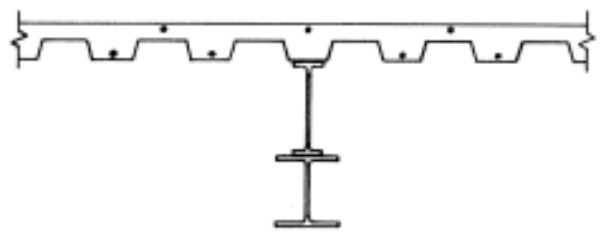

(a) Arranjo com 7 vergalhões

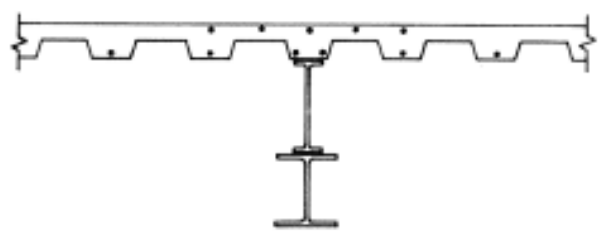

(c) Arranjo com 11 vergalhões

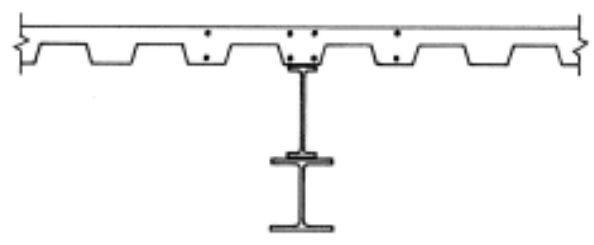

(b) Arranjo com 8 vergalhões

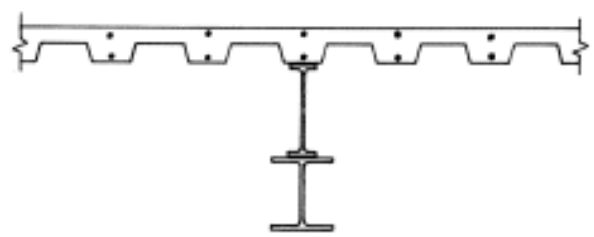

(d) Arranjo com 10 vergalhões

Nota: O reforço longitudinal à laje deve ocorrer dentro da largura efetiva da mesma

Figura 2.3. Reforço longitudinal da laje de concreto [2]

\subsection{Layout dos stubs e do banzo inferior}

Na maioria dos prédios construídos com o sistema stub-girder, o mesmo apresenta vãos variando entre 11,5 e 13,5 metros, com 3 vigas intermediárias, ou seja, 4 stubs entre os suportes do banzo inferior. Ocasionalmente, também podem ser utilizados arranjos com 3 stubs ou 5 stubs. A Figura 2.4 apresenta os arranjos típicos para o sistema stub-girder. As recomendações para largura das aberturas dos stub-girders são apresentadas na Tabela 2.2. 


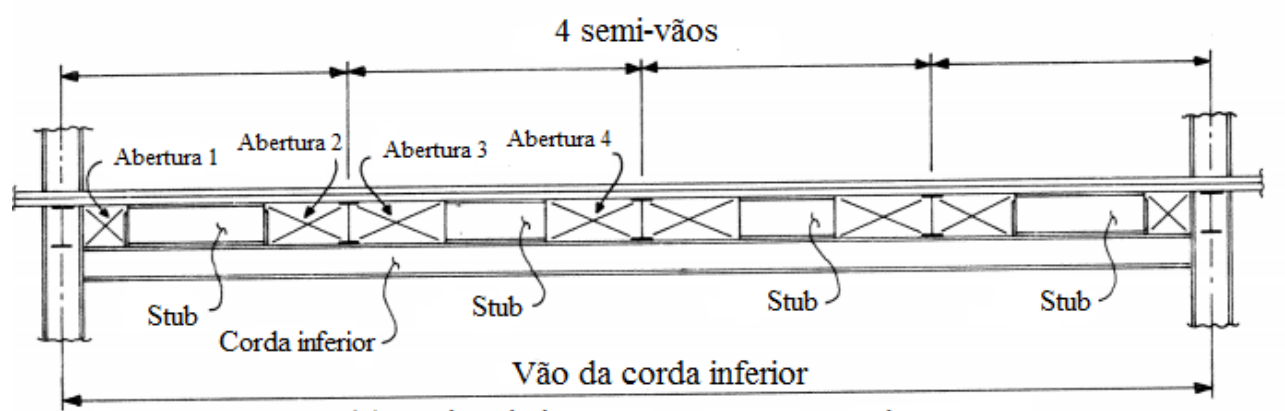

(a) Stub-Girder composto por 4 stubs

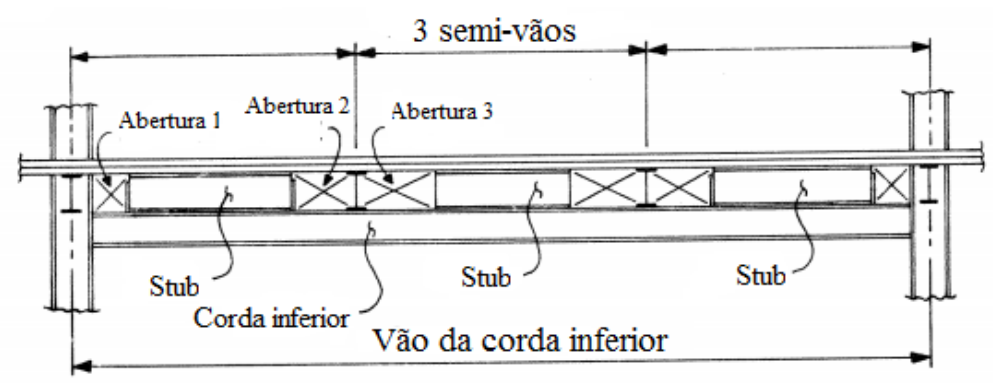

(b) Stub-Girder composto por 3 stubs

Figura 2.4. Stub-Girders usuais [2]

Tabela 2.2 Larguras adequadas para as aberturas do Stub-Girder [3]

Largura da abertura como porcentagem

$\mathrm{N}^{\mathrm{o}}$ da abertura do vão total da Stub-Girder

\begin{tabular}{ccc}
\cline { 2 - 3 } & Stub-Girder com 3 stubs & Stub-Girder com 4 stubs \\
\hline 1 & $*$ & $*$ \\
\hline 2 & 7,5 a 8,5 & 6 a 7 \\
\hline 3 & 9,5 & 8 \\
\hline 4 & - & 8
\end{tabular}

\subsection{Modelagem estrutural do Stub-Girder para análise computacional}

A análise computacional dos Stub-Girders por meio do método dos elementos finitos e por meio do modelo Vierendel foram ilustradas por Colaco [1] em 1972. Os dois modelos mostraram bons resultados no que tange a tensões no aço, concreto e deslocamentos, quando comparados a modelos em escala real. O modelo criado através do método dos elementos finitos não foi considerado adequado para o projeto prático devido à alta demanda de cálculos e computacionais. Entretanto, ele serviu o seu propósito de pesquisa, por verificar a adequação do modelo Vierendeel. 
O modelo Vierendeel de uma viga típica Stub-Girder com 4 stubs é apresentado, como modelo de barras, na figura 2.5. Nota-se que os stubs entre os banzos superior e inferior foram transformados em barras verticais. Este método de análise foi usado para fornecer os esforços de projeto de 5 testes de laboratório em escala real que foram executados em algumas universidades canadenses. A correlação entre as forças calculadas e as encontradas em laboratório foi excelente. Com a ajuda de um programa como o Ftool [10], um engenheiro civil pode facilmente analisar um stub-girder.

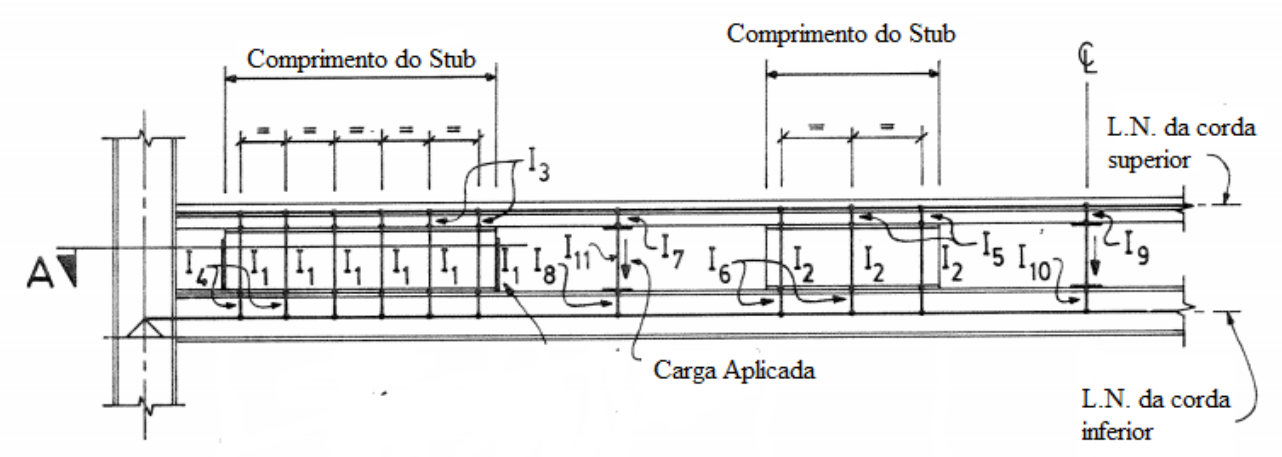

Figura 2.5 Modelo estrutural Vierendeel para análise computacional [2]

\subsection{Verificação da resistência dos elementos do Stub-Girder}

O projetista deve verificar as resistências dos banzos superior e inferior em várias localidades críticas. Para um stub-girder típico composto por 3 ou 4 stubs podem haver até 7 seções críticas. As verificações necessárias para o projeto de cada uma dessas seções são especificadas na Tabela 2.3.

Tabela 2.3. Verificações necessárias para os elementos do Stub-Girder

\begin{tabular}{cc}
\hline Seção & $\begin{array}{c}\text { Verificações } \\
\text { Momento Fletor } \\
\text { Cortante }\end{array}$ \\
\hline 2 & Flexo-tração \\
\hline 3 & Flexo-tração \\
\hline 4 & Compressão \\
& Não-uniforme \\
\hline 5 & Compressão
\end{tabular}




\begin{tabular}{cc}
\hline & Não-uniforme \\
\hline 6 & Compressão Local \\
& Cortante na laje adjacente aos stubs \\
\hline 7 & Compressão \\
& Não-uniforme \\
\hline
\end{tabular}

\subsection{Projeto dos conectores de cisalhamento}

Conectores de cisalhamento são utilizados comumente para garantir que exista a transferência de cisalhamento entre os stubs e as lajes mistas e o efeito combinado de dois tipos de forças (tração e cisalhamento) é considerado nessas conexões. Uma abordagem conservadora é adotada para que cada conector forneça resistência ao cisalhamento ou à tração, nunca a ambos. A resistência fatorada dos conectores é computada utilizando-se as Eq. 2.1 e 2.2, retiradas da CAN S16-10:

1) Para lajes maciças:

$q_{r s}=0,5 \phi_{\mathrm{sc}} A_{s c} \sqrt{f c^{\prime} E c} \leq \phi_{\mathrm{sc}} A_{s c} F_{u q}$

em que

qrs é a resistência do conector fatorada;

$\mathrm{A}_{\text {sc }}$ é a área do conector;

$\phi_{\text {sc }}$ é o fator de resistência, que deve ser tomado como 0,80 ;

$\mathrm{f}_{\mathrm{c}}$ ' é a resistência característica do concreto;

$\mathrm{E}_{\mathrm{c}}$ é o módulo de elasticidade longitudinal do concreto;

$\mathrm{F}_{\mathrm{uq}}$ é a tensão de ruptura do conector.

\subsection{Projeto das soldas do Stub-Girder}

Durante o projeto do stub-girder, é desejável selecionar stubs e corda inferior compatíveis no que diz respeito à ligação destes elementos. Uma diferença de largura das mesas do stub e da corda inferior de pelo menos $17 \mathrm{~mm}$ é necessária para que filetes de solda de $8 \mathrm{~mm}$ possam ser utilizados. Para soldas de filete de 10 mm essa diferença deve ser de no mínimo $22 \mathrm{~mm}$. 


\subsection{Verificação dos deslocamentos}

Devido às aberturas do sistema, o stub-girder comporta-se como uma viga Vierendeel. Deslocamentos devido ao efeito de viga de alma aberta devem ser adicionados e também devem ser considerados os efeitos de retração e deformação lenta do concreto.

\subsection{Verificações de escoramentos}

O projeto dos stub-girders é baseado na hipótese da construção mista escorada. Uma avaliação detalhada do stub-girder e elementos de escoramento para subsequente construção é essencial. Escoramentos desnecessários podem causar danos aos stub-girders dos primeiros pavimentos. Por outro lado, a remoção prematura dos escoramentos pode levar a deslocamentos maiores que os previstos na fase de projeto e até mesmo levar o sistema à ruína caso o concreto não tenha atingido níveis de resistência satisfatórios. Para prédios de múltiplos andares, são usuais um máximo de 5 andares e um mínimo de 3 andares escorados [2].

\subsection{Sistema Stub-Girder modificado: considerações iniciais e mudanças propostas}

O sistema modificado será composto por 2 stubs “contínuos", isto é, parte dos perfis metálicos que compõem os stubs serão ligadas a ambos os banzos superior e inferior, e parte será ligada apenas ao banzo superior, formado pela laje de concreto, esta seção será chamada de "stub misto". Isto quer dizer que, ao contrário do sistema original, o banzo inferior não apresentará o mesmo comprimento do superior. Como no sistema original, o modificado será calculado como simplesmente apoiado. A Figura 2.6 apresenta o sistema de vigamento de piso tipo stub-girder modificado.

\begin{tabular}{|l|l|l|l|}
\hline & Banzo superior & \multicolumn{2}{c}{ Abertura } \\
\hline & & & \\
\hline
\end{tabular}




\section{Figura 2.6. Sistema modificado}

É importante frisar que neste estudo, a interação entre stubs e a laje de concreto será considerada completa, por meio do controle do número de conectores de cisalhamento. As ligações entre stubs e corda inferior serão feitas por meio de soldas de filete por toda a extensão da união entre os perfis. Análises mais aprofundadas a respeito destes aspectos serão feitas em pesquisas futuras.

A análise não-linear inelástica do sistema será realizada, primeiramente, apropriando-se do método dos elementos finitos através do software ANSYS 15 com uso de elementos sólidos (cúbicos possuindo 8 nós). Em um segundo momento será verificado se uma modificação do modelo proposto por Colaco [1] (ilustrado na Fig. 2.5) e pelo modelo simplificado proposto por Ritchie e Chien [2] fornecem resultados satisfatórios quando comparados aos do modelo sólido.

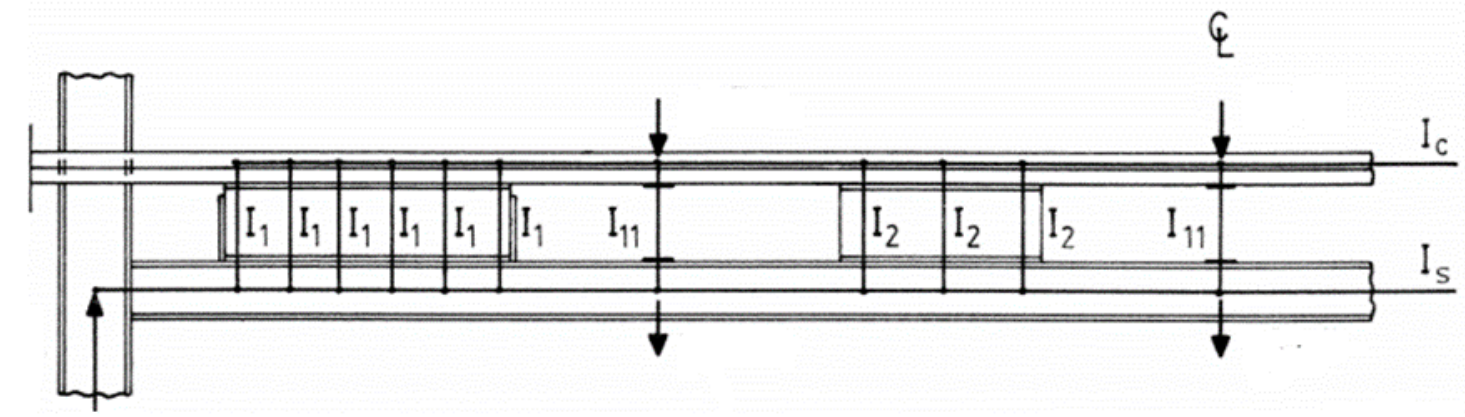

Figura 2.7. Modelo simplificado proposto por Ritchie e Chien [2]

Confirmadas estas hipóteses, alguns parâmetros deverão ser analisados, uma vez que o objetivo da pesquisa é encontrar um sistema que possa competir com as vigas mistas secundárias em construções metálicas, mais comumente utilizadas no mercado brasileiro. As seções dos perfis utilizados para a corda inferior terão altura de $150 \mathrm{~mm}$ e as seções dos stubs terão altura igual a $250 \mathrm{~mm}$, uma vez que o objetivo da pesquisa é utilizar alturas menores e vãos que não superem 6 metros.

Tais análises serão realizadas com a corda superior formada por laje maciça de concreto e, caso os resultados sejam satisfatórios, o cálculo da resistência do sistema também se dará considerando a corda superior do sistema uma laje mista (steel-deck). Após confirmadas as novas hipóteses, serão feitas considerações finais a respeito das armaduras da laje bem como sobre escoramentos e efeitos de deformação lenta e retração do concreto 


\section{3 Análise computacional}

\subsection{Software de modelagem estrutural}

O ANSYS Structural Mechanics é um software CAE-CAD (Computer-Aided Engineering - Design), isto é, um software utilizado para auxiliar engenheiros e pesquisadores na área de modelagem estrutural e projeto assistido por computador e é utilizado para análises tipo linear, não-linear, estática ou dinâmicas. A interface gráfica do usuário (GUI) do software é mostrada na Figura 3.1.

O software executa a análise por meio do Método dos elementos finitos utilizando os dados de entrada inseridos pelo usuário. $\mathrm{O}$ desenvolvimento do modelo e a definição dos parâmetros da simulação são feitos utilizando a linguagem paramétrica do software (em inglês APDL, ANSYS Parametric Design Language). O programa inclui uma ferramenta de pós-processamento capaz de gerar resultados que são dependentes da variável "tempo" (na análise estática, este tempo é o carregamento máximo, seja ele força, seja deslocamento) presente no software.

\subsection{Definição e geometria dos modelos estudados}

A análise paramétrica do sistema será executada para 14 modelos distintos. A escolha destes perfis foi feita de modo a serem empregados perfis laminados mais leves de cada série existente no mercado. A espessura da laje será a mesma para todos os modelos, bem como a largura das aberturas e o comprimento da ligação entre stubs e corda inferior. As variáveis da análise serão as seções utilizadas para a corda inferior e stubs. A descrição de cada modelo é apresentada na Tabela 3.1. 
Tabela 3.1. Informações pertinentes aos modelos

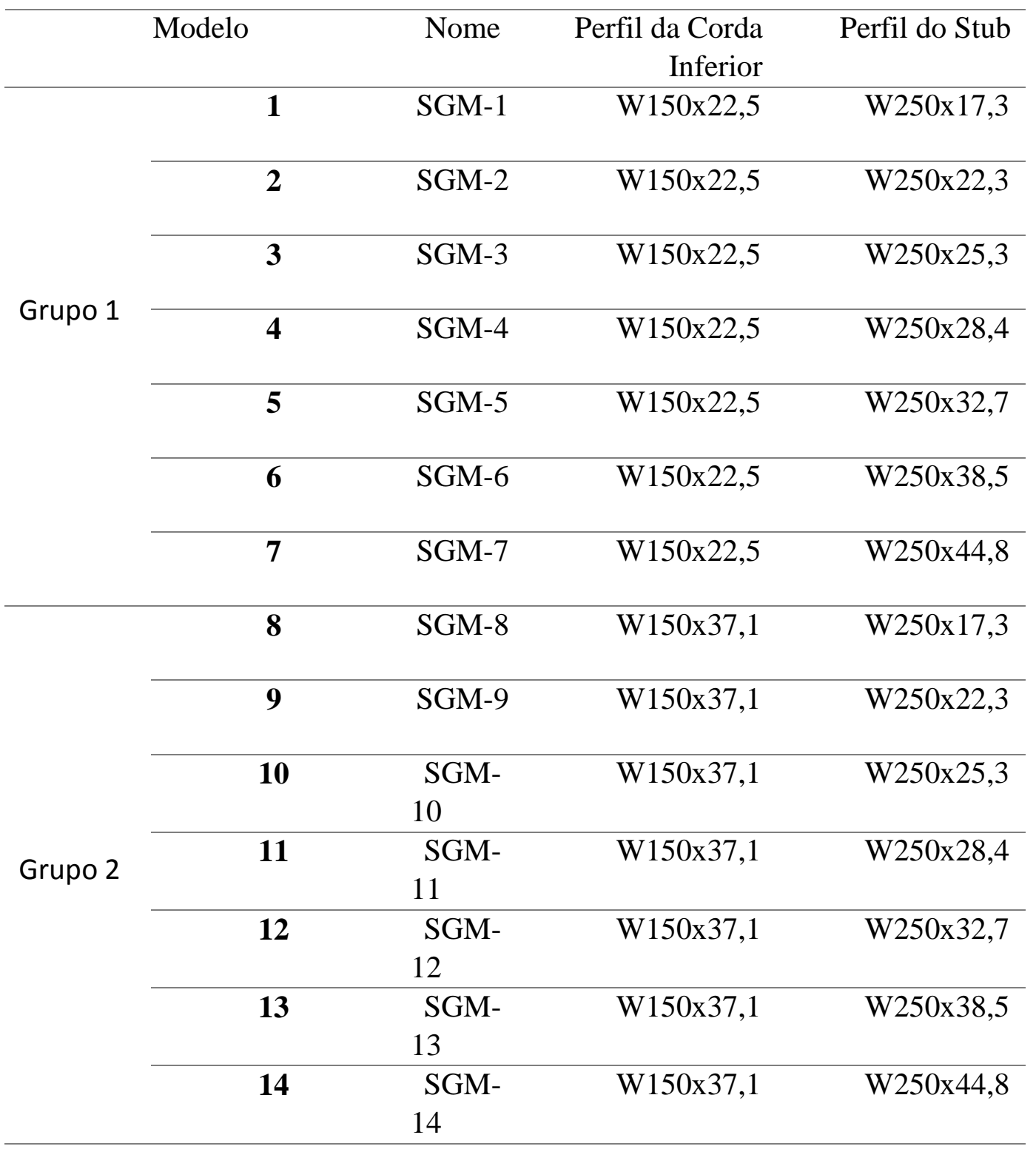

O sistema modificado é formado por dois stubs de comprimento igual a 2520 $\mathrm{mm}$ que proporcionam uma abertura de $480 \mathrm{~mm}$ tendo em vista o vão total de 6.000 mm. O banzo superior é formado por laje maciça de concreto armado, com espessura igual a $100 \mathrm{~mm}$ e largura efetiva, obtida conforme a CAN S16-10, igual a $1.500 \mathrm{~mm}$ (1/4 do comprimento total). O banzo inferior tem comprimento igual a $2360 \mathrm{~mm}$.

A partir da modelagem do sistema, foi decidido que a interação entre os stubs e a laje maciça é considerada completa, ou seja, deslizamento nulo entre as duas partes. É importante salientar que a carga aplicada será dividida entre o banzo superior e o banzo inferior, de acordo com o rateio de seus momentos de inércia, 
como ocorre no sistema stub-girder tradicional. Os modelos serão representados com diversos elementos estruturais no plano X-Y-Z (Modelo 3-D). O sistema modificado é mostrado na Figura 3.1 e os cortes A, B e C nas Figuras 3.2, 3.3 e 3.4.

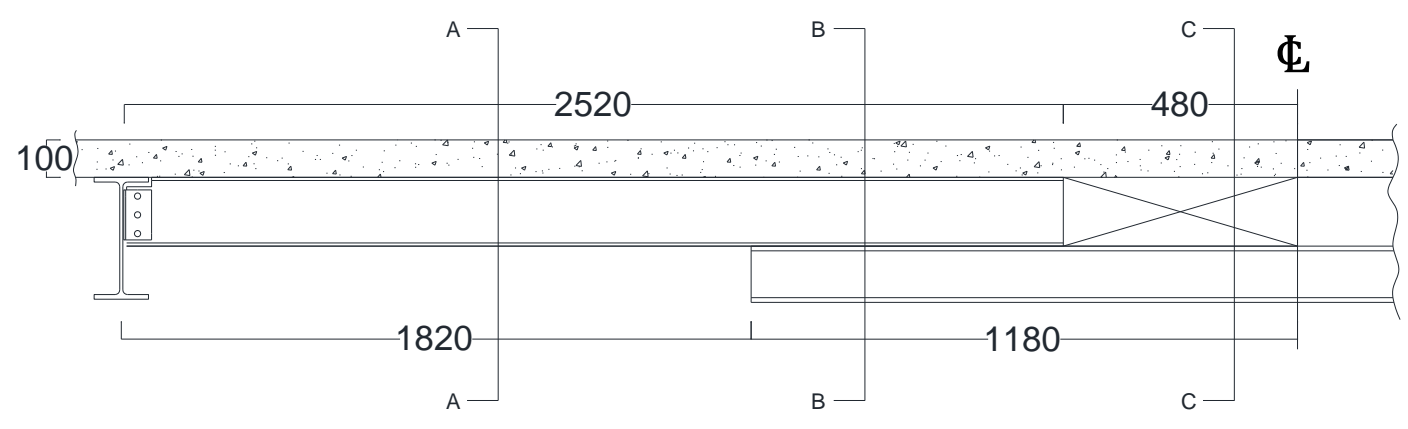

Figura 3.1. Sistema modificado longitudinalmente

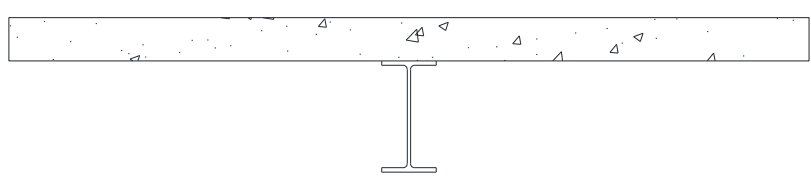

Seção a

(Corte A-A)

Figura 3.2. Seção a

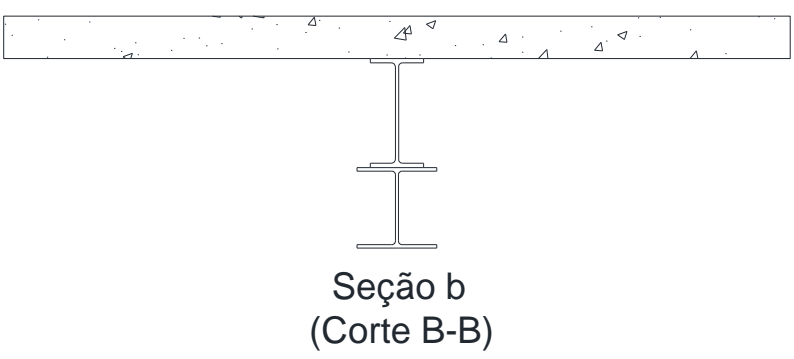

Figura 3.3. Seção b

$\Delta \Delta^{\Delta} \Delta \Delta^{\Delta} \Delta \Delta^{\Delta} \Delta \Lambda$

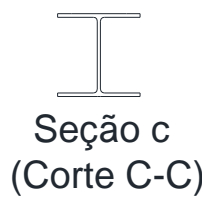

Figura 3.4. Seção c 


\subsection{Unidades}

Não é necessário declarar quais unidades estão sendo utilizadas para forças, deslocamentos, tensões etc. É importante apenas que estes valores resultem em informações que tenham sentido físico. Como $1 \mathrm{MPa}=\frac{1 \mathrm{~N}}{\mathrm{~mm}^{2}}$, as unidades utilizadas serão estas e estão mostradas na Tabela 2.

Tabela 3.2. Unidades utilizadas

\begin{tabular}{ccc}
\hline Dimensão & Unidade & Símbolo \\
\hline Comprimento & Milímetro & {$[\mathrm{mm}]$} \\
Força & Newton & {$[\mathrm{N}]$} \\
\hline Tensão & MegaPascal & {$[\mathrm{MPa}]$} \\
\hline
\end{tabular}

\subsection{Modelo Geométrico}

Os modelos numéricos foram elaborados utilizando-se elementos sólidos SOLID185, presentes na biblioteca de elementos do software ANSYS 15 [11]. O elemento SOLID185 é utilizado para modelagem tridimensional de sólidos. O elemento é definido por oito nós com três graus de liberdade em cada nó: translações nas direções $\mathrm{X}, \mathrm{Y}$ e Z. Este elemento possui propriedades de plasticidade, hiperelasticidade, enrijecimento devido ao estado de tensões, deformações devidas à fluência e grandes deformações e rotações. Este elemento pode ter formato prismático, tetraédrico e piramidal A geometria do elemento é apresentada na Figura 3.5.
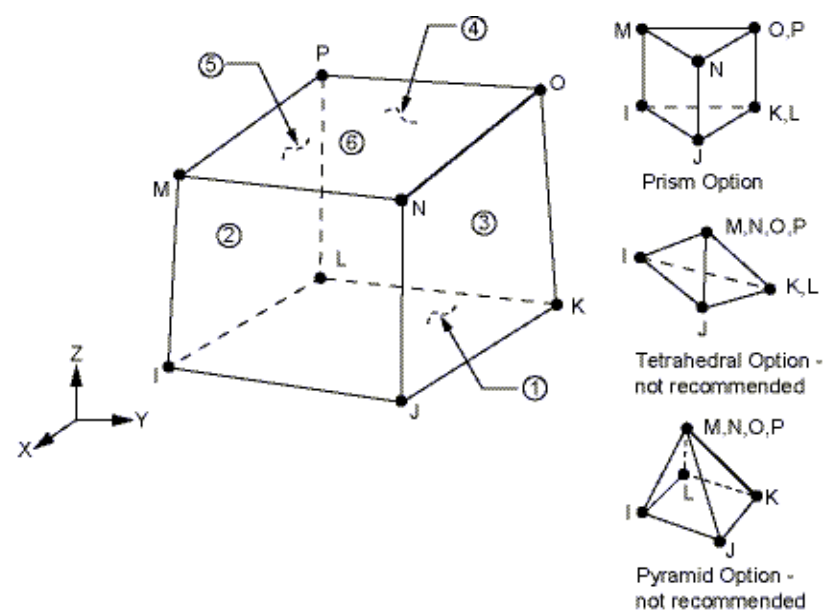

Figura 3.5. Elemento SOLID185 


\subsection{Propriedades dos materiais}

O aço A-572 Grau-50 é utilizado nos perfis laminados, disponíveis no mercado brasileiro, e sua tensão limite de escoamento (fy) é igual a $345 \mathrm{MPa}$, valor retirado da Tabela A.2 (Aços de uso frequente especificados pela ASTM para uso estrutural) da NBR 8800:2008 [12]. De acordo com o item 4.5.2.9 da referida norma, o seu módulo de elasticidade longitudinal (E) é assumido como sendo igual a 200.000 MPa e o coeficiente de Poisson (v) tem valor 0,3. Para as propriedades não-lineares deste material, foi escolhido o modelo bilinear que obedece ao critério de escoamento de Hill [12], em que ao ser atingida a tensão limite de escoamento do material, ocorre o endurecimento isotrópico do mesmo, provocando um aumento uniforme (relacionado ao coeficiente angular $\alpha$, que para esta análise foi considerado $20 \mathrm{MPa}$ ) do tamanho da superfície de escoamento e resulta em um aumento do valor da tensão.

O concreto é um material cuja modelagem é desafiadora. Por ele apresentar comportamentos diferentes devido aos esforços de compressão e de tração, o modelo constitutivo deve ser escolhido de maneira cuidadosa para obter resultados de qualidade. Para a análise deste trabalho, não foram avaliados efeitos de fissuração no concreto. $\mathrm{O}$ módulo de elasticidade $\left(\mathrm{E}_{\mathrm{c}}\right)$, obtido da sua curva tensão versus deformação é igual a $32.903 \mathrm{MPa}$ (para $\mathrm{f}_{\mathrm{ck}}$ igual a $30 \mathrm{MPa}$ ). O coeficiente de Poisson do concreto $\left(v_{c}\right)$ é igual a 0,2. Para as propriedades não-lineares do material, o modelo constitutivo que foi escolhido é multilinear, cujas características são similares às do modelo bilinear, entretanto, existem mais coeficientes angulares, e a tensão varia a partir do escoamento, de acordo com cada um deles.

Baseando-se no que foi exposto, será apresentada a curva tensão-deformação multilinear do concreto na Figura 3.6. 


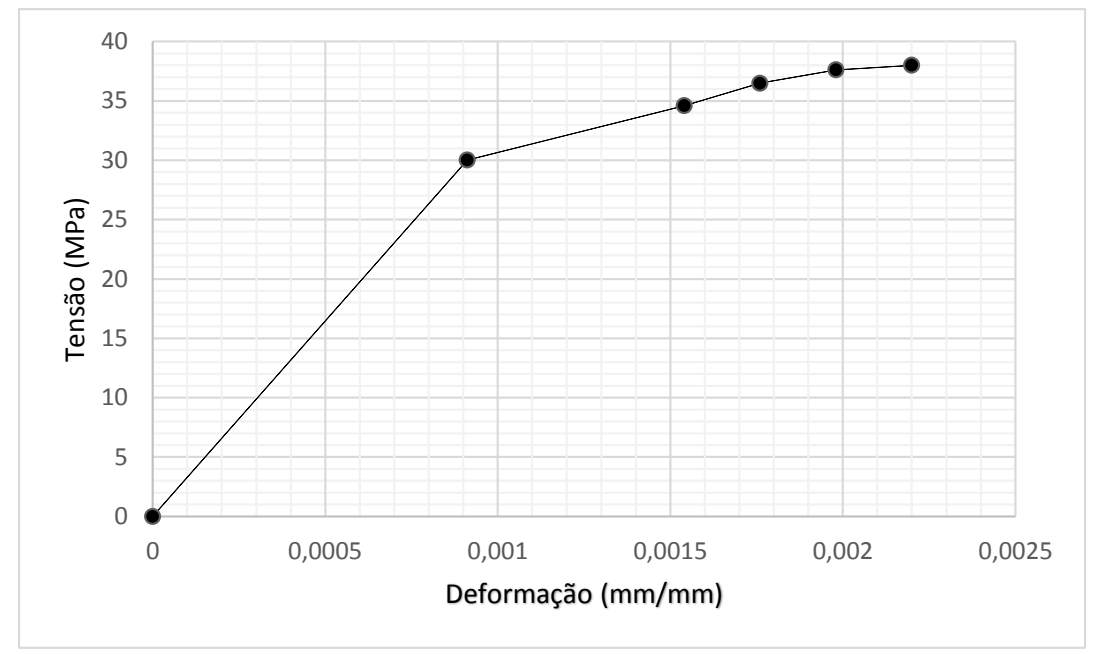

Figura 3.6. Curva tensão versus deformação do concreto

As propriedades dos materiais, inclusive elementos escolhidos para a malha, estão dispostos na Tabela 3.3. 
Tabela 3.3. Propriedades dos materiais

\begin{tabular}{|c|c|c|c|c|}
\hline $\begin{array}{c}\text { Modelo do } \\
\text { Material }\end{array}$ & $\begin{array}{l}\text { Tipo de } \\
\text { elemento }\end{array}$ & \multicolumn{3}{|c|}{ Propriedades do Material } \\
\hline \multirow{6}{*}{1} & \multirow{6}{*}{ SOLID185 } & \multicolumn{3}{|c|}{ Isotrópico Linear } \\
\hline & & EX & \multicolumn{2}{|c|}{$200000 \mathrm{MPa}$} \\
\hline & & PRXY & \multicolumn{2}{|c|}{0,3} \\
\hline & & \multicolumn{3}{|c|}{ Isotrópico Bilinear } \\
\hline & & $\mathrm{f}_{\mathrm{y}}$ & \multicolumn{2}{|c|}{$345 \mathrm{MPa}$} \\
\hline & & $\alpha$ & \multicolumn{2}{|c|}{$20 \mathrm{MPa}$} \\
\hline & \multirow{10}{*}{ SOLID185 } & \multicolumn{3}{|c|}{ Isotrópico Linear } \\
\hline & & EX & 3290 & \\
\hline & & PRXY & & \\
\hline & & \multicolumn{3}{|c|}{ Isotrópico Multilinear } \\
\hline \multirow{6}{*}{2} & & Ponto & Deformação & $\begin{array}{l}\text { Tensão } \\
(\mathrm{MPa})\end{array}$ \\
\hline & & 1 & 0,00091 & 30,00 \\
\hline & & 2 & 0,00154 & 34,59 \\
\hline & & 3 & 0,00176 & 36,49 \\
\hline & & 4 & 0,00198 & 37,62 \\
\hline & & 5 & 0,00220 & 38,00 \\
\hline
\end{tabular}

\subsection{Condições de contorno e aplicação de carregamentos}

Possuir condições de contorno corretas é essencial para uma solução satisfatória do modelo computacional. No caso do sistema proposto, as condições de contorno são idênticas às de uma viga bi-apoiada. Para tanto, a sua aplicação é feita utilizando-se o método Multipoint Constraints (Rigid Surface Constraint), que consiste na criação de um nó piloto ao qual são ligados um nó ou um conjunto de nós pelo Método master-slave. Por meio desse método, as condições aplicadas ao 
nó piloto (master) serão aplicadas também ao conjunto de nós selecionados (slaves). Os graus de liberdade restringidos no primeiro apoio são os translacionais nos eixos Y e Z, e no segundo apoio, o translacional no eixo Y. Similarmente, o deslocamento aplicado no centro da viga foi criado com uma restrição no eixo translacional Y no nó piloto localizado no centro do Stub-Girder.

\subsection{Tipo de Análise}

A análise estrutural não-linear é feita pelo ANSYS por meio da aplicação do método Newton-Raphson. Com a finalidade de realizar uma previsão do comportamento não linear do material, a carga aplicada (deslocamento no eixo Y) foi dividida em uma série de passos (substeps) que são incrementados imediatamente após o critério de convergência do passo anterior ter sido atendido. A carga é aplicada com incrementos menores durante a fase de escoamento dos materiais. A ruína ocorre quando a solução não atende ao critério de convergência, mesmo com incrementos de carga muito pequenos.

\subsection{Exemplo de modelo geométrico}

A primeira etapa consiste na implementação das propriedades dos materiais bem como os tipos de elemento utilizados para a análise do modelo. As Figuras 3.8 e 3.9 apresentam estas informações após sua implementação no software ANSYS 15. A segunda etapa consiste na criação do modelo geométrico propriamente dito, através da criação de volumes que representem o sistema stub-girder modificado. Nesta etapa são inseridos valores como espessura da laje, largura efetiva da laje, comprimento total do sistema, largura da abertura, comprimento da ligação entre stubs e corda inferior, espessuras das almas e mesas dos stubs e corda inferior, largura das mesas dos stubs e corda inferior e altura da alma dos stubs e corda inferior. Após a criação dos volumes, é o utilizado o comando $N U M M R G$ (para Keypoints), que faz a compatibilidade entre os keypoints dos volumes. As Figuras a seguir ilustram o sistema após a criação dos volumes no ANSYS 15.

A criação da malha em si é a próxima etapa. O primeiro passo a ser tomado é dividir as linhas do modelo com o uso do comando LESIZE, em que se escolhe o número de divisões para cada linha ou o tamanho das divisões. Nos modelos criados para esta pesquisa foram usados o número de divisões. 
O próximo passo após as divisões das linhas é a criação da malha. Para este processo, é necessário escolher quais elementos e materiais serão utilizados para o aço e para o concreto e em seguida, utilizar os comandos MSHKEY e VMESH, cujas funções são respectivamente fazer com que a malha siga a disposição das linhas divididas em criação da malha. As Figuras 3.7 e 3.8 ilustram o modelo após a criação da malha.

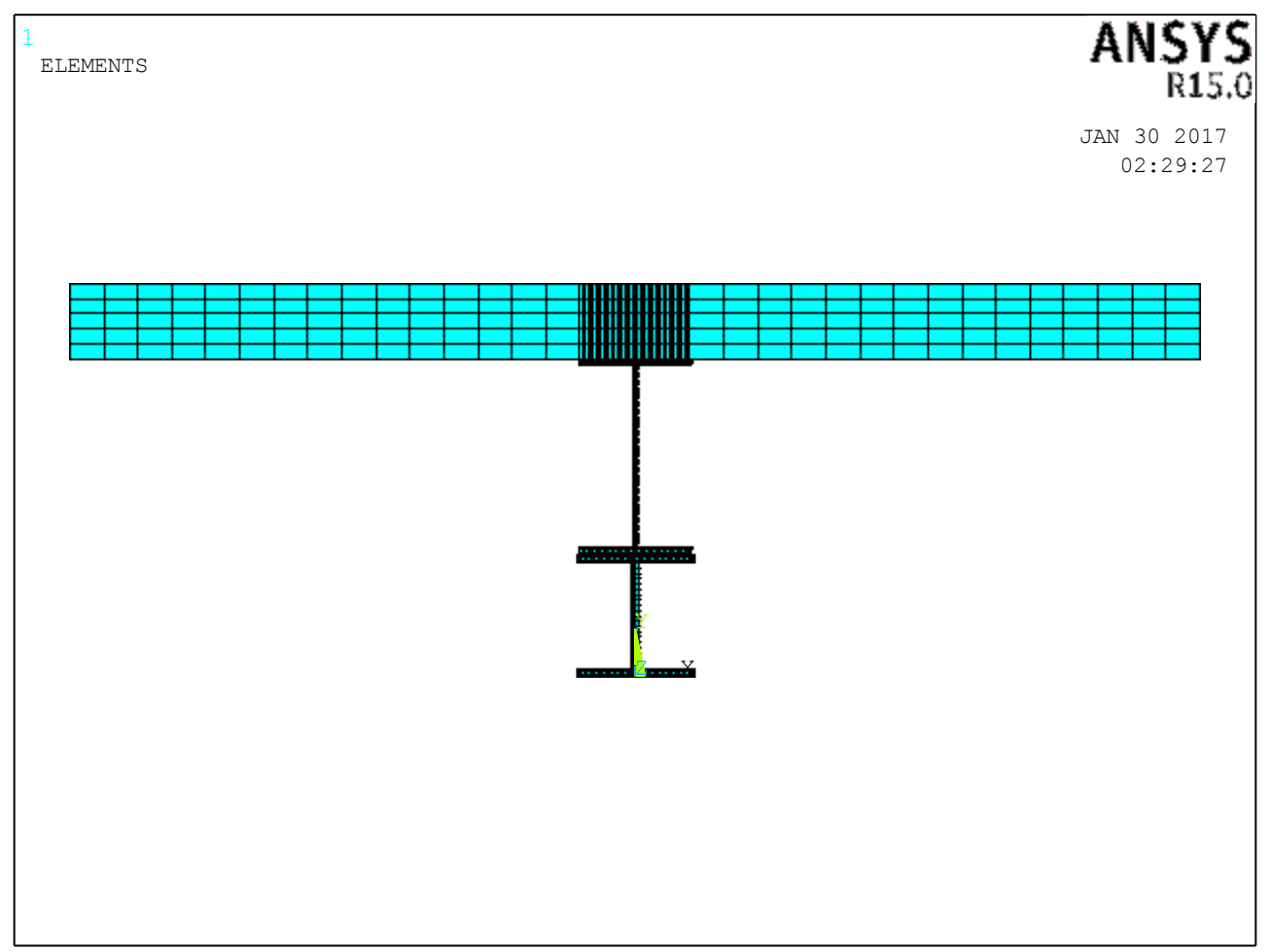

Figura 3.7. Malha criada vista frontalmente 


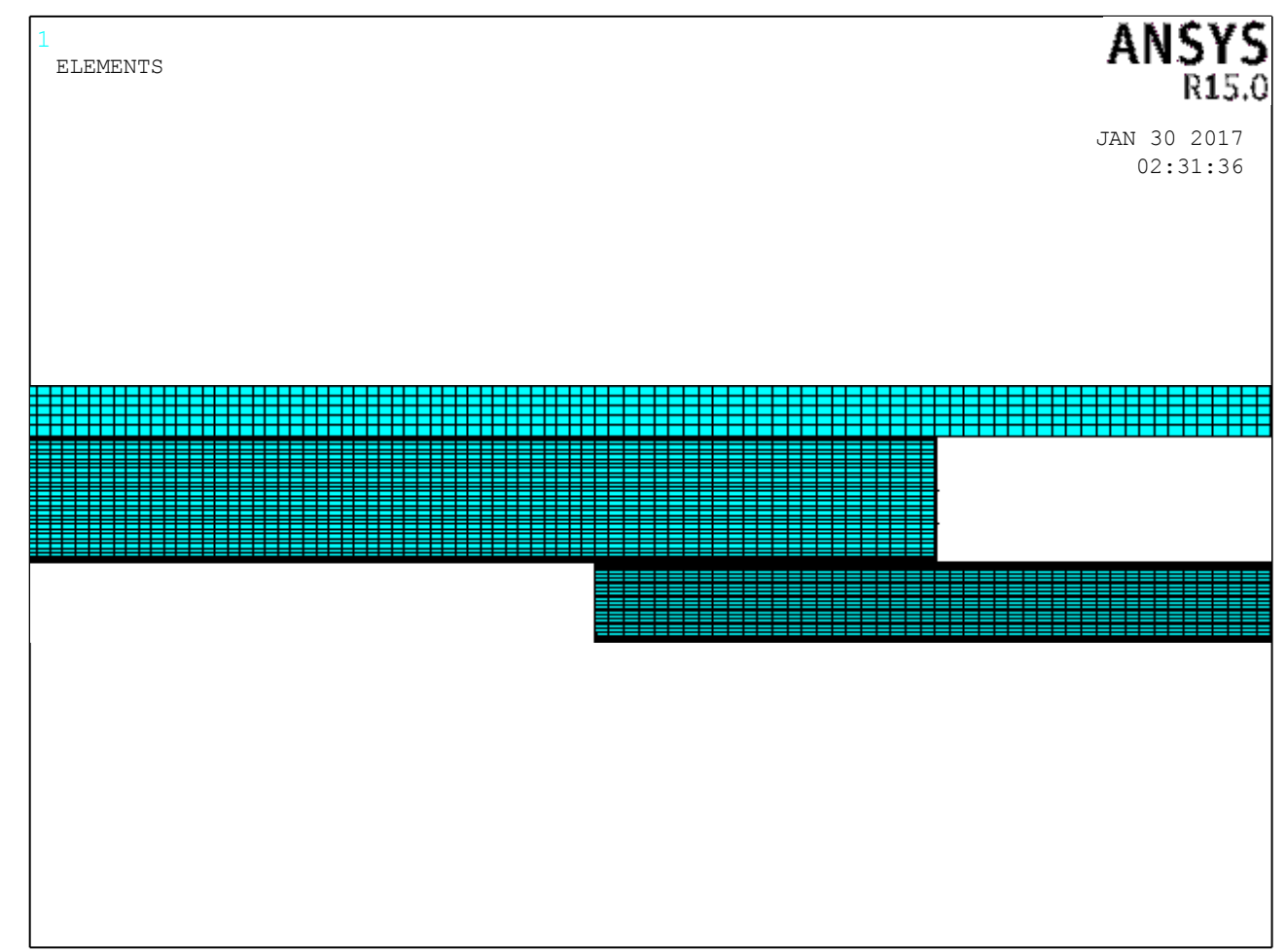

\section{Figura 3.8. Malha criada vista lateralmente}

Após a criação da malha, o comando $N U M M R G$ (para os nós) é novamente utilizado para a compatibilização dos nós da estrutura. Este comando faz com que a ligação completa entre o aço e o concreto, bem como a ligação entre os perfis que compõe os stubs e a corda inferior seja efetuada.

A próxima etapa consiste na criação dos apoios e implementação do deslocamento aplicado no centro do sistema modificado. Para este fim, é utilizado o assistente Contact Manager, que é responsável pela criação do nó piloto e dos nós que recebem suas características de deslocamento nulo nos apoios e deslocamento vertical no centro do sistema através do método master-slave. A Figura 3.16 apresenta a janela do Contact Manager.

No assistente deve ser escolhida a criação do nó piloto, que no caso dos modelos utilizados nesta pesquisa, consiste de um nó criado anteriormente.

Um componente de nós que fazem parte do sistema modificado deve ser criado para que os mesmos sejam acoplados ao nó piloto e compartilhem os deslocamentos com o mesmo.

$\mathrm{Na}$ próxima etapa é necessário escolher quais deslocamentos serão compartilhados entre o nó piloto e os nós do componente criado. Para o primeiro apoio, os deslocamentos escolhidos são X, Y e Z translacionais e Z rotacional. Para 
o segundo apoio, os deslocamentos são apenas X e Y translacionais, o que cria a simulação do modelo biapoiado. Esta etapa é mostrada na Figura 3.19.

Após esta etapa, devem ser aplicados os deslocamentos aos nós pilotos criados. A Figura 3.9 ilustra o sistema após a criação de todos os seus componentes.

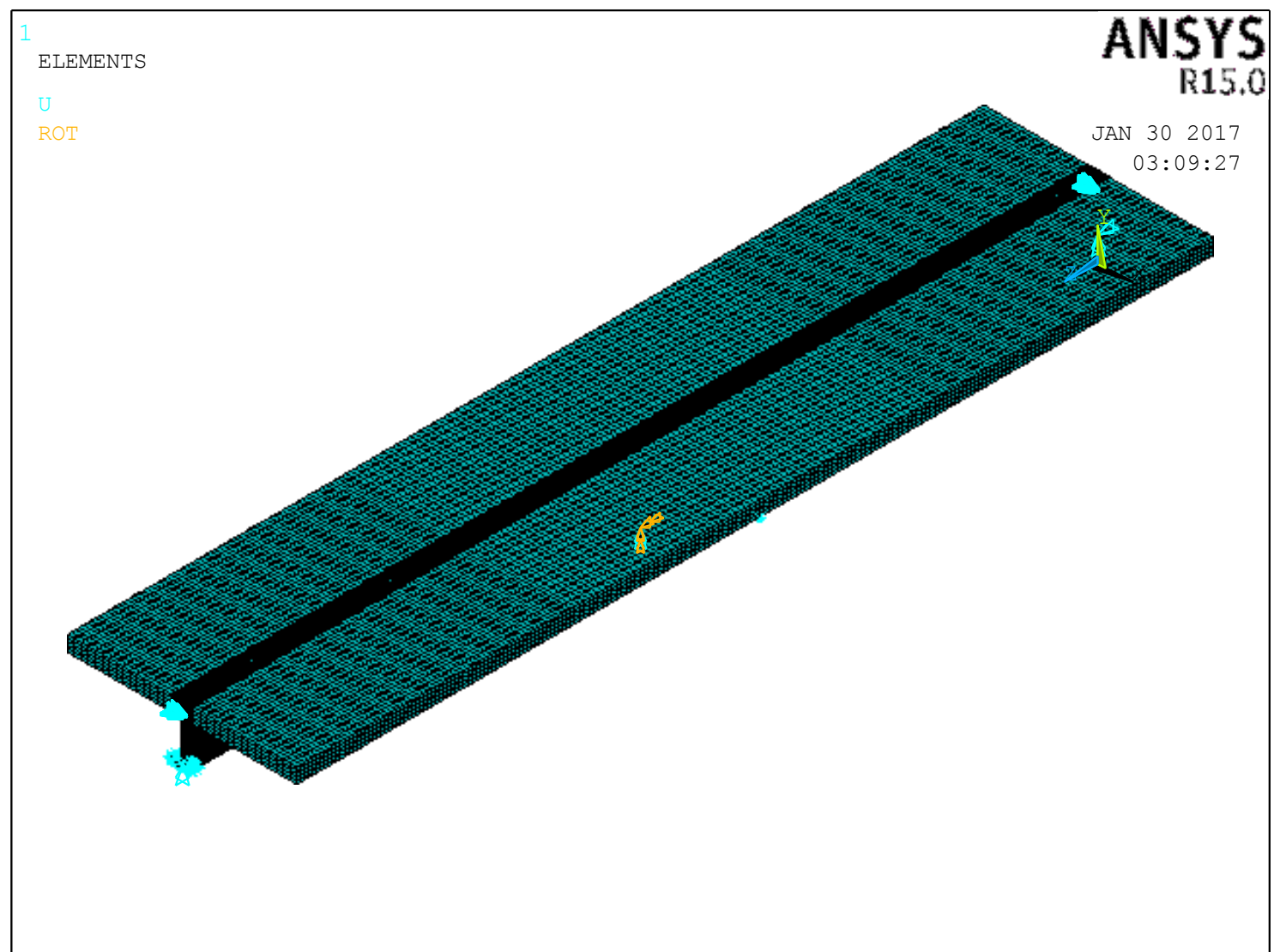

Figura 3.9. Sistema após a criação de apoios e deslocamentos aplicados

A última etapa consiste na escolha dos componentes da análise do sistema.

Eles consistem na escolha da análise estática, escolhida pelo comando ANTYPE, ativação da geometria não-linear por meio do comando NLGEOM, escolha do número de substeps, com a utilização do comando NSUBST, no qual são escolhidos o número de substeps para a análise, bem como o número mínimo e número máximo dos mesmos. O comando OUTRES é responsável pelo armazenamento de todos os dados para cada substep e o comando AUTOTS é utilizado para ativar a mudança no tamanho de cada incremento de carga de acordo com o avanço da análise. Finalmente, os comandos LNSRCH e NEQIT são responsáveis pela ativação do comando line search, que auxilia na convergência da análise e escolha do número máximo de interações. 


\section{4}

\section{Análise e discussão dos resultados}

\subsection{Força versus deslocamento nos modelos}

A análise não-linear física e geométrica foi realizada para os 14 modelos e, no pós-processamento, obtidos os gráficos de força aplicada versus deslocamento. A partir destes gráficos são obtidas as cargas críticas para cada modelo.

Destes gráficos podem ser retiradas importantes informações que auxiliarão no entendimento do sistema no que diz respeito à análise não-linear geométrica e física e ao projeto do sistema por meio do método dos estados limites de acordo com a norma canadense CAN-S16.

Os gráficos condensados para os modelos 1 a 7, em que a seção do perfil utilizado para a corda inferior é W150 x 22,5 são apresentados na Figura 4.1. 


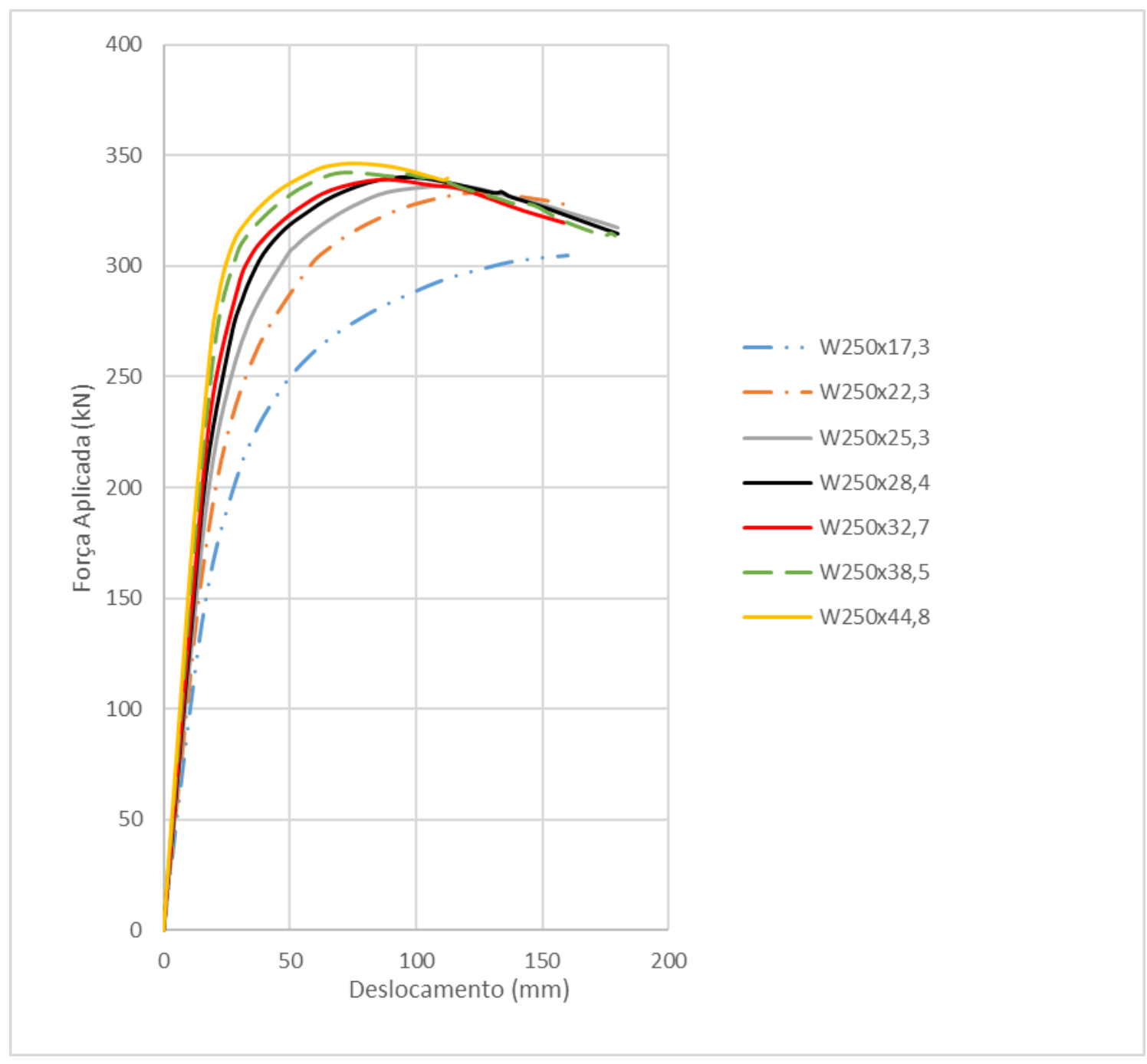

Figura 4.1. Força Aplicada versus Deslocamento dos modelos 1 a 7

Os gráficos condensados para os modelos 8 a 14, em que a seção do perfil utilizado para corda inferior é W150 x 37,1 estão expostos na figura 4.2. 


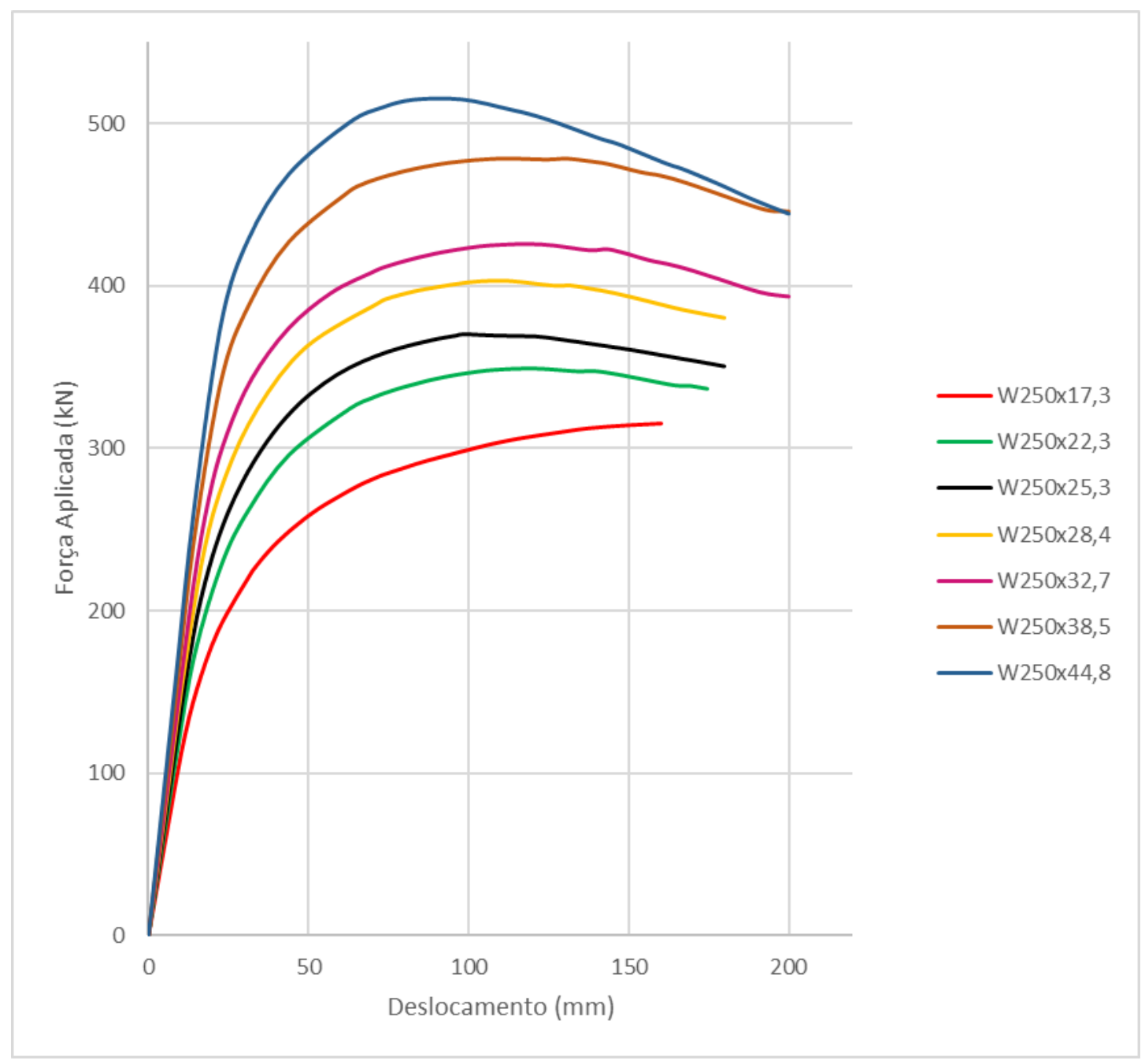

Figura 4.2. Força Aplicada versus Deslocamento dos modelos 8 a 14

Outro aspecto importante a ser analisado é como os stub-girders modificados comportam-se quando a seção do stub é a mesma, mas a da corda inferior é alterada. Estes comparativos são apresentados nas Figuras 3 a 9. 
44

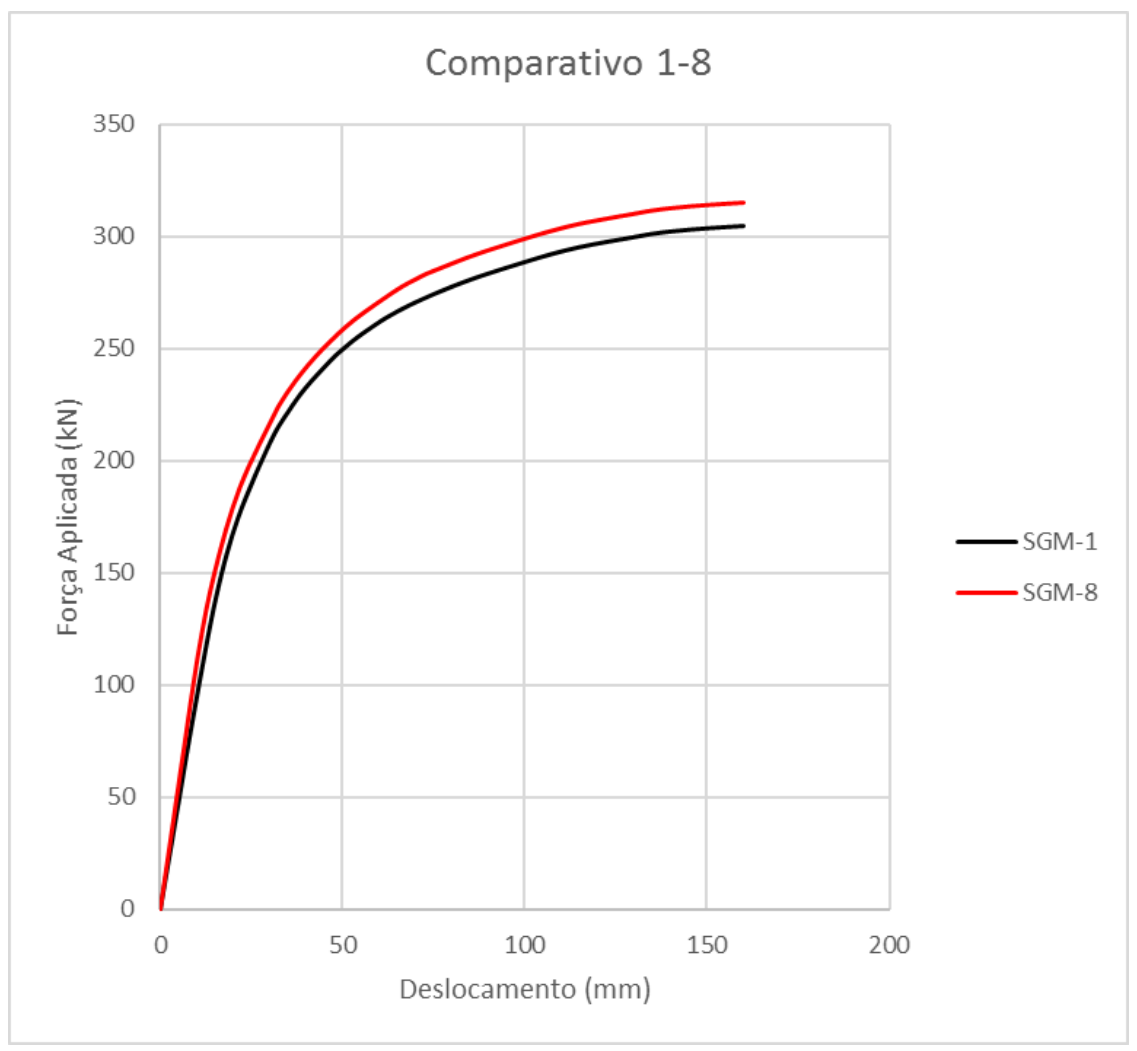

Figura 4.3. Comparativo entre SGM-1 e SGM-8

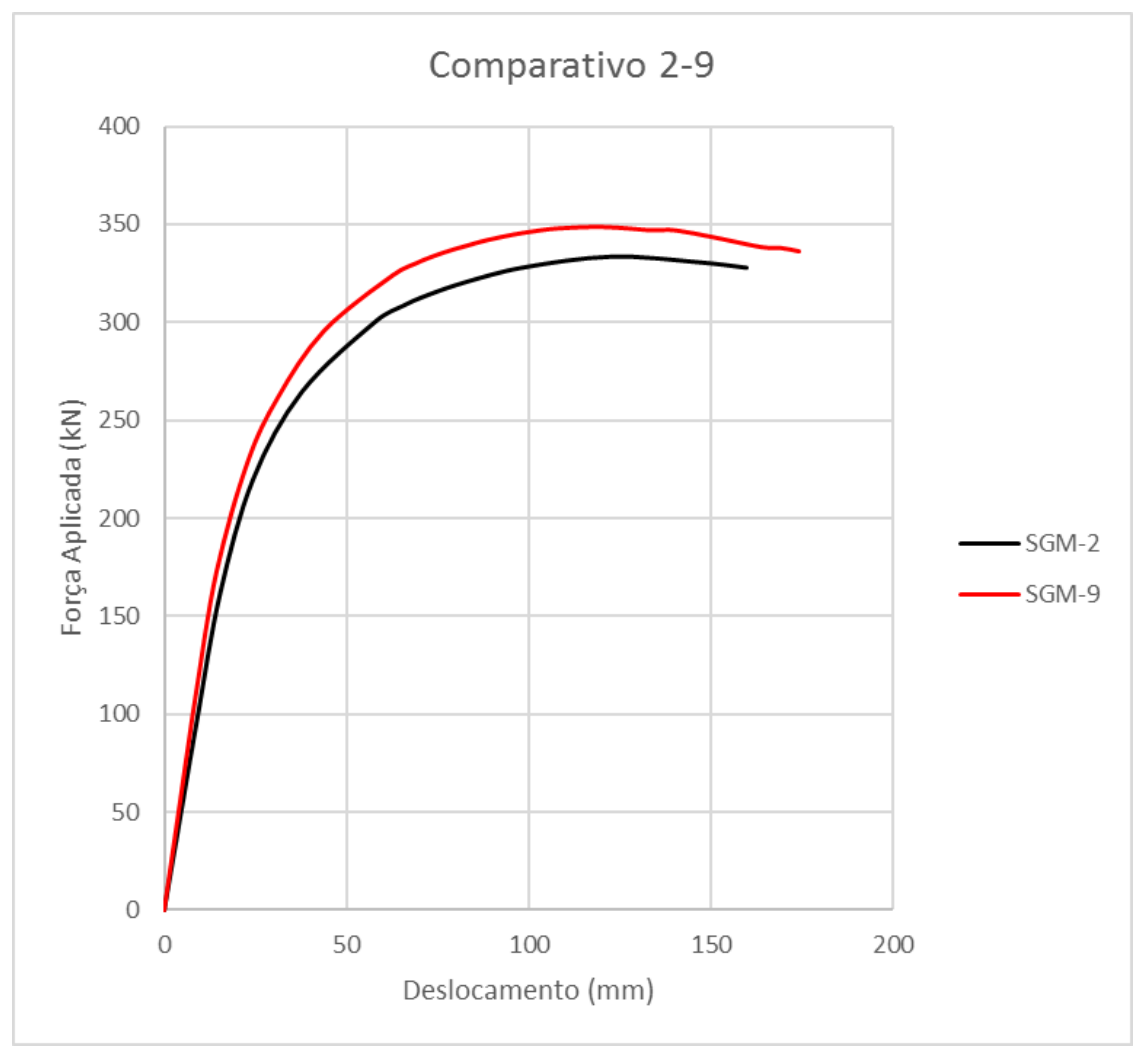

Figura 4.4. Comparativo entre SGM-2 e SGM-9 


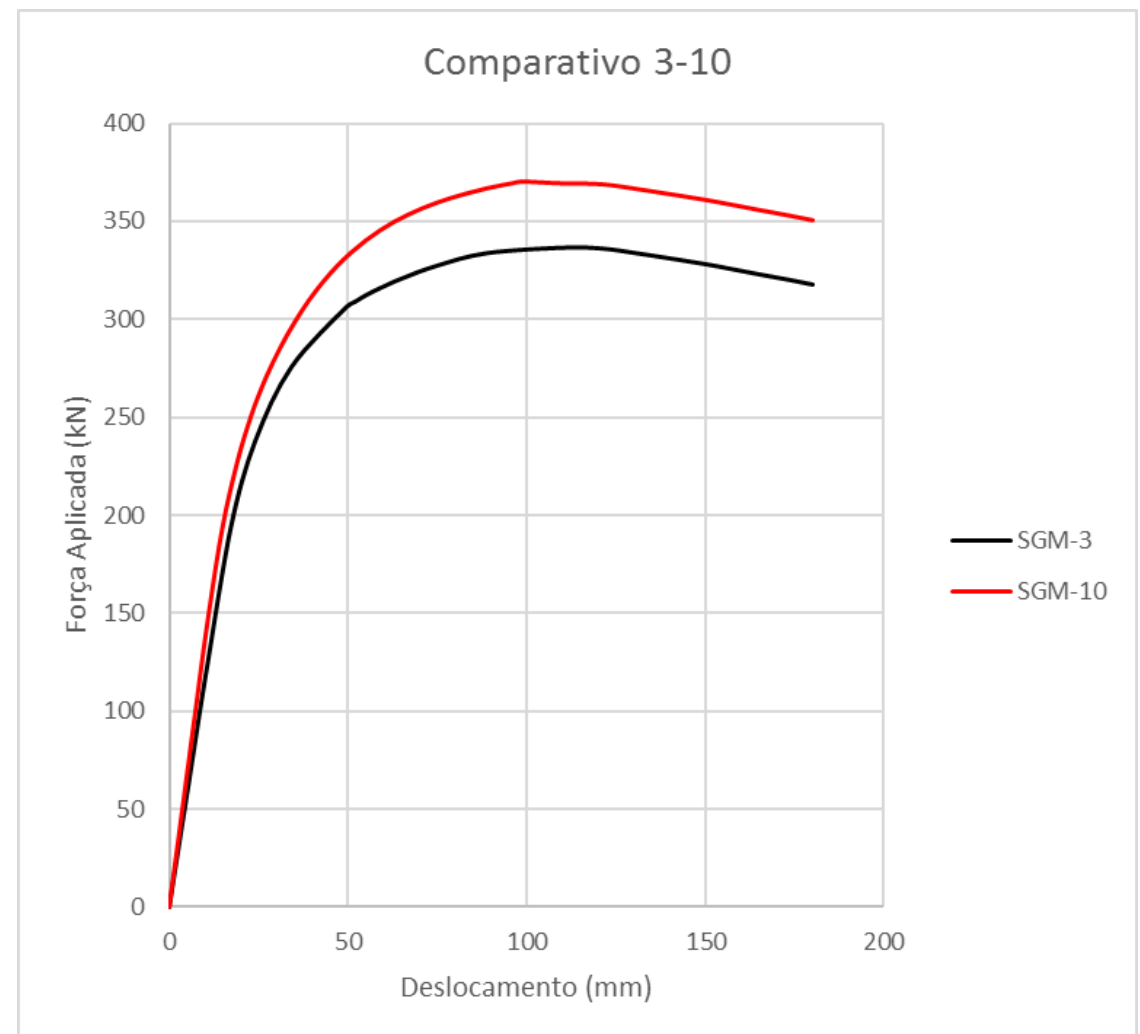

Figura 4.5. Comparativo entre SGM-3 e SGM-10

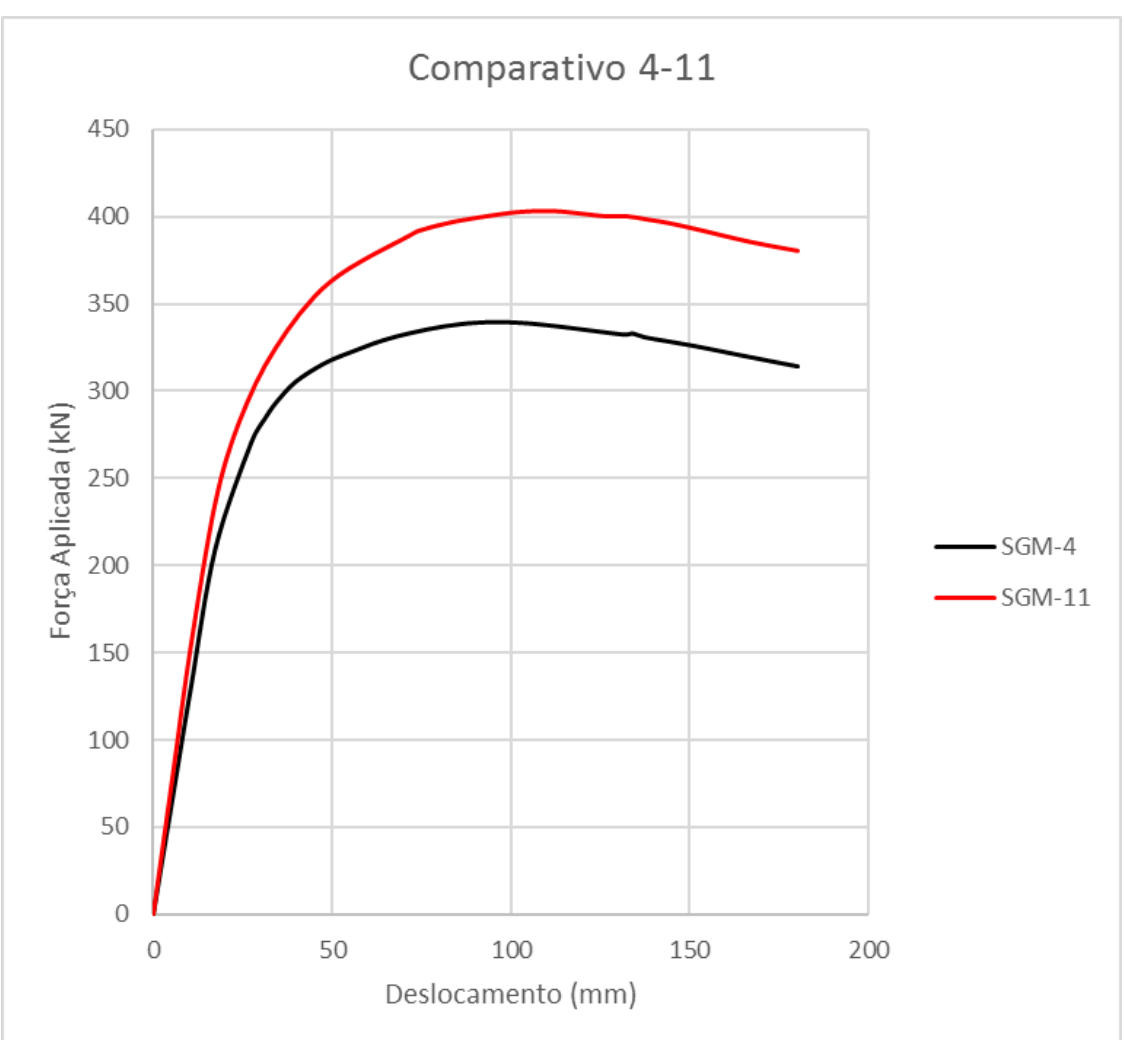

Figura 4.6. Comparativo entre SGM-4 e SGM-11 


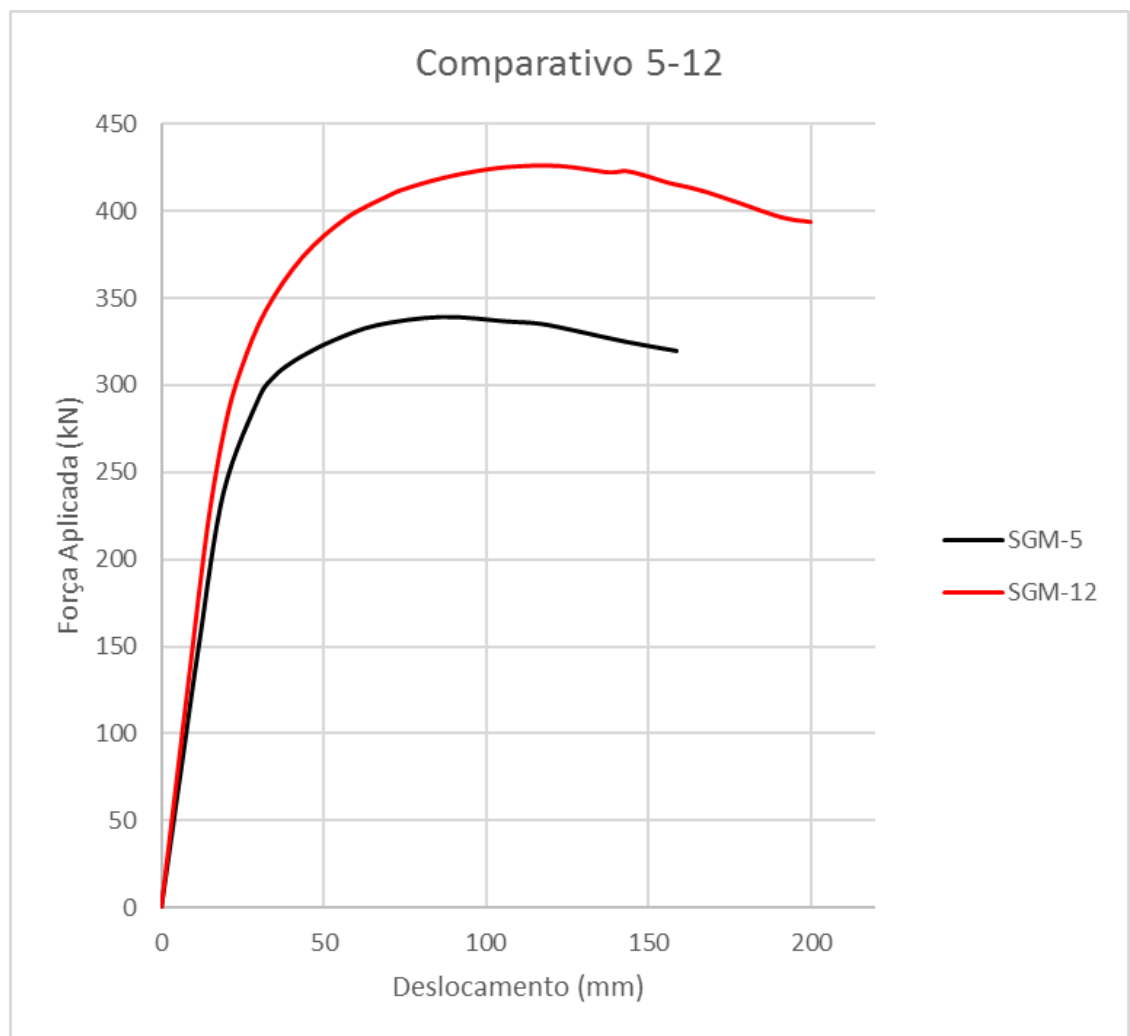

Figura 4.7. Comparativo entre SGM-5 e SGM-12

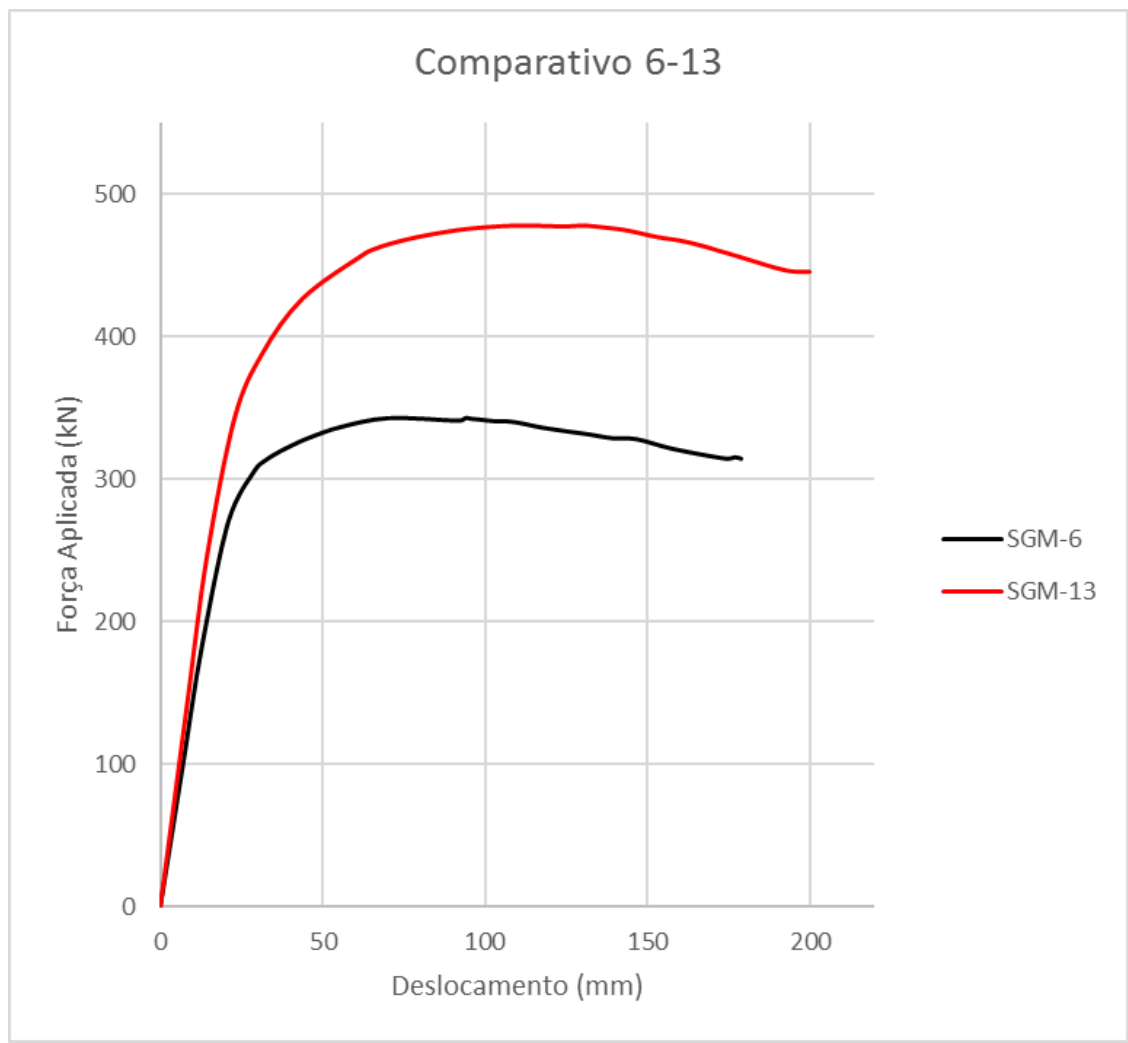

Figura 4.8. Comparativo entre SGM-6 e SGM-13 


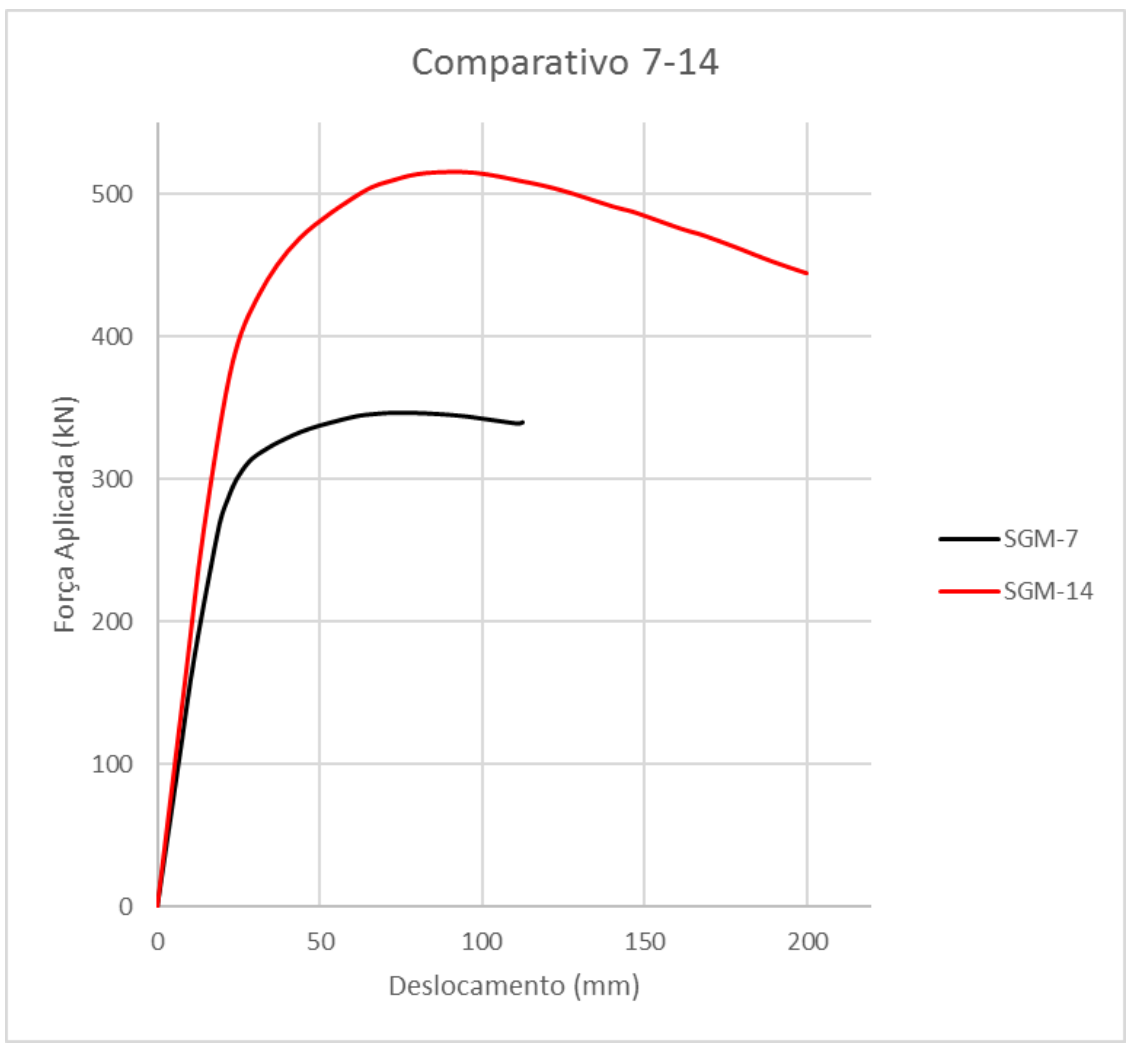

Figura 4.9. Comparativo entre SGM-7 e SGM-14

\subsubsection{Cargas Máximas}

As cargas máximas de cada modelo foram obtidas nas fases de pósprocessamento de cada modelo, e são apresentadas na Tabela 4.1.

Tabela 4.1. Cargas Máximas

\begin{tabular}{cc}
\hline Modelo & Carga máxima $\mathrm{F}_{\mathrm{u}}(\mathrm{kN})$ \\
\hline SGM-1 & 305,60 \\
\hline SGM-2 & 333,42 \\
\hline SGM-3 & 336,40 \\
\hline SGM-4 & 339,87 \\
\hline SGM-5 & 338,90 \\
\hline SGM-6 & 342,48 \\
\hline SGM-7 & 346,46 \\
\hline SGM-8 & 315,07 \\
\hline SGM-9 & 348,87 \\
\hline SGM-10 & 370,26 \\
\hline SGM-11 & 403,32 \\
\hline
\end{tabular}




\begin{tabular}{lc}
\hline SGM-12 & 422,99 \\
\hline SGM-13 & 478,07 \\
\hline SGM-14 & 515,035 \\
\hline
\end{tabular}

\subsection{Critério de plastificação de Von Mises}

O critério de plastificação de von Mises [14], em sua versão simplificada, sugere que a plastificação dos materiais começa quando a tensão equivalente de von Mises $\left(\sigma_{\mathrm{v}}\right)$ atinge um valor crítico, a tensão limite de escoamento $\left(\mathrm{f}_{\mathrm{y}}\right)$. Uma vez que este limite é atingido, a deformação plástica é iniciada. Caso o material empregado possua característica de encruamento, ocorre então a alteração da superfície de escoamento de von Mises de acordo com o aumento da seção que atingiu o limite de escoamento, deste modo, permitindo que os estados de tensão para o escoamento subsequente sejam estabelecidos e possíveis. Este critério é parte da teoria de plasticidade e se aplica melhor a materiais dúcteis, como metais.

Este critério também é utilizado para a análise da deformação plástica de materiais dúcteis, pois o início da plastificação nos mesmos não depende da componente hidrostática do tensor de tensões. A equação geral do critério é apresentada a seguir (Eq. 4.1).

$$
\sigma_{v}=\sqrt{\frac{1}{2}\left[\left(\sigma_{11}-\sigma_{22}\right)^{2}+\left(\sigma_{22}-\sigma_{33}\right)^{2}+\left(\sigma_{33}-\sigma_{11}\right)^{2}+6\left(\tau_{12}^{2}+\tau_{23}^{2}+\tau_{31}^{2}\right)\right]}
$$

A partir do que foi exposto, serão apresentadas as regiões onde ocorreu a plastificação, e na área de discussão será feito o paralelo entre as tensões de Von Mises e a carga de máxima de cada modelo, em que a tensão limite de escoamento do aço $\left(f_{y}\right)$ é de $345 \mathrm{MPa}$. 


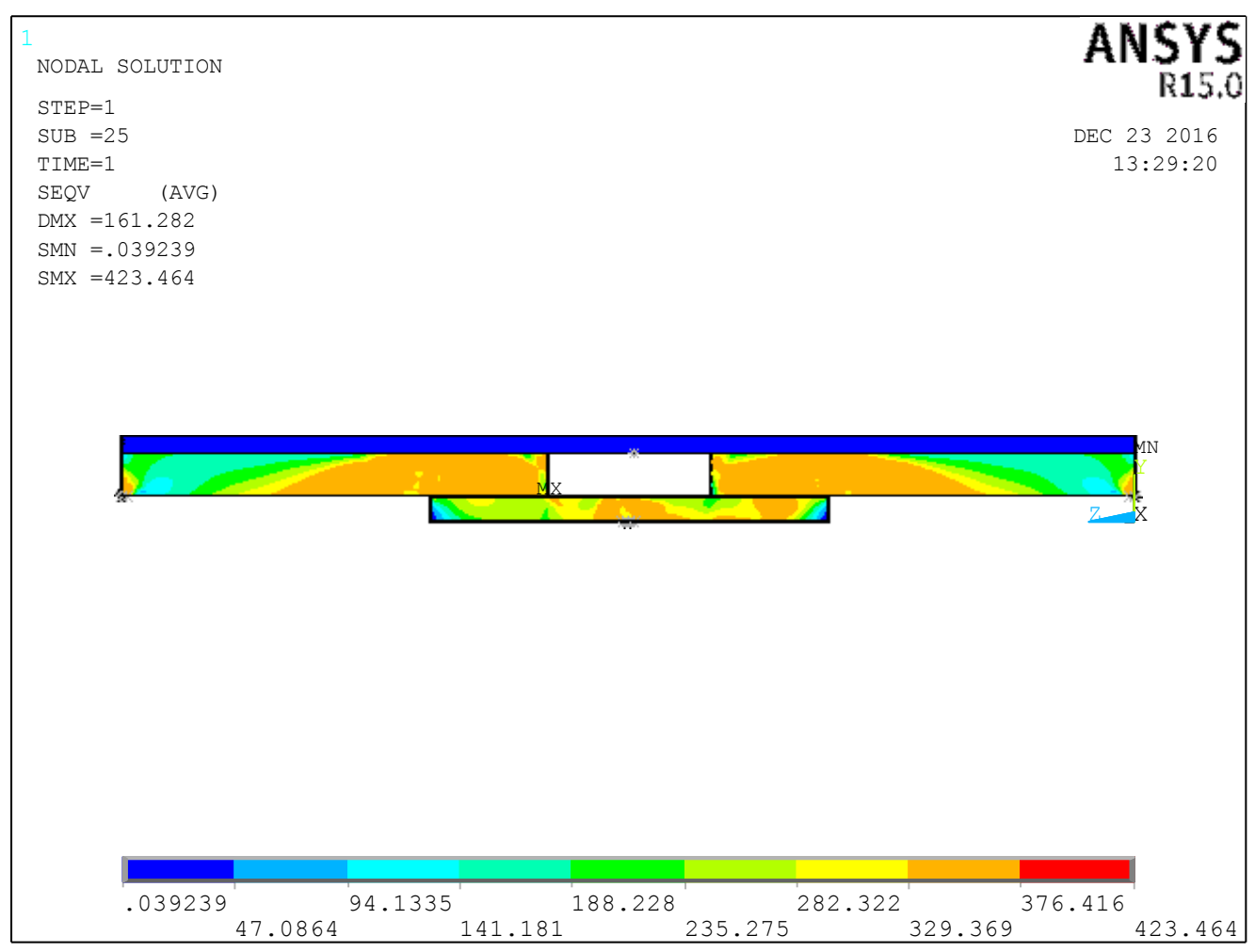

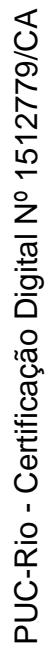

Figura 4.10. Tensões de von Mises no modelo SGM-1

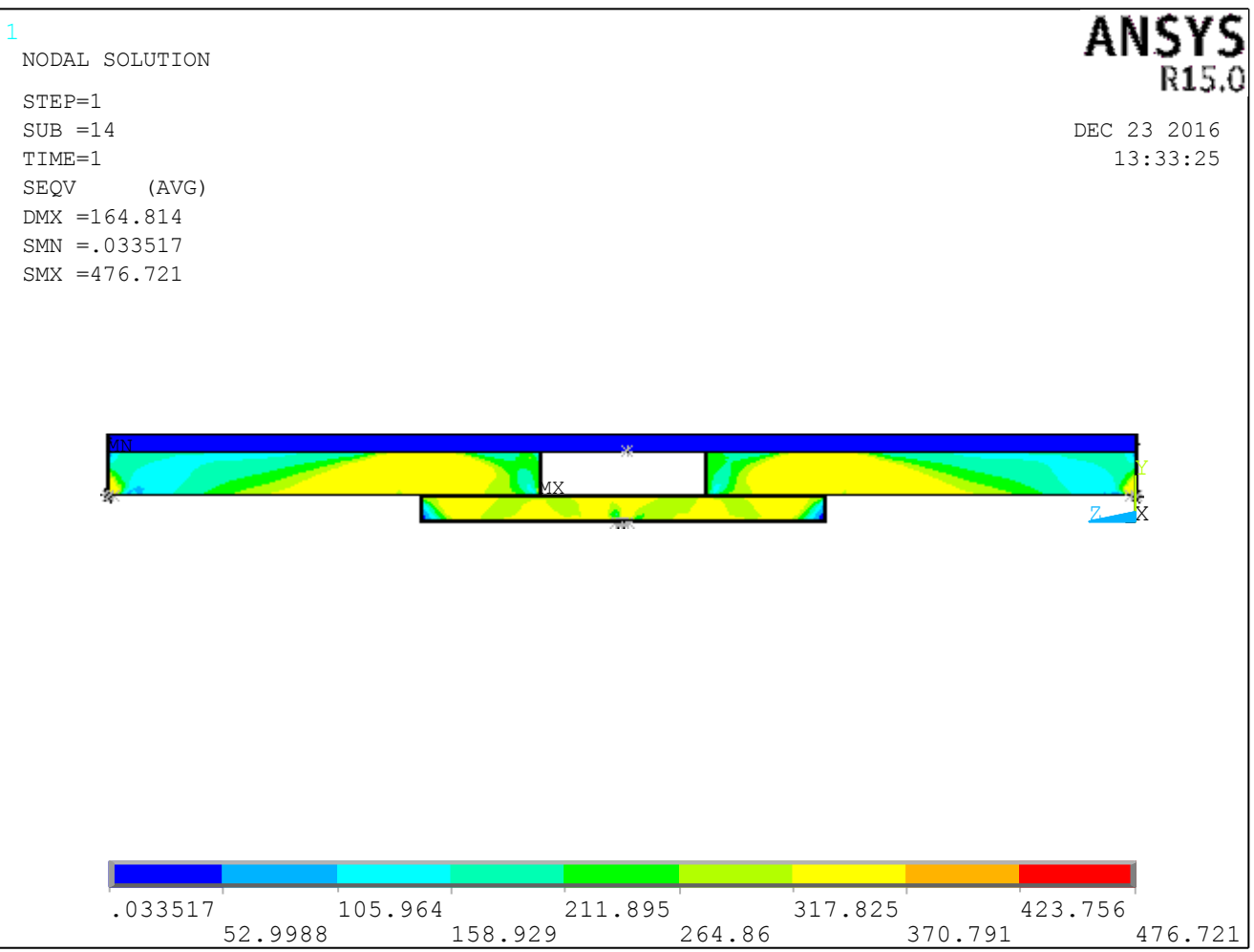

Figura 4.11. Tensões de von Mises no modelo SGM-2 


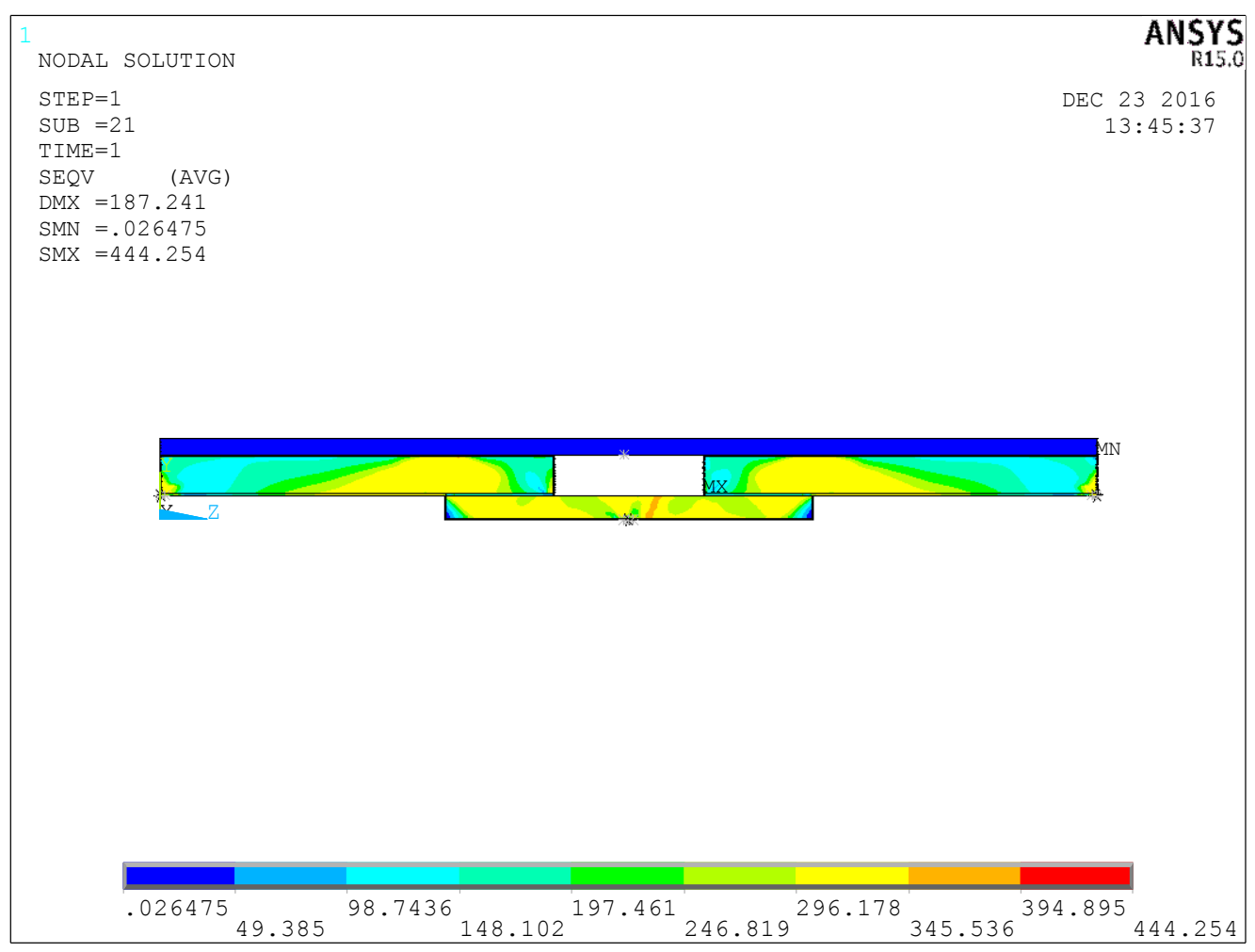

Figura 4.12. Tensões de von Mises no modelo SGM-3

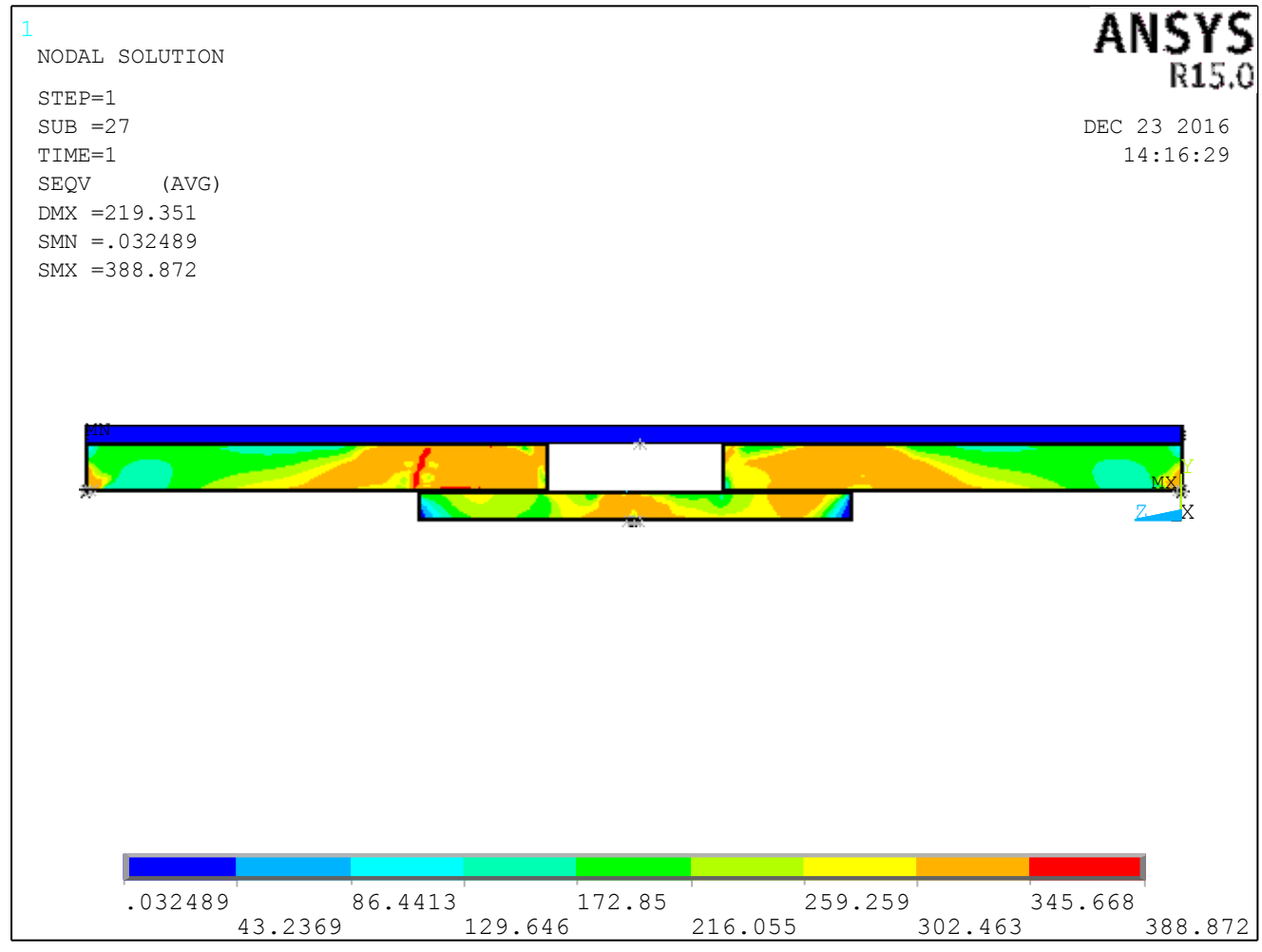

Figura 4.13. Tensões de von Mises no modelo SGM-12 


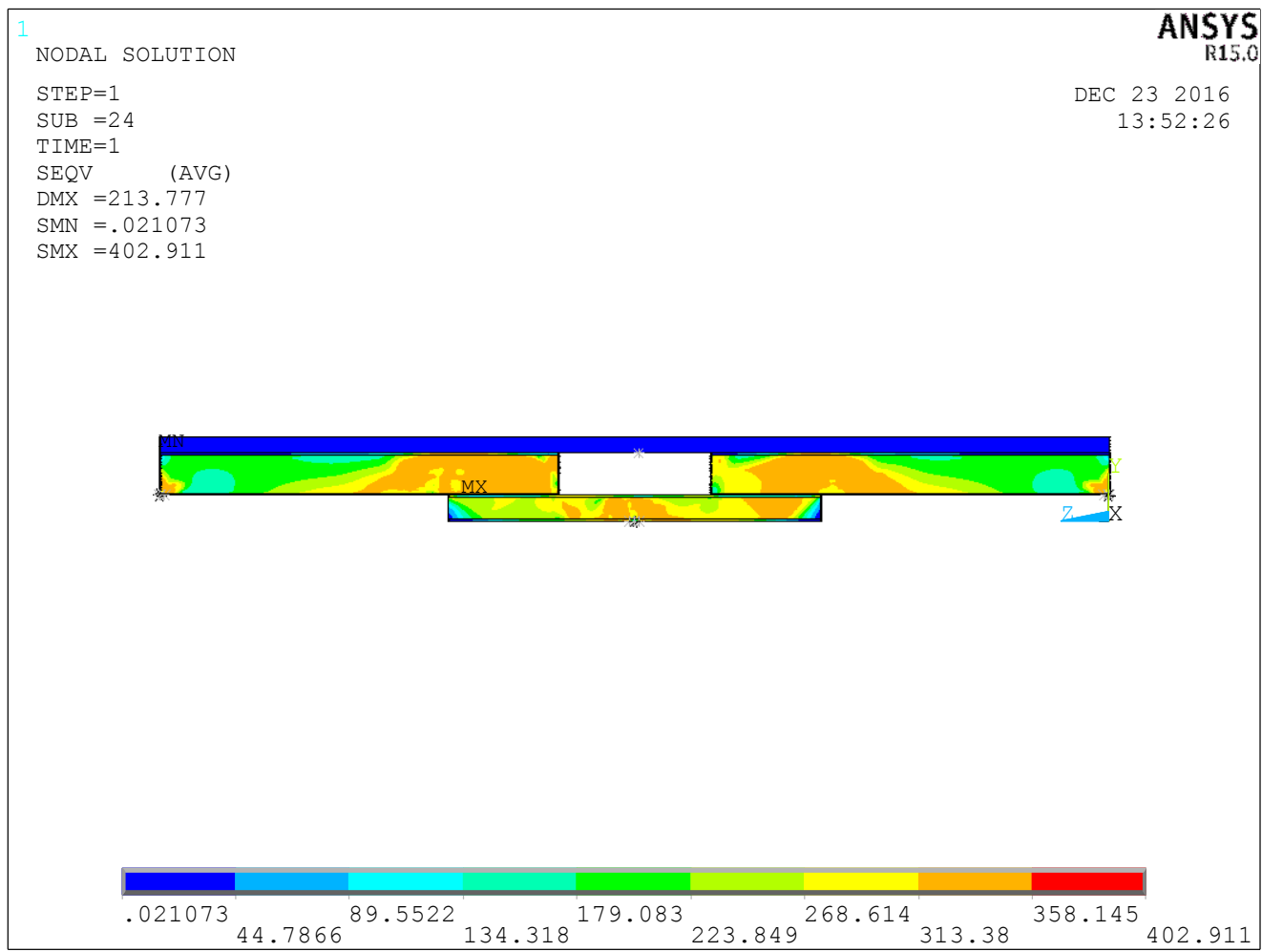

Figura 4.14. Tensões de von Mises no modelo SGM-13

Com base nessas informações, pode-se observar que o sistema modificado possui duas seções críticas: a região central da corda inferior e a região de transição entre stubs e corda inferior. A relação da área e momento de inércia entre essas seções é importante, pois, a partir dela, pode-se verificar se um destes elementos está sendo subutilizado. Nas Figuras 4.15 a 4.20, a seguir, é apresentada a evolução da tensão de von Mises nas duas seções críticas em função do deslocamento vertical no centro do sistema modificado para os modelos SGM-2, SGM-3, SGM-4, SGM12, SGM-13 e SGM-14. 


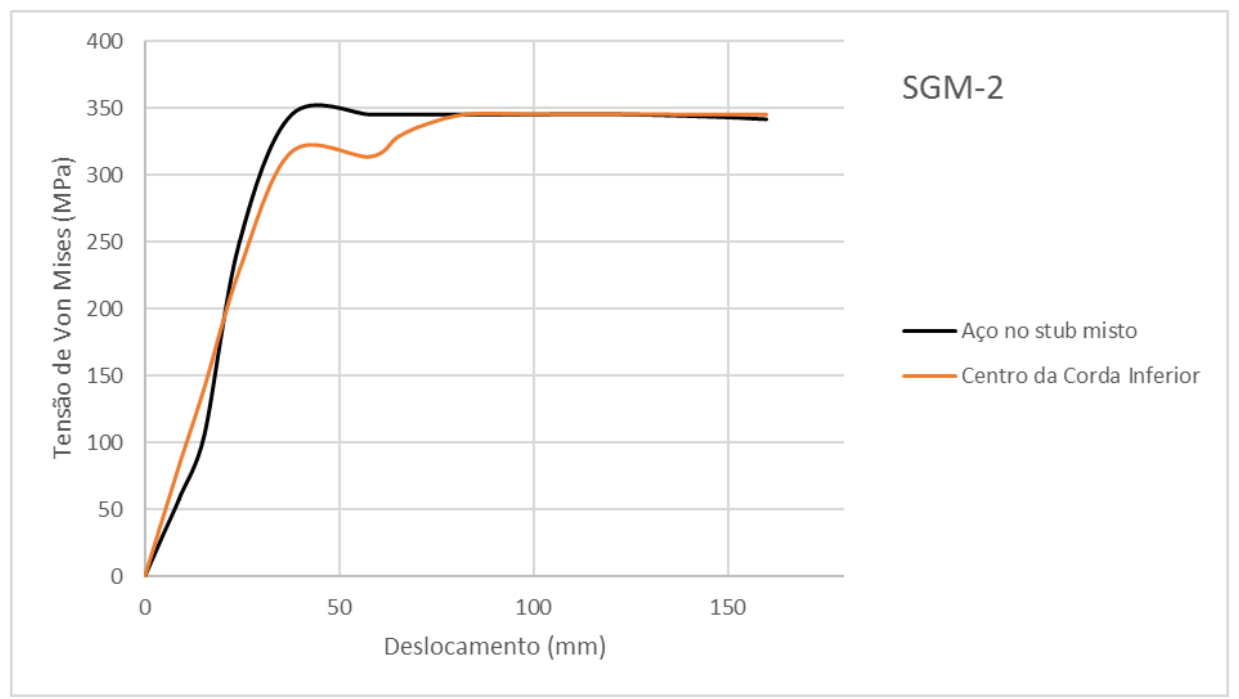

Figura 4.15. Tensões de Von Mises nas seções críticas do modelo SGM-2

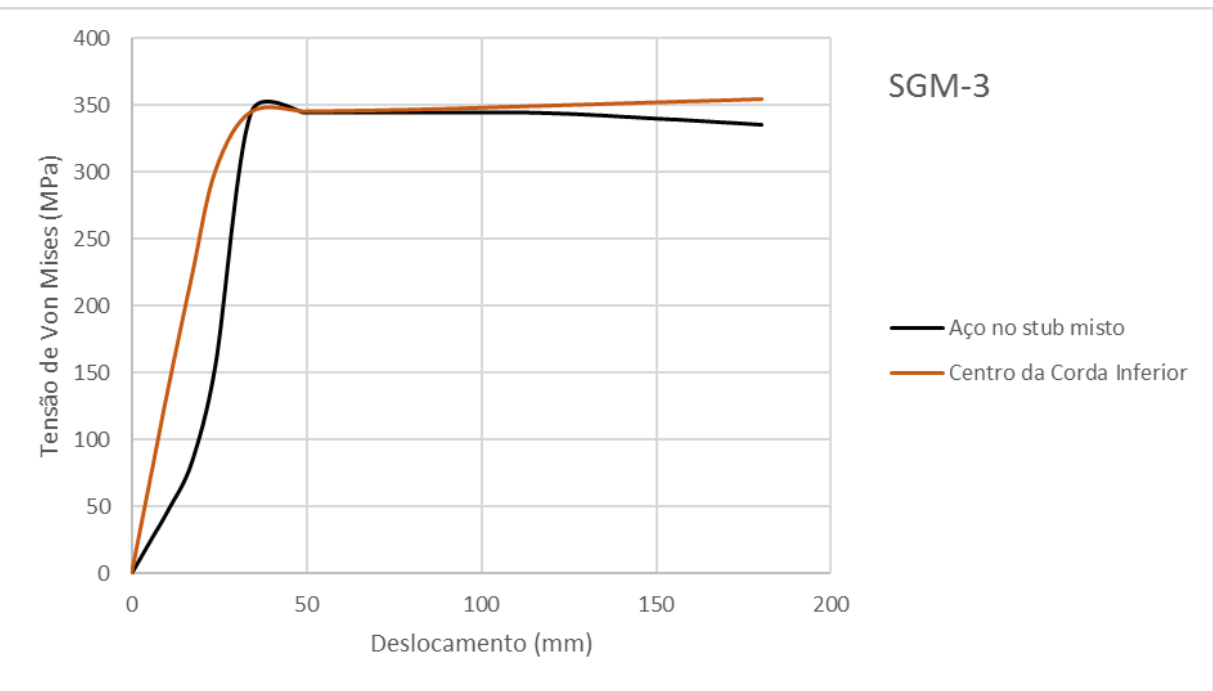

Figura 4.16. Tensões de Von Mises nas seções críticas do modelo SGM-3

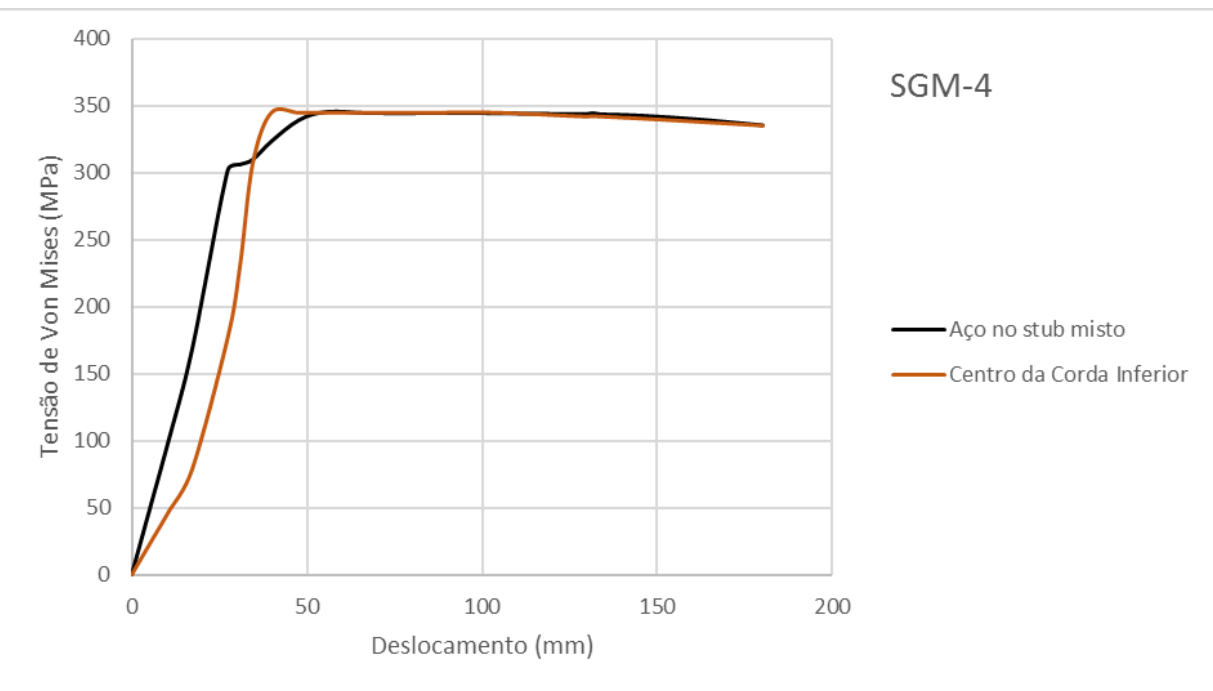

Figura 4.17. Tensões de Von Mises nas seções críticas do modelo SGM-4 


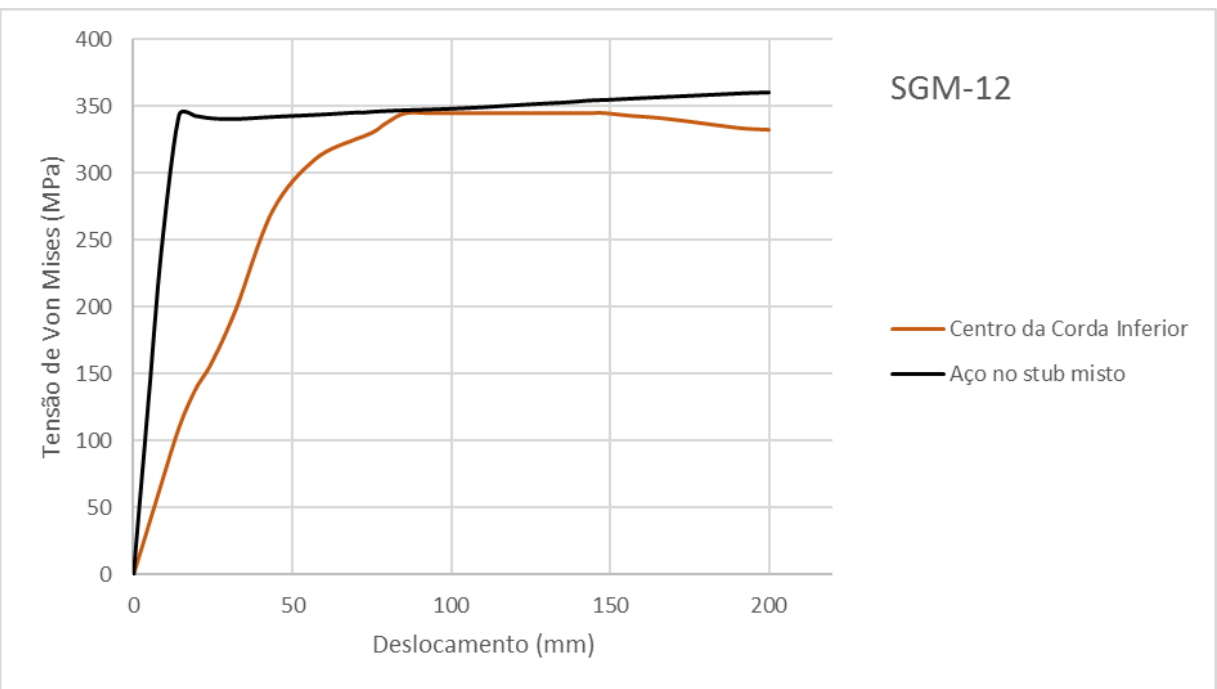

Figura 4.18. Tensões de Von Mises nas seções críticas do modelo SGM12

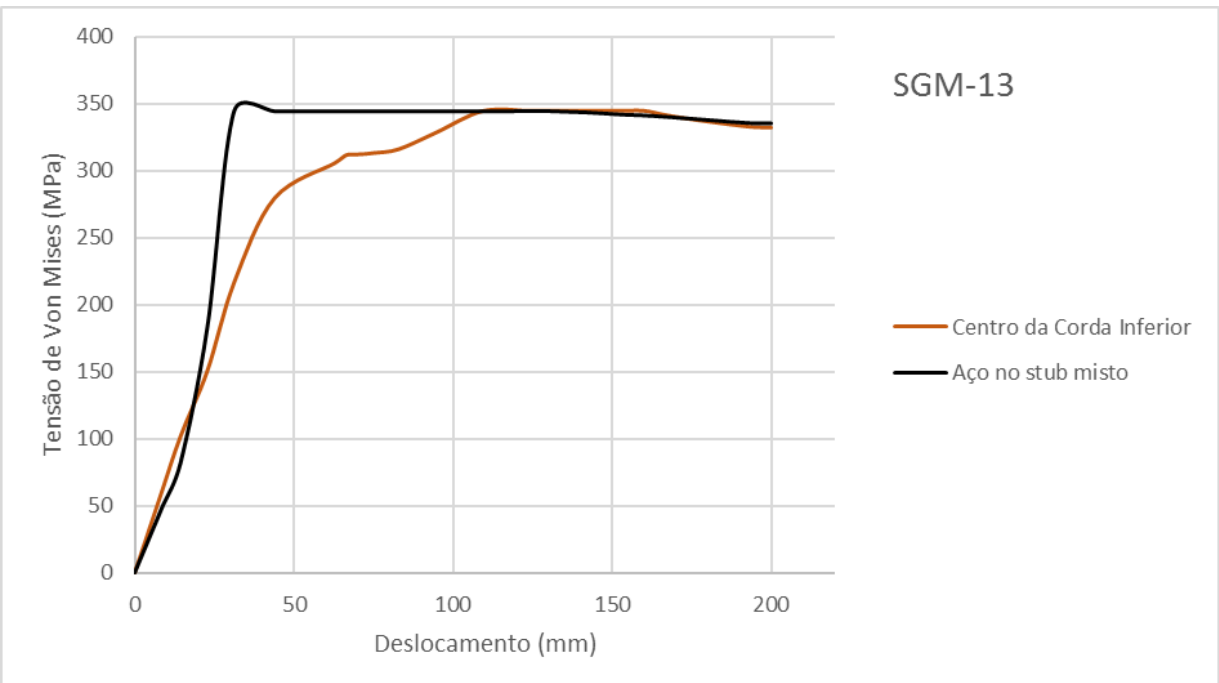

Figura 4.19. Tensões de Von Mises nas seções críticas do modelo SGM13 


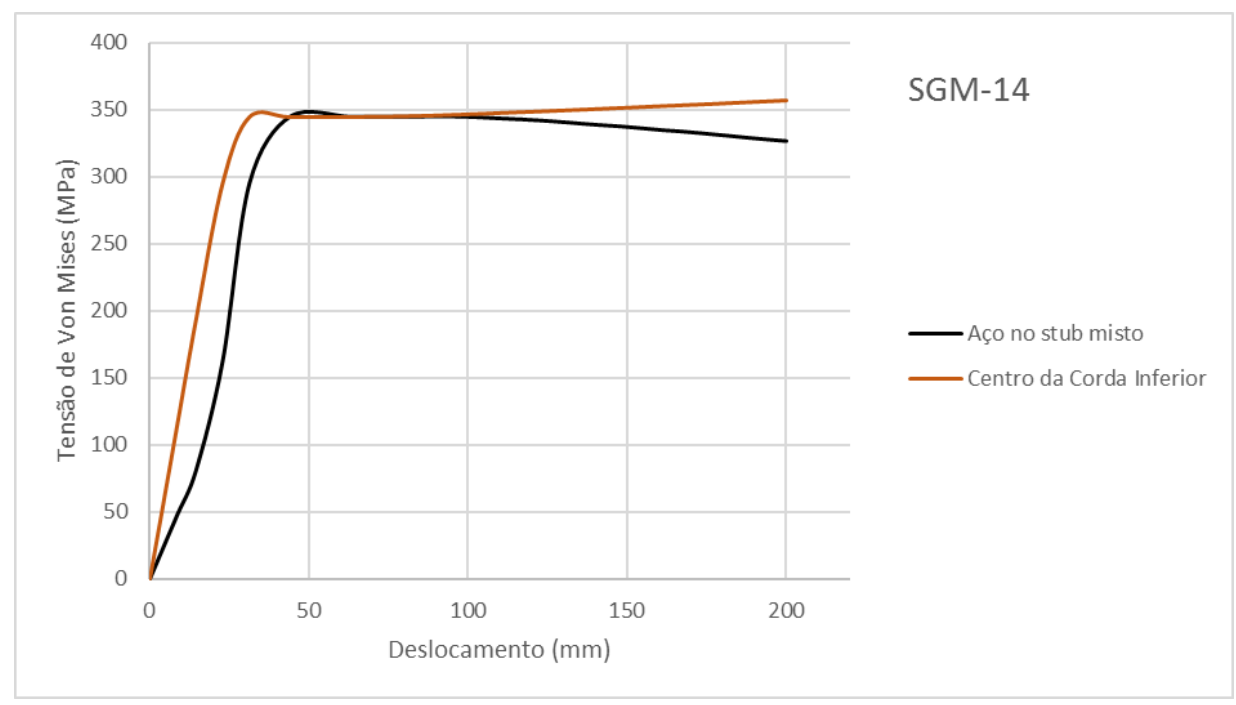

Figura 4.20. Tensões de Von Mises nas seções críticas do modelo SGM14

\subsection{Cargas de serviço}

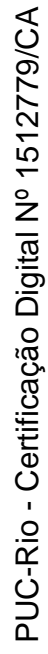

A partir dos gráficos obtidos no item 4.1, foram obtidas as cargas de serviço para todos os modelos estudados, apresentadas na Tabela 2.

Tabela 4.2. Cargas de serviço dos modelos 1 a 14

\begin{tabular}{cc}
\hline Modelo & Carga de Serviço $\mathrm{F}_{\mathrm{w}}(\mathrm{kN})$ \\
\hline SGM-1 & 141,96 \\
\hline SGM-2 & 174,22 \\
\hline SGM-3 & 207,40 \\
\hline SGM-4 & 214,42 \\
\hline SGM-5 & 234,00 \\
\hline SGM-6 & 237,24 \\
\hline SGM-7 & 235,24 \\
\hline SGM-8 & 142,42 \\
\hline SGM-9 & 174,60 \\
\hline SGM-10 & 205,34 \\
\hline SGM-11 & 214,32 \\
\hline SGM-12 & 277,11 \\
\hline SGM-13 & 305,87 \\
\hline SGM-14 & 354,84 \\
\hline
\end{tabular}




\subsection{Relação entre carga de escoamento e carga de máxima}

A relação entre cargas máximas e cargas de escoamento está exposta na Tabela 4.3. Esta relação é utilizada para quantificar a ductibilidade do sistema.

Tabela 4.3. Relação entre $F_{u}$ e $F_{w}$

\begin{tabular}{cc}
\hline Modelo & $\begin{array}{r}\mathbf{F u} / \mathbf{F w} \\
(\mathrm{mm} / \mathrm{mm})\end{array}$ \\
\hline SGM-1 & 2,149 \\
\hline SGM-2 & 1,867 \\
\hline SGM-3 & 1,621 \\
\hline SGM-4 & 1,583 \\
\hline SGM-5 & 1,448 \\
\hline SGM-6 & 1,4435 \\
\hline SGM-7 & 1,473 \\
\hline SGM-8 & 2,212 \\
\hline SGM-9 & 1,998 \\
\hline SGM-10 & 1,803 \\
\hline SGM-11 & 1,671 \\
\hline SGM-12 & 1,537 \\
\hline SGM-13 & 1,563 \\
\hline SGM-14 & 1,451 \\
\hline
\end{tabular}

\subsection{Deslocamentos}

Os deslocamentos limites de escoamento e máximos, $\delta_{\mathrm{w}}$ e $\delta_{\mathrm{u}}$, discutidos no item 4.1 deste trabalho, estão expostos na Tabela 4.4. O deslocamento de serviço, $\delta_{\mathrm{w}}$, é de vital importância para o projeto da estrutura nos estados limites, tendo em vista que as normas vigentes, no Brasil ou no exterior, impõem limitações que podem ocorrer quanto aos deslocamentos de serviço. 
Tabela 4.4. Deslocamentos de escoamento e máximos

\begin{tabular}{|c|c|c|c|}
\hline Modelo & $\delta_{\mathrm{w}}(\mathrm{mm})$ & $\delta_{\mathrm{u}}(\mathrm{mm})$ & $\begin{array}{r}\boldsymbol{\delta} \mathbf{u} / \boldsymbol{\delta} \mathbf{w} \\
(\mathrm{mm} / \mathrm{mm})\end{array}$ \\
\hline SGM-1 & 14,8 & - & - \\
\hline SGM-2 & 16,1 & 98,8 & 6,137 \\
\hline SGM-3 & 17,8 & 110,1 & 6,185 \\
\hline SGM-4 & 17,2 & 103,6 & 6,023 \\
\hline SGM-5 & 17,9 & 86,3 & 4,821 \\
\hline SGM-6 & 16,6 & 94,1 & 5,910 \\
\hline SGM-7 & 15,3 & 74,3 & 4,856 \\
\hline SGM-8 & 12,8 & - & - \\
\hline SGM-9 & 13,7 & 120,8 & 8,818 \\
\hline SGM-10 & 15,0 & 98,3 & 6,553 \\
\hline SGM-11 & 16,3 & 113,3 & 6,951 \\
\hline SGM-12 & 17,8 & 122,5 & 6,882 \\
\hline SGM-13 & 17,7 & 130,6 & 7,378 \\
\hline SGM-14 & 19,1 & 97,8 & 5,120 \\
\hline
\end{tabular}

\subsection{Discussão}

A partir dos resultados expostos neste capítulo, é possível fazer uma análise criteriosa a respeito do comportamento do sistema modificado. Como pode ser observado, quando a corda inferior é composta pela seção W150x22,5, a mudança da seção dos stubs nos SGM-2 a SGM-7 não gera grande variação no valor da carga máxima. Em números, o aumento da carga máxima do modelo SGM-2 para o SGM7 é de 3,91\%, ou 13,04 kN. Essa situação é diferente quando a corda inferior é composta pela seção W150x37,1, que devido à maior área e momento de inércia, se mostra mais eficiente quando usada junto aos stubs de altura igual a $250 \mathrm{~mm}$. A diferença entre a carga máxima do SGM-14 para SGM-9 é de 166,2 kN, equivalente a um aumento de 47,63\%. Essas informações podem ser analisadas nos gráficos apresentados nas Figuras 4.16 e 4.17. 
Também foi observada a utilização de stubs idênticos e cordas inferiores diferentes. Quando a seção utilizada para o stub tem área e momento de inércia muito maiores que os da seção da corda inferior, nela vai acontecer o modo de ruína. Essa situação pode ser observada nos modelos SGM-3, SGM-4, SGM-5, SGM-6 e SGM-7. O fato de suas cargas máximas não apresentarem grande diferença é devido à seção da corda inferior ser menos robusta quando comparada às seções dos stubs, fazendo com que a ruptura sempre ocorra na corda inferior.

De maneira semelhante, quando a corda inferior é formada pela seção W150x37,1, seção robusta quando comparada às dos primeiros perfis de altura 250 mm, a ruptura sempre ocorrerá nos stubs. Nestes casos, não é interessante utilizar as seções W250 x 17,3 e W250 x 22,3 quando a corda inferior é formada pela seção W150 x 37,1, pois a diferença entre estes modelos, SGM-8 e SGM-9, é muito pequena comparada aos modelos SGM-1 e SGM-2, que utilizam as mesmas seções para os stubs e possuem menor peso total. Estas diferenças podem ser observadas na Tabela 4.5 .

Tabela 4.5.a. Carga máxima com stubs W250 x 17,3

\begin{tabular}{rccc} 
Modelo & $\mathrm{F}_{\mathrm{u}}(\mathrm{kN})$ & $\begin{array}{l}\text { Peso total } \\
(\mathrm{kg})\end{array}$ & $\begin{array}{c}\text { Peso linear } \\
(\mathrm{kg} / \mathrm{m})\end{array}$ \\
\hline SGM-1 & 305,07 & 140,3 & 23,4 \\
$(\mathrm{~W} 150 \times 22,5)$ & & & \\
\hline SGM-8 & 315,06 & 174,7 & 29,1 \\
$(\mathrm{~W} 150 \times 37,1)$ & & & \\
\hline
\end{tabular}

Tabela 4.5.b. Carga máxima com stubs W250 x 22,3

\begin{tabular}{rccc}
\hline Modelo & Fu $(\mathrm{kN})$ & $\begin{array}{l}\text { Peso total } \\
(\mathrm{kg})\end{array}$ & $\begin{array}{c}\text { Peso linear } \\
(\mathrm{kg} / \mathrm{m})\end{array}$ \\
\hline $\begin{array}{r}\text { SGM-2 } \\
(\mathrm{W} 150 \times 22,5)\end{array}$ & 333,42 & 165,5 & 27,6 \\
\hline SGM-9 & 348,87 & 199,9 & 33,3 \\
$(\mathrm{~W} 150 \times 37,1)$ & & & \\
\hline
\end{tabular}


A partir do modelo SGM-10, que usa a mesma seção de stub que o modelo SGM-3, a mudança é justificada, pois o aumento de carga ocorre de maneira acentuada. Estas mudanças são observadas na continuação da Tabela 4.5.

Tabela 4.5.c. Carga máxima com stubs W250 x 25,3

\begin{tabular}{rccc}
\hline Modelo & $\mathrm{F}_{\mathrm{u}}(\mathrm{kN})$ & $\begin{array}{c}\text { Peso total } \\
(\mathrm{kg})\end{array}$ & $\begin{array}{c}\text { Peso linear } \\
(\mathrm{kg} / \mathrm{m})\end{array}$ \\
\hline SGM-3 & 336,32 & 180,6 & 30,1 \\
$(\mathrm{~W} 150 \times 22,5)$ & & & 35,8 \\
\hline SGM-10 & 370,26 & 215,1 & \\
\hline
\end{tabular}

Tabela 4.5.d. Carga máxima com stubs W250 x 28,4

\begin{tabular}{rccc}
\hline Modelo & $\mathrm{Fu}_{\mathrm{u}}(\mathrm{kN})$ & $\begin{array}{l}\text { Peso total } \\
(\mathrm{kg})\end{array}$ & $\begin{array}{c}\text { Peso linear } \\
(\mathrm{kg} / \mathrm{m})\end{array}$ \\
\hline $\begin{array}{r}\text { SGM-4 } \\
(\mathrm{W} 150 \times 22,5)\end{array}$ & 339,39 & 196,2 & 32,7 \\
\hline SGM-11 & & & 38,4 \\
$(\mathrm{~W} 150 \times 37,1)$ & 403,31 & 230,7 & \\
\hline
\end{tabular}

Tabela 4.5.e. Carga máxima com stubs W250 x 32,7

\begin{tabular}{rccc}
\hline Modelo & $F_{\mathrm{u}}(\mathrm{kN})$ & $\begin{array}{l}\text { Peso total } \\
(\mathrm{kg})\end{array}$ & $\begin{array}{c}\text { Peso linear } \\
(\mathrm{kg} / \mathrm{m})\end{array}$ \\
\hline SGM-5 & 338,90 & 217,9 & 36,3 \\
$(\mathrm{~W} 150 \times 22,5)$ & & & \\
\hline SGM-12 & 425,92 & 252,4 & 42,1 \\
$(\mathrm{~W} 150 \times 37,1)$ & & & \\
\hline
\end{tabular}


Tabela 4.5.f. Carga máxima com stubs W250 x 38,5

\begin{tabular}{rccc} 
Modelo & $\mathrm{Fu}_{\mathrm{u}}(\mathrm{kN})$ & $\begin{array}{l}\text { Peso total } \\
(\mathrm{kg})\end{array}$ & $\begin{array}{c}\text { Peso linear } \\
(\mathrm{kg} / \mathrm{m})\end{array}$ \\
\hline $\begin{array}{r}\text { SGM-6 } \\
(\mathrm{W} 150 \times 22,5)\end{array}$ & 342,48 & 247,1 & 41,2 \\
\hline SGM-13 & & & 46,9 \\
$(\mathrm{~W} 150 \times 37,1)$ & 425,92 & 281,6 & \\
\hline
\end{tabular}

Tabela 4.5.g. Carga máxima com stubs W250 x 44,8

\begin{tabular}{rccc}
\hline Modelo & $\mathrm{Fu}_{\mathrm{u}}(\mathrm{kN})$ & $\begin{array}{c}\text { Peso total } \\
(\mathrm{kg})\end{array}$ & $\begin{array}{c}\text { Peso linear } \\
(\mathrm{kg} / \mathrm{m})\end{array}$ \\
\hline $\begin{array}{r}\text { SGM-7 } \\
(\mathrm{W} 150 \times 22,5)\end{array}$ & 346,46 & 278,9 & 46,5 \\
\hline SGM-14 & 515,04 & 313,3 & 52,2 \\
$(\mathrm{~W} 150 \times 37,1)$ & & & \\
\hline
\end{tabular}

Através das tensões de von Mises, é possível confirmar estas informações. Nos modelos em que a ruptura ocorre na corda inferior, a tensão crítica de von Mises é atingida antes nesta região. Isso acontece nos modelos SGM-3, SGM-4, SGM-5, SGM-6 e SGM-7. Nos modelos SGM-8 e SGM-9, a tensão de von Mises é atingida primeiro nos stubs. Nos outros modelos, SGM-1, SGM-2, SGM-10, SGM-11, SGM-12, SGM-13 e SGM-14, a tensão de von Mises nas localidades críticas evoluem de maneira semelhante de acordo com o deslocamento aplicado no centro do vão do sistema, fazendo, desta maneira, um melhor aproveitamento de ambas as seções, sem subutilização em nenhuma delas.

No que se refere às cargas de serviço $F_{w}$, ocorrem as mesmas situações. A diferença de momento de inércia e área entre as seções influencia fortemente na resistência do sistema. A Tabela 4.6 expõe as comparações entre os modelos no que tange às cargas de serviço. 
Tabela 4.6.a. Carga de serviço com stubs W250 x 17,3

\begin{tabular}{rccc} 
Modelo & $F_{\mathrm{w}}(\mathrm{kN})$ & $\begin{array}{l}\text { Peso total } \\
(\mathrm{kg})\end{array}$ & $\begin{array}{c}\text { Peso linear } \\
(\mathrm{kg} / \mathrm{m})\end{array}$ \\
\hline $\begin{array}{r}\text { SGM-1 } \\
(\mathrm{W} 150 \times 22,5)\end{array}$ & 141,96 & 140,3 & 23,4 \\
\hline SGM-8 & & & \\
$(\mathrm{W} 150 \times 37,1)$ & 142,43 & 174,7 & 29,1 \\
\hline
\end{tabular}

Tabela 4.6.b. Carga de serviço com stubs W250 x 22,3

\begin{tabular}{rccc}
\hline Modelo & $F_{\mathrm{w}}(\mathrm{kN})$ & $\begin{array}{c}\text { Peso total } \\
(\mathrm{kg})\end{array}$ & $\begin{array}{c}\text { Peso linear } \\
(\mathrm{kg} / \mathrm{m})\end{array}$ \\
\hline SGM-2 & 178,55 & 165,5 & 27,6 \\
$(\mathrm{~W} 150 \times 22,5)$ & & & 33,3 \\
\hline SGM-9 & 174,59 & 199,9 & \\
\hline
\end{tabular}

Tabela 4.6.c. Carga de serviço com stubs W250 x 25,3

\begin{tabular}{rccc}
\hline Modelo & $F_{\mathrm{w}}(\mathrm{kN})$ & $\begin{array}{l}\text { Peso total } \\
(\mathrm{kg})\end{array}$ & $\begin{array}{c}\text { Peso linear } \\
(\mathrm{kg} / \mathrm{m})\end{array}$ \\
\hline $\begin{array}{r}\text { SGM-3 } \\
(\mathrm{W} 150 \times 22,5)\end{array}$ & 207,41 & 180,6 & 30,1 \\
\hline SGM-10 & & & 35,8 \\
$(\mathrm{~W} 150 \times 37,1)$ & 205,34 & 215,1 & \\
\hline
\end{tabular}

A partir do modelo SGM-11, que usa a mesma seção de stub que o modelo SGM-4, a mudança é justificada, pois o aumento de carga ocorre de maneira acentuada. Estas mudanças são apresentadas na continuação da Tabela 6 . 
Tabela 4.6.d. Carga de serviço com stubs W250 x 28,4

\begin{tabular}{rccc} 
Modelo & $\mathrm{F}_{\mathrm{w}}(\mathrm{kN})$ & $\begin{array}{l}\text { Peso total } \\
(\mathrm{kg})\end{array}$ & $\begin{array}{c}\text { Peso linear } \\
(\mathrm{kg} / \mathrm{m})\end{array}$ \\
\hline $\begin{array}{r}\text { SGM-4 } \\
(\mathrm{W} 150 \times 22,5)\end{array}$ & 214,42 & 196,2 & 32,7 \\
\hline SGM-11 & 241,32 & 230,7 & 38,4 \\
$(\mathrm{~W} 150 \times 37,1)$ & & &
\end{tabular}

Tabela 4.6.e. Carga de serviço com stubs W250 x 32,7

\begin{tabular}{rccc}
\hline Modelo & $F_{\mathrm{w}}(\mathrm{kN})$ & $\begin{array}{c}\text { Peso total } \\
(\mathrm{kg})\end{array}$ & $\begin{array}{c}\text { Peso linear } \\
(\mathrm{kg} / \mathrm{m})\end{array}$ \\
\hline SGM-5 & 234,00 & 217,9 & 36,3 \\
$(\mathrm{~W} 150 \times 22,5)$ & & & \\
\hline SGM-12 & 277,11 & 252,4 & 42,1 \\
\hline
\end{tabular}

Tabela 4.6.f. Carga de serviço com stubs W250 x 38,5

\begin{tabular}{rccc}
\hline Modelo & $\mathrm{F}_{\mathrm{w}}(\mathrm{kN})$ & $\begin{array}{l}\text { Peso total } \\
(\mathrm{kg})\end{array}$ & $\begin{array}{c}\text { Peso linear } \\
(\mathrm{kg} / \mathrm{m})\end{array}$ \\
\hline SGM-6 & 237,25 & 247,1 & 41,2 \\
$(\mathrm{~W} 150 \times 22,5)$ & & & \\
\hline SGM-13 & 305,87 & 281,6 & 46,9 \\
\hline
\end{tabular}

Tabela 4.6.g Carga de serviço com stubs W250 x 44,8

\begin{tabular}{rccc}
\hline Modelo & $\mathrm{F}_{\mathrm{w}}(\mathrm{kN})$ & $\begin{array}{c}\text { Peso total } \\
(\mathrm{kg})\end{array}$ & $\begin{array}{c}\text { Peso linear } \\
(\mathrm{kg} / \mathrm{m})\end{array}$ \\
\hline SGM-7 & 235,24 & 278,9 & 46,5 \\
\hline (W150x22,5) & & & \\
\hline
\end{tabular}


SGM-14

354,84

313,3

52,2

(W150x37,1)

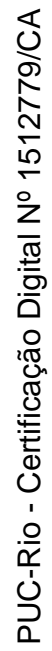




\section{5 \\ Modelo de Análise Unifilar}

\subsection{Introdução}

$\mathrm{Na}$ análise estrutural feita com uso de modelo de pórtico plano foi empregado o software Ftool [10]. O software é de fácil uso e entendimento, possuindo eficiente criação do modelo em sua fase de pré-processamento, uma análise rápida e visualização de resultados efetiva em sua fase de pós-processamento

O único tipo de análise disponível na versão atual do Ftool é a linear-elástica, que serve perfeitamente ao propósito deste capítulo - verificar comparativamente os esforços obtidos no ANSYS com os obtidos no modelo plano. Notar que os níveis de carga adotados para as comparações correspondem a estados de tensões onde o domínio linear-elástico seja válido.

\subsection{Modelo Simplificado de Ritchie e Chien [2]}

A análise computacional do sistema stub-girder foi executada por Colaco[1] por meio do método dos elementos finitos e do modelo viga tipo Vierendeel. Os dois meios mostraram bons resultados no que se refere a deslocamentos no centro do vão, tensões no concreto e tensões no aço quando comparados aos resultados de testes em escala real. O modelo criado por meio do método dos elementos finitos mostrou não ser adequado para o uso no projeto estrutural devido à alta demanda computacional. Apesar disso, ele serviu seu propósito de pesquisa na verificação da adequação do modelo viga tipo Vierendeel. Ritchie e Chien [3] propuseram uma simplificação no modelo de Colaco [1], que também obteve ótimos resultados quando comparados aos ensaios em escala real. O modelo simplificado de Ritchie está exposto na Figura 5.1 . 


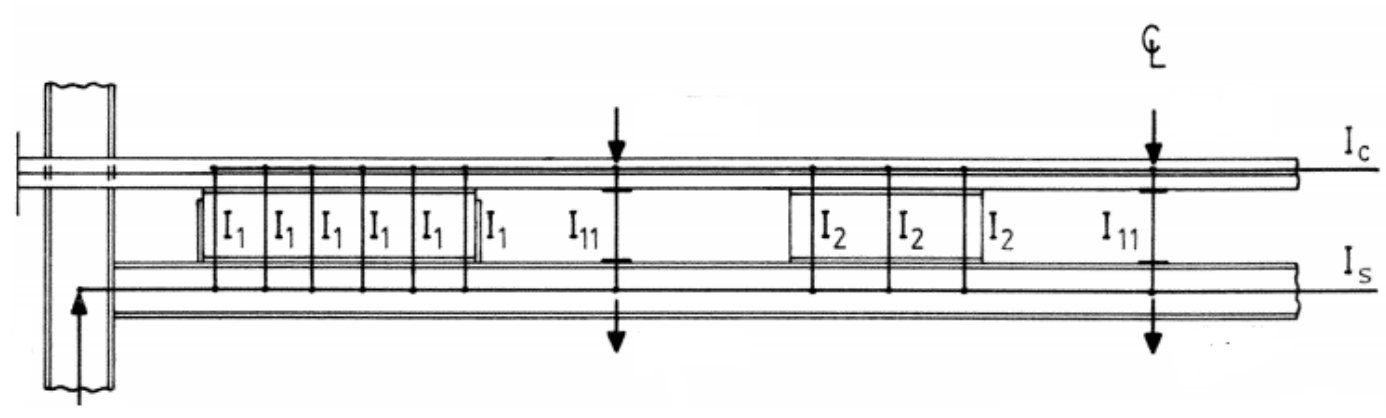

Figura 5.1. Modelo simplificado proposto por Ritchie e Chien [3]

Neste modelo, o stub externo é representado por seis barras verticais e o interno por três barras verticais.

$I_{c}$ é o momento de inércia da laje maciça de concreto;

$\mathrm{I}_{\mathrm{S}}$ é o momento de inércia da seção da corda inferior;

$\mathrm{I}_{1}$ e $\mathrm{I}_{2}$ são os momentos de inércia dos stubs, calculados de forma semelhante, conforme a Equação 5.1,

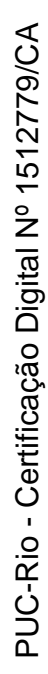

$$
I_{i}=\frac{t_{w} \times L_{s}^{3}}{12 \times n_{i}}
$$

nesta equação, $\mathrm{t}_{\mathrm{w}}$ é a espessura da alma do $s t u b, \mathrm{~L}_{\mathrm{s}}$ é o comprimento da ligação entre $s t u b$ e corda inferior, e $\mathrm{n}_{\mathrm{i}}$ é o número de divisões do $s t u b$, escolhido para o modelo simplificado com base no comprimento $\mathrm{L}_{\mathrm{s}}$.

Na Figura 5.2 é apresentado um modelo simplificado do sistema stub-girder tradicional criado no FTOOL e cujas informações estão expostas na Tabela 5.1.

Tabela 5.1. Informações do Stub-girder SG-EX.

\begin{tabular}{lcccccc}
\hline \multicolumn{1}{c}{ Elemento } & $\begin{array}{c}\text { Comprimento } \\
(\mathrm{mm})\end{array}$ & Seção & $\begin{array}{c}\text { Altura } \\
(\mathrm{mm})\end{array}$ & $\begin{array}{c}\text { Área } \\
\left(\mathrm{mm}^{2}\right)\end{array}$ & $\begin{array}{c}\mathrm{I}_{\mathrm{x}}\left(\mathrm{x} 10^{6}\right. \\
\left.\mathrm{mm}^{4}\right)\end{array}$ & $\begin{array}{r}\text { Proporção } \\
\text { de Carga }\end{array}$ \\
\hline Corda Inferior & 11.500 & $\mathrm{~W} 310 \times 79$ & 299 & 10.000 & 163,16 & 0,805 \\
\hline Stub externo & 1.500 & $\mathrm{~W} 41 \times 38,8$ & 399 & 5.030 & 127,77 & - \\
\hline Stub Interno & 1.075 & $\mathrm{~W} 410 \times 38,8$ & 399 & 5.030 & 127,77 & - \\
\hline Corda Superior & 11.500 & $473 \mathrm{~mm}$ & 100 & 47.300 & 39,41 & 0,195 \\
(transformada) & & x $100 \mathrm{~mm}$ & & & &
\end{tabular}

Adicionadas a estas informações, as aberturas externas têm largura igual a $625 \mathrm{~mm}$, as internas $1.650 \mathrm{~mm}$ e a central $1.800 \mathrm{~mm}$. Por meio da Equação 1 foram obtidos os valores de I1 e I2, sendo eles 300 x 106 e 165,6 x 106 mm$^{4}$. Note-se 
também que a distância entre a corda inferior e a corda superior, exemplificada na Figura 5.5, é igual a 598,5 mm (altura do stub é igual a $399 \mathrm{~mm}$, centroide da corda superior igual a $50 \mathrm{~mm}$ e centroide da corda inferior igual a $149,5 \mathrm{~mm}$ ). A Figura 5.2 apresenta o modelo simplificado para o stub-girder exemplo SG-EX e a Figura 5.3 apresenta o corte no mesmo para que as distâncias entre os centroides possam ser vistas.

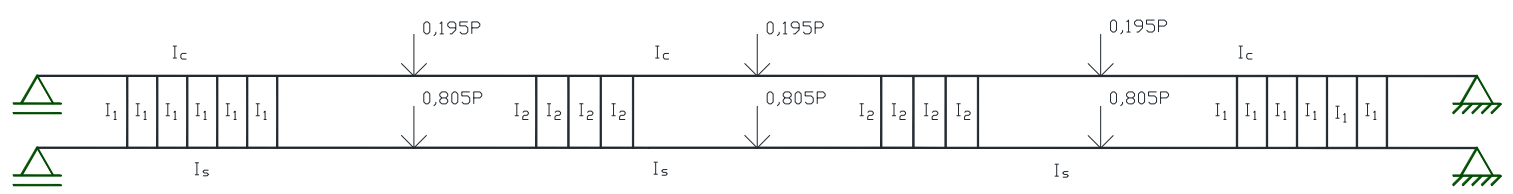

Figura 5.2. Modelo Simplificado SG-EX no FTOOL.

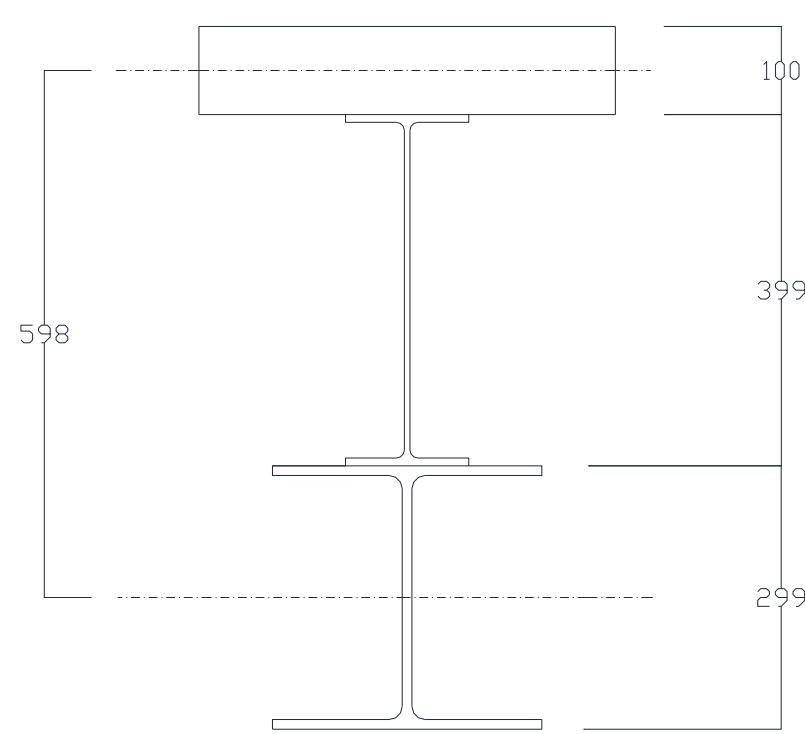

Figura 5.3. Corte no sistema Stub-girder tradicional.

\subsection{Modelagem do sistema modificado}

O modelo simplificado do sistema modificado segue as mesmas bases do modelo criado por Ritchie e Chien [2] no que diz respeito aos stubs, sendo calculado pela Equação 5.1, e sendo a única diferença o número de divisões, no caso do 
modelo simplificado igual a 4 em todos os casos. A principal diferença é que na seção a (exposta na Figura 3.3), será considerado que a seção que forma o stub e a laje maciça de concreto armado formarão a seção homogeneizada de uma viga mista e a seção será chamada de "stub misto". O modelo simplificado do sistema modificado é apresentado na Figura 5.4.

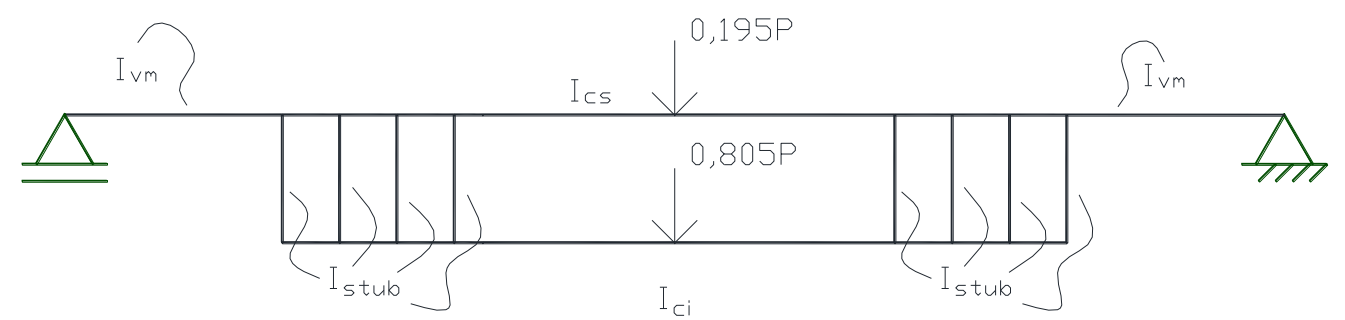

Figura 5.4. Modelo simplificado do sistema modificado.

Neste modelo, $\mathrm{I}_{\mathrm{vm}}$ representa o momento de inércia da seção homogeneizada da viga mista, cujo valor é dado pela Equação 5.2.

$$
I_{v m}=I_{c s}+A_{c s} \times\left(\bar{y}_{c s}-\bar{y}_{v m}\right)^{2}+I_{s t u b}+A_{s t u b} \times\left(\bar{y}_{s t u b}-\bar{y}_{v m}\right)^{2}
$$

em que $\mathrm{I}_{s t u b}$ é o momento de inércia da seção do stub;

$\mathrm{A}_{\text {stub }}$ é a área da seção do stub;

$\bar{y}_{\text {stub }}$ é o centroide da seção do $s t u b$;

$\mathrm{I}_{\mathrm{cs}}$ é o momento de inércia da corda superior, formada pela laje maciça de concreto;

$A_{c s}$ é a área da seção da corda superior;

$\bar{y}_{c s}$ é o centroide da seção da corda superior;

$\bar{y}_{v m}$ é o centroide da seção homogeneizada da viga mista.

A proporção da carga aplicada entre a seção da corda superior e corda inferior continua sendo considerado válido.

\subsection{Comparação de resultados}

Nesta seção será verificado se os resultados para os esforços solicitantes apresentados pelo modelo simplificado utilizando o software Ftool são confiáveis 
e podem ser utilizados para o projeto do sistema através do método dos estados limites. O modelo SGM-12, em que a corda inferior é um perfil de seção W150x37,1 e os stubs são perfis de seção W250x32,7, será utilizado como exemplo de obtenção dos esforços solicitantes através do software ANSYS.

O primeiro passo a ser dado é escolher um substep que esteja no domínio linear-elástico, ou seja, antes do início da plastificação. O substep escolhido foi o de número 4, correspondente a um deslocamento vertical no centro do vão igual a 14,375 mm. A Figura 5.5 ilustra a curva Força Aplicada versus deslocamento para este modelo, garantindo que o passo escolhido esteja no domínio linear-elástico.

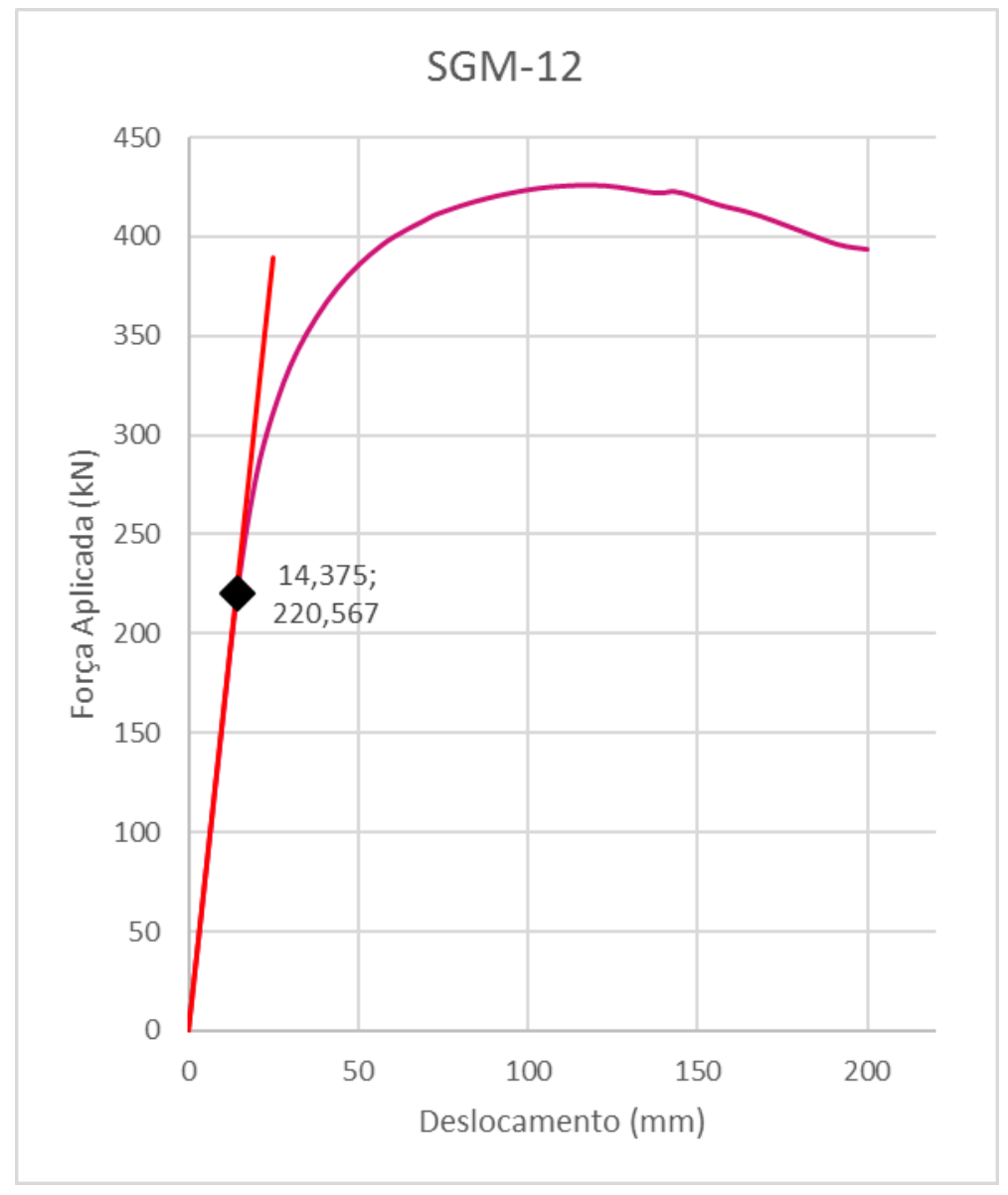

Figura 5.5. Força aplicada versus deslocamento do modelo SGM-12

A obtenção das tensões que são associadas aos esforços solicitantes será feita primeiramente na região do sistema modificado em que a barra é considerada viga mista. Primeiramente, é importante citar que a força aplicada para que tal deslocamento seja obtido é igual a $220,57 \mathrm{kN}$. 


\subsubsection{Seção homogeneizada da viga mista (stub-misto)}

A primeira seção selecionada para comparação de resultados situa-se a uma distância de $800 \mathrm{~mm}$ de um dos apoios, região tratada como viga mista formada entre a seção do $s t u b$ e a laje de concreto. O diagrama da tensão normal na seção transversal está exposto na Figura 5.6.

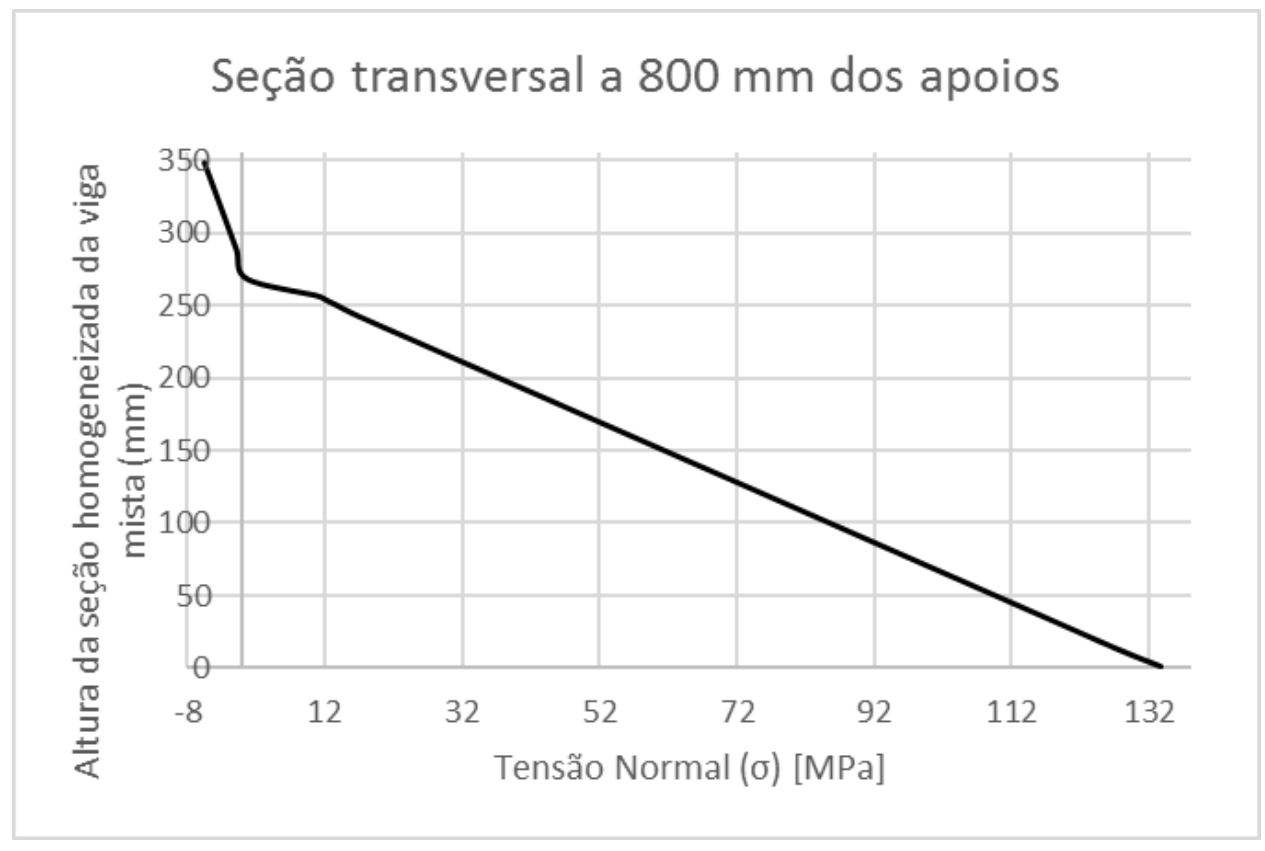

Figura 5.6. Tensão normal na seção transversal do stub misto.

Este gráfico permite a obtenção da posição do centroide e dos esforços internos da seção do stub misto. O centroide da seção homogeneizada da seção transversal formada pelo stub, cuja seção é W250 x 32,7 e a laje de concreto de espessura igual a $100 \mathrm{~mm}$ localiza-se a uma distância de $275,30 \mathrm{~mm}$ da face inferior.

Através dos resultados obtidos, foi feita a verificação quanto ao momento fletor e esforços axiais. Acima do centroide, a força axial de compressão obtida foi de 381,2 kN. Abaixo do centroide, a força axial de tração obtida foi de 387,0 kN. O momento fletor solicitante correspondente a essas tensões é de 81,3 kN.m.

O modelo simplificado para o modelo SGM-12 é mostrado na Figura 5.7. A proporção da carga aplicada resulta em $115,10 \mathrm{kN}$ aplicados na corda inferior e $105,50 \mathrm{kN}$ na superior. Na Figura 5.8 é ilustrado o diagrama de momentos fletores do modelo. 


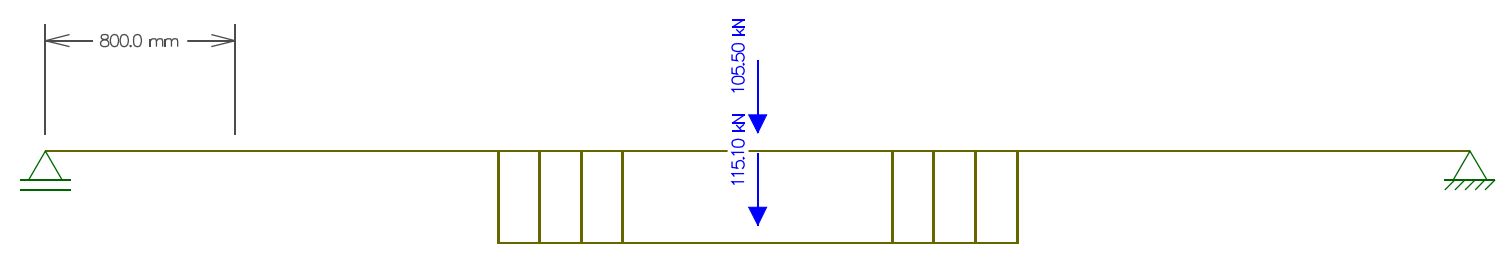

Figura 5.7. Modelo SGM-12 simplificado.

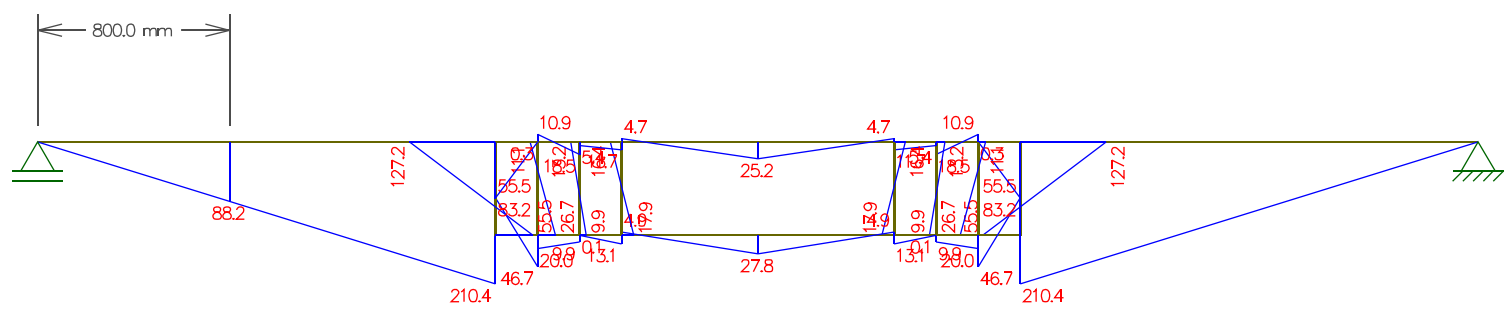

Figura 5.8. Diagrama de momentos fletores do modelo SGM-12 simplificado.

A Tabela 5.2 expõe o comparativo entre o modelo tridimensional e simplificado, cujas análises foram realizadas nos softwares ANSYS [11] e no FTOOL [10], respectivamente.

Tabela 5.2. Comparativo entre resultados do ANSYS e FTOOL.

\begin{tabular}{ccc}
\hline Modelo SGM-12 & $\begin{array}{c}\text { Momento Fletor } \\
(\mathrm{kN} . \mathrm{m})\end{array}$ & $\begin{array}{c}\text { Deslocamento } \\
(\mathrm{mm})\end{array}$ \\
\hline ANSYS & 81,3 & 14,375 \\
\hline FTOOL & 88,2 & 15,5 \\
\hline Discrepância (\%) & 7,82 & 7,26
\end{tabular}

Os valores obtidos com o Ftool são satisfatórios, pois a diferença existente entre os modelos é pequena. Isso se deve ao fato de que, no modelo simplificado, a região considerada da viga mista possuir um comprimento maior que no modelo tridimensional, e tal processo ocorre para que os stubs sejam modelados de maneira mais próxima à realidade. 


\subsubsection{Corda Inferior}

O mesmo procedimento do item anterior foi realizado, desta vez para a seção central da viga, que abrange dois elementos distintos: a corda inferior e a corda superior. O diagrama da tensão normal na seção transversal está exposto na Figura 5.9 .

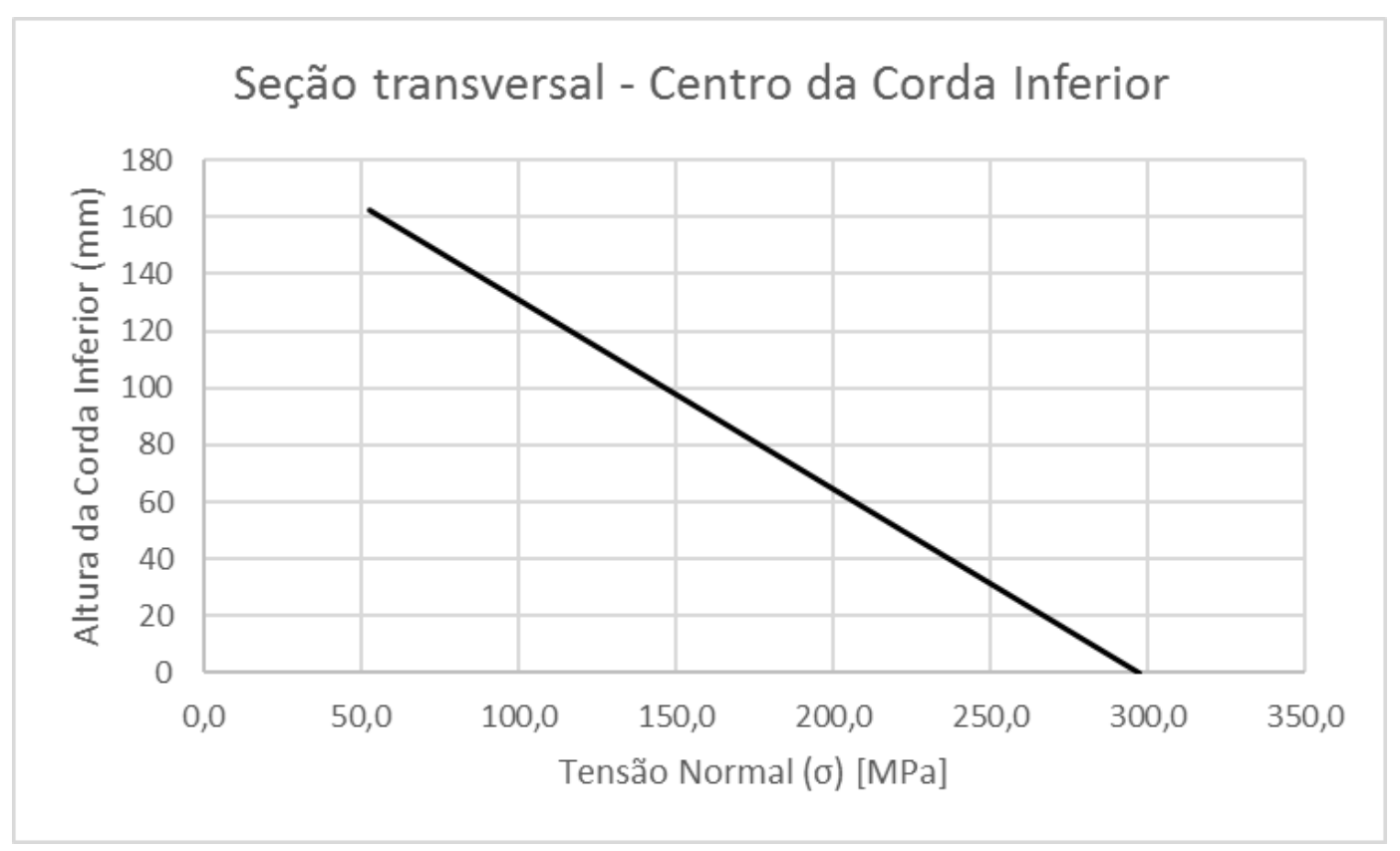

Figura 5.9. Diagrama de tensão normal no centro da corda inferior.

A Figura 5.10 apresenta os resultados obtidos para a Flexo-tração na seção da corda inferior, onde são separadas as partes de flexão e tração.
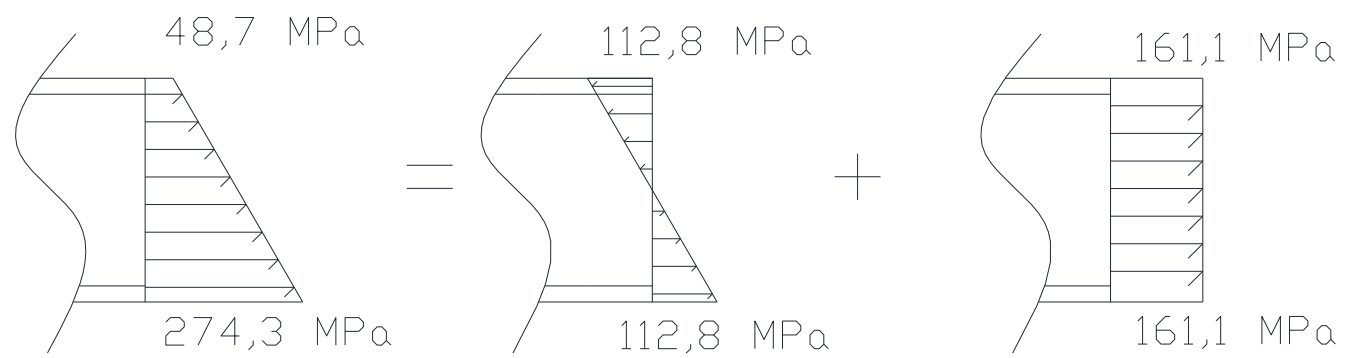

Figura 5.10. Diagrama de tensão normal no centro da corda inferior. 
De acordo com as tensões obtidas no diagrama acima, foi obtido um momento fletor igual a 31,25 kN.m e esforço de tração igual a 770,06 kN. O comparativo com o FTOOL está exposto na Tabela 5.3.

Tabela 5.3. Comparativo entre ANSYS e FTOOL para a corda inferior

\begin{tabular}{ccc}
\hline Modelo SGM-12 & $\begin{array}{c}\text { Momento Fletor } \\
(\mathrm{kN} . \mathrm{m})\end{array}$ & $\begin{array}{c}\text { Esforço normal de } \\
\text { Tração }(\mathrm{kN})\end{array}$ \\
\hline ANSYS & 31,25 & 770,06 \\
\hline FTOOL & 29,00 & 714,5 \\
\hline Discrepância (\%) & 7,2 & 7,2 \\
\hline
\end{tabular}

Novamente, para esta seção os resultados foram satisfatórios, sendo os erros possivelmente devido à ocorrência de concentração de tensões no modelo tridimensional, pois o ponto de aplicação da carga está justamente nesta região. Além disso, o comprimento desta seção é maior no modelo simplificado.

\subsubsection{Corda Superior}

A última seção analisada para verificação dos resultados é o centro da corda superior, formada pela laje de concreto armado. O diagrama da tensão normal na seção transversal está exposto na Figura 5.11.

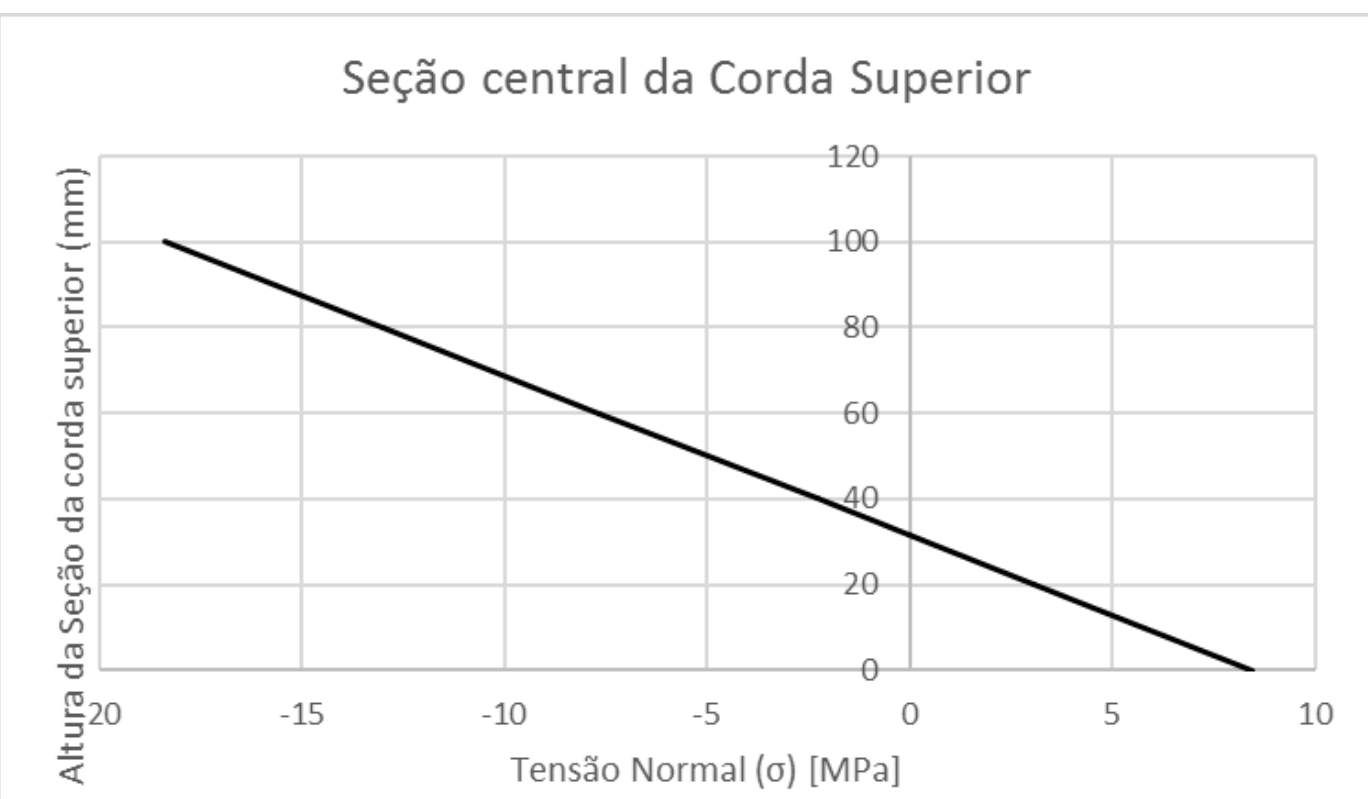




\section{Figura 5.11. Diagrama de tensão normal no centro da corda superior.}

De acordo com as tensões obtidas no diagrama acima, foi obtido um momento fletor igual a 22,95 kN.m e esforço de tração igual a 743,98 kN. O comparativo com o Ftool está exposto na Tabela 5.4.

Tabela 5.4. Comparativo entre ANSYS e FTOOL para a corda superior

\begin{tabular}{ccc}
\hline Modelo SGM-12 & $\begin{array}{c}\text { Momento Fletor } \\
(\mathrm{kN} . \mathrm{m})\end{array}$ & $\begin{array}{c}\text { Esforço normal de } \\
\text { Compressão }(\mathrm{kN})\end{array}$ \\
\hline ANSYS & 22,95 & 743,98 \\
\hline FTOOL & 25,2 & 714,5 \\
\hline Discrepância (\%) & 8,93 & 3,96 \\
\hline
\end{tabular}

Os resultados são satisfatórios considerando as diferenças presentes na análise linear no Ftool [10], como o comprimento da seção, maior que no modelo tridimensional e o fato de haver tensões de tração no concreto da laje.

As discrepâncias mantêm essa tendência para todos os modelos analisados, da ordem de 7\%, validando assim os resultados do software Ftool [10].

A partir do que foi exposto no capítulo 5, chegou-se à conclusão de que os esforços de projeto podem ser obtidos por meio do uso da modificação do modelo simplificado de Ritchie e Chien [2], que apresentou bons resultados quando comparada ao modelo tridimensional do software ANSYS 15 [11].

A Tabela 5.5 apresenta os tipos de esforço a que cada elemento do sistema modificado está sendo solicitado. É importante ressaltar que os esforços nos stubs serão considerados os mesmos que ocorrem no modelo simplificado de Ritchie e Chien [2], pois a modelagem usada para ambos é a mesma. 
Tabela 5.5. Esforços solicitantes atuantes nos elementos do sistema modificado

\begin{tabular}{ccc}
\hline Seção & Elemento & Esforços solicitantes \\
\hline a & Viga Mista & Momento Fletor e Esforço Cortante \\
& & Vertical \\
\hline b & Stub & Esforço Cortante Horizontal \\
\hline c.1 & Banzo Inferior & Flexotração \\
\hline c. 2 & Banzo Superior & Flexocompressão \\
\hline
\end{tabular}

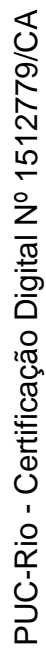




\section{6 \\ Projeto do sistema de vigamento modificado}

\subsection{Método dos estados limites}

Segundo Kennedy [13], Estados Limites são os estados ou condições limites na estrutura de modo que a mesma deixa de cumprir os requisitos funcionais previstos e a probabilidade de excedê-los deve ser mantida a níveis aceitáveis e relativamente baixos.

O projeto nos estados limites consiste no reconhecimento dos diversos estados limites, escolhendo elementos de modo que as probabilidades sejam atendidas. A classificação dos estados limites é dada da seguinte maneira:

- $\quad$ estados limites de utilização: são os estados limites associados com o funcionamento da estrutura em serviço, tais como flechas, vibrações, fissuração, deflexões permanentes, etc. Estes estados devem ser satisfeitos durante toda a vida útil da estrutura quando sujeita a níveis de carregamentos que têm probabilidade de ocorrer frequentemente e são conhecidos como cargas de serviço ou cargas especificadas;

- estados limites últimos: são os estados limites associados à ruína de parte ou totalidade da estrutura. Nestes limites estão incluídos a ruína, esmagamento, flambagens local e global, momento crítico, momento de escoamento, plastificação, formação de rótulas plásticas, tombamento, deslizamento, escorregamento, recalques de apoios, etc. Estes estados devem ser satisfeitos durante a fase de construção e vida útil da estrutura, em níveis de carregamentos que tem pequena probabilidade de serem excedidos;

- estados limites de fadiga: são os estados limites associados à ocorrência de fissuras em uma faixa de variação de tensões ocorridas em condições de serviço, motivo pelo qual podem ser considerados estados limites de serviço. Também podem ser considerados estados limites últimos, pois levam a estrutura à ruína ao serem atingidos. 
O projeto nos estados limites proporciona um enfoque unificado no qual o projetista reconhece os vários estados limites ou modos de ruína e projeta a estrutura de acordo com os mesmos, considerando as variações estatísticas das ações e das resistências.

\subsection{Resistências de projeto dos elementos segundo a CSA S16.1 [3]}

Nesta seção, será exposta a metodologia de cálculo da resistência de projeto dos elementos do sistema Stub-Girder modificado, segundo a CSA S16.1, Limit States Design of Steel Structures [3].

\subsubsection{Viga Mista (stub misto)}

Como apresentado nas seções anteriores, a seção 'a', que está ilustrada na Figura 3.3, é considerada uma viga mista formada entre as seções do stub e laje maciça de concreto armado. O cálculo da resistência destes elementos é encontrado no capítulo 17 da S16.1 [3].

O cortante vertical causado pela carga aplicada no centro do sistema modificado deve ser resistido somente pela alma da seção do stub. O cálculo da resistência da alma de um perfil fletido ao cisalhamento está explicitado na seção 13.4.1.1 (Análise elástica) da CSA S16. A resistência fatorada ao cortante, $\mathrm{V}_{\mathrm{r}}$, é mostrada abaixo.

$$
V_{r}=\phi A_{w} F_{s}
$$

em que $\mathrm{A}_{\mathrm{w}}$ é a área de cisalhamento da seção e $\mathrm{F}_{\mathrm{s}}$ calculado conforme exposto nas Equações abaixo:

(a) quando $\frac{h}{t_{w}} \leq 439 \sqrt{\frac{k_{v}}{F_{y}}}$

$$
F_{s}=0,66 F_{y}
$$

(b) quando $439 \sqrt{\frac{k_{v}}{F_{y}}}<\frac{h}{t_{w}} \leq 502 \sqrt{\frac{k_{v}}{F_{y}}}$

$$
F_{s}=F_{c r i}
$$

(c) quando $502 \sqrt{\frac{k_{v}}{F_{y}}}<\frac{h}{t_{w}} \leq 621 \sqrt{\frac{k_{v}}{F_{y}}}$ 


$$
F_{s}=F_{c r i}
$$

(d) quando $\frac{h}{t_{w}}>621 \sqrt{\frac{k_{v}}{F_{y}}}$

$$
F_{s}=F_{\text {cre }}
$$

em que $k_{v}$ é o coeficiente de cisalhamento, calculado de duas maneiras:

(i) quando $a / h<1$

$$
k_{v}=4+\frac{5,34}{(a / h)^{2}}
$$

(ii) quando $a / h \geq 1$

$$
k_{v}=5,34+\frac{4}{(a / h)^{2}}
$$

em que $a / h$ é a relação entre espaçamento entre os enrijecedores e a altura da alma do perfil e $F_{\text {cri }}$ e $F_{\text {cre }}$ são calculados conforme as Equações 6.5 e 6.6.

$$
\begin{gathered}
F_{c r i}=290 \frac{\sqrt{F_{y} k_{v}}}{\left(h / t_{w}\right)} \\
F_{c r e}=\frac{180000 k_{v}}{\left(h / t_{w}\right)^{2}}
\end{gathered}
$$

A resistência da viga mista ao momento fletor depende de diversos fatores, como taxa de interação entre concreto e stub, considerada completa neste trabalho. $\mathrm{O}$ momento resistente fatorado, $\mathrm{M}_{\mathrm{rc}}$ da seção mista deve ser calculada conforme as Equações expostas a seguir, em que $\phi=0,90$ e $\phi_{c}=0,65$.

Caso 1: interação completa entre a seção de aço e a de concreto, bem como linha neutra plástica na laje de concreto. Neste caso, $Q_{r} \geq \phi A_{s} F_{y}$ e $\phi A_{s} F_{y} \leq \alpha_{1} \phi_{c} b t_{c} f_{c}^{\prime}$, onde $\mathrm{Q}_{\mathrm{r}}$ é a soma das resistências fatoradas de todos os conectores de cisalhamento entre os pontos de momento igual a zero e momento máximo. $\alpha_{1}=0,85-0,0015 f^{\prime}{ }_{c}$, que não pode ser menor que 0,67 . $\mathrm{O}$ momento resistente de cálculo é obtido conforme por meio de Equação 6.7.

$$
M_{r c}=T_{r} e^{\prime}=\phi A_{s} F_{y} e^{\prime}
$$

em que $e^{\prime}$ é o braço de alavanca entre a linha neutra plástica e calculado conforme as Equações 6.8 e 6.9 : 


$$
\begin{aligned}
& e^{\prime}=\frac{d}{2}+t_{0}+\frac{a}{2} \\
& a=\frac{\phi A_{s} F_{y}}{\alpha_{1} \phi_{c} b f_{c}^{\prime}}
\end{aligned}
$$

Caso 2: interação completa entre a seção de aço e a de concreto, além de linha neutra plástica na seção de aço. Neste caso, $\alpha_{1} \phi_{c} b t_{c} f_{c}^{\prime}<\phi A_{s} F_{y}$ e $Q_{r} \geq \alpha_{1} \phi_{c} b t_{c} f_{c}^{\prime}$, sendo preciso verificar se a linha neutra se encontra na alma ou na mesa do perfil. O momento resistente de cálculo é obtido conforme a Equação 6.10 e as forças que formam seu binário são obtidas conforme as Equações 6.11 e 6.12. Os braços de alavanca são calculados conforme as Equações 6.13 a 6.15 ou 6.16 a 6.19, conforme a posição da linha neutra plástica.

$$
\begin{gathered}
M_{r c}=C_{r} e+C_{r}^{\prime} e^{\prime} \\
C_{r}^{\prime}=\alpha_{1} \phi_{c} b t_{c} f_{c}^{\prime}
\end{gathered}
$$

(a) Caso a L.N.P. esteja na mesa do perfil $\left(C_{r} \leq \phi b t_{f} F_{y}\right)$

$$
\begin{aligned}
& e=\frac{\left(A_{s} d-b t_{1}^{2}\right)}{2\left(A_{s}-b t_{1}\right)}-\frac{t_{1}}{2} \\
& e^{\prime}=e+\frac{t_{1}}{2}+t_{0}-\frac{t_{c}}{2} \\
& t_{1}=\frac{C_{r}}{\phi b F_{y}}
\end{aligned}
$$

(b) Caso a L.N.P. esteja na alma do perfil $\left(C_{r}>\phi b t_{f} F_{y}\right)$

$$
\begin{aligned}
& e=d-d_{2}-d_{3} \\
& e^{\prime}=d+t_{0}-d_{2}-\frac{t_{c}}{2} \\
& d_{1}=\left(A_{c r}-b t_{f}\right) / t_{w} \\
& d_{3}=\frac{b t_{f}^{2} / 2+d_{1} t_{w}\left(t_{f}+d_{1} / 2\right)}{A_{c r}} \\
& d_{2}=\frac{A_{s} d / 2-A_{c r}\left(d-d_{3}\right)}{A_{s}-A_{c r}}
\end{aligned}
$$




$$
A_{c r}=\frac{C_{r}}{\phi F_{y}}
$$

Caso 3: A interação entre perfil de aço e laje de concreto é parcial. Neste caso, $Q_{r}<\phi A_{s} F_{y} \mathrm{e}<\alpha_{1} \phi_{c} b t_{c} f_{c}^{\prime}$.

$$
\begin{aligned}
& M_{r c}=C_{r} e+C_{r}^{\prime} e^{\prime} \\
& C_{r}^{\prime}=Q_{r} \\
& a=\frac{Q_{r}}{\alpha_{1} \phi_{c} b_{1} f_{c}^{\prime}} \\
& C_{r}=\frac{\phi A_{s} F_{y}-Q_{r}}{2}
\end{aligned}
$$

em que $e$ e $e^{\prime}$ são calculados da mesma maneira que no caso 2, com a exceção de que $t_{c}$ deve ser substituído por $a$ nas Equações 6.16 a 6.21 .

\subsubsection{Stubs}

Nos stubs, o esforço a ser transmitido na interface concreto/aço é o esforço cortante horizontal, $\mathrm{V}_{\mathrm{hd}}$, causado pelo esforço de compressão no banzo superior $\left(\mathrm{N}_{\mathrm{d}}\right)$, formado pela laje maciça de concreto. A Figura 6.1 apresenta os esforços solicitantes.

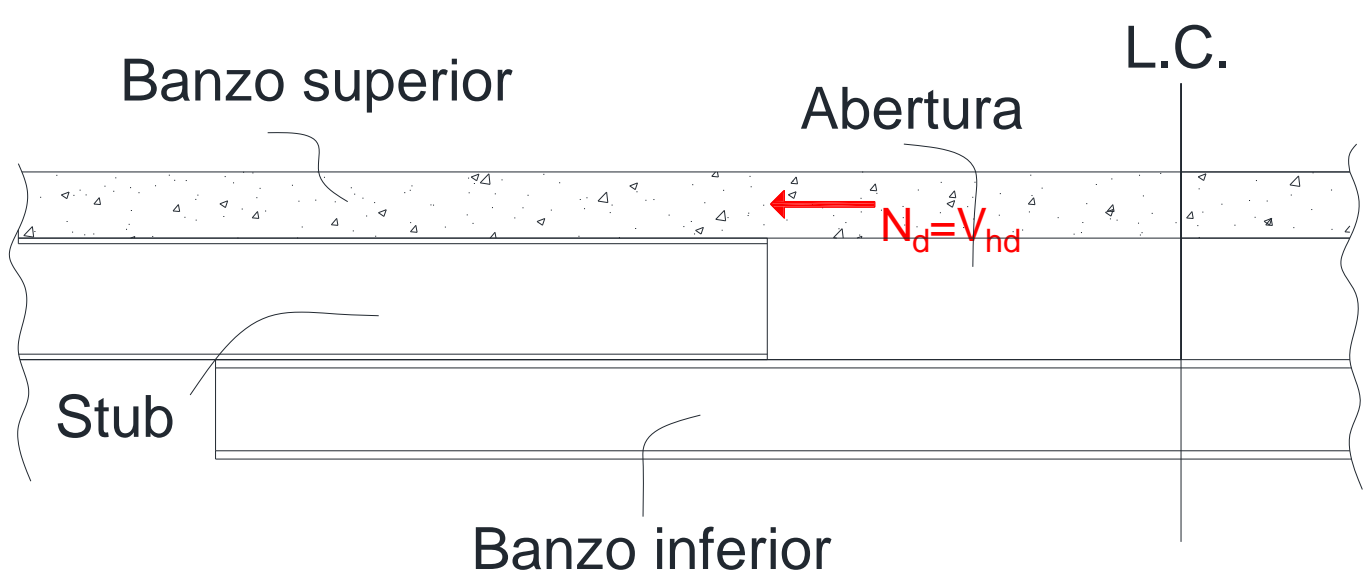

Figura 6.1. Esforços solicitantes nos stubs

A resistência ao cortante horizontal é calculada de acordo com as Equações 6.1 a 6.6, sendo a única diferença a relação $a / h$. No caso do cortante horizontal, $a$ é a distância entre as mesas do stub e $h$ é o comprimento do stub, Ls. Esta 
resistência deve ser maior ou igual ao esforço de compressão solicitante na laje de concreto, $\mathrm{N}_{\mathrm{d}}$ ou $\mathrm{V}_{\mathrm{hd}}$.

\subsubsection{Banzo Superior}

O banzo superior, calculado segundo Ritchie e Chien [2], que resiste a esforços de compressão axial e momento fletor. A relação entre estes esforços resulta na excentricidade $e$, calculada conforme a Equação 6.26.

$$
e=\frac{M_{d}}{N_{d}}
$$

Além disso, é necessário calcular o raio de giração do banzo superior, $r$, obtido por meio da Equação 6.27.

$$
r=\sqrt{\frac{I_{c s}}{A_{c s}}}
$$

em que $I_{c s}$ e $A_{c s}$ são o momento de inércia e a área transformados da laje de concreto, respectivamente.

Para que o efeito de esbeltez da laje de concreto possa ser desconsiderado, deve ser respeitada a relação

$$
\frac{L_{c s}}{r}<34-12\left(M_{1} / M_{2}\right) \text {. }
$$

onde $\mathrm{L}_{\mathrm{cs}}$ é o comprimento do banzo inferior e $\mathrm{M}_{1}$ e $\mathrm{M}_{2}$ são os momentos na borda e no centro do mesmo. A resistência à ruína deve ser calculada por aproximação, supondo-se a posição da linha neutra distante ' $a$ ' da face superior da laje. O cálculo das tensões atuantes na seção é feito de modo iterativo, onde deformações nas fibras extremas são calculadas por meio das Equações 6.28 e 6.29:

$$
\begin{aligned}
& \varepsilon_{s}=\frac{0,85 d \varepsilon_{u}}{a}-\varepsilon_{u} \\
& \varepsilon_{s}^{\prime}=\frac{a-0,85 d^{\prime}}{a} \varepsilon_{u}
\end{aligned}
$$

(a) caso $\varepsilon_{s}<\frac{f_{y}}{E_{s}}$ das barras de aço da armadura da laje de concreto,

$$
f_{s}=E_{s} \varepsilon_{s}
$$

(b) caso $\varepsilon_{s} \geq \frac{f_{y}}{E_{s}}$, 


$$
f_{s}=f_{y}
$$

em que $\mathrm{f}_{\mathrm{y}}$ é a tensão limite de escoamento do aço utilizado na armadura da laje de concreto. As mesmas relações são assumidas para o cálculo de $f_{s}^{\prime}$. Ao fim desta etapa, deve ser calculada a resistência nominal à compressão da laje de concreto, $\mathrm{C}_{\mathrm{u}}$, exposta na Equação 6.31 .

$$
C_{u}=0,85 f_{c}^{\prime} a b_{1}+f_{s}^{\prime} A_{s}^{\prime}+f_{s} A_{s}
$$

Encontrada esta resistência, a próxima etapa trata da obtenção da excentricidade entre as resistências à compressão e ao momento fletor da laje de concreto, $e$.

$$
(e+d-\bar{y}) C u=0,85 f_{c}^{\prime} a b_{1}\left(d-\frac{a}{2}\right)+f_{s}^{\prime} A_{s}^{\prime}\left(d-d^{\prime}\right)
$$

Caso $e$ não resulte igual a excentricidade calculada na Equação 6.26, deve ser usado outro valor para $a$ até que os valores sejam idênticos. Então, as resistências finais devem ser calculadas conforme as Equações 6.32 e 6.33.

$$
\begin{aligned}
& C_{r u}=\phi_{c} C_{u} \\
& M_{r l}=e C_{r}
\end{aligned}
$$

As taxas de utilização devem ser menor que 1 e estão expressas nas Equações 6.34.a e 6.34.b.

$$
\begin{gathered}
\text { T.U.M. }=\frac{M_{d}}{M_{r l}} \\
\text { T.U.C. }=\frac{N_{d}}{C_{r c}}
\end{gathered}
$$

Além da resistência à flexo-compressão, é necessário calcular a resistência da laje ao esforço cortante vertical. Na laje de concreto maciça, a área que resiste ao cisalhamento é sua área total, $A_{w}=b_{e f} t_{c}$. As Equações seguintes apresentam a metodologia de cálculo do cortante resistente da laje, $V_{r}$, calculado conforme as Equações 6.35 a 6.37 .

$$
\begin{aligned}
& v_{c 1}=0,3 \sqrt{f_{c}^{\prime}} \sqrt{1+0,3 N_{d} / A_{g}} \\
& V_{n}=v_{c} b_{e f} d \\
& V_{r c}=\phi_{v} V_{n}
\end{aligned}
$$

onde $\phi_{v}=0,60$. 


\subsubsection{Banzo Inferior}

O banzo inferior resiste a esforços de tração e momento fletor simultaneamente. A resistência da seção a tração é calculada conforme o item (i) da seção 13.2 da S16.1 [3], já que não existem furos na seção do perfil.

$$
T_{r}=\phi A_{g} F_{y}
$$

O momento fletor resistente de cálculo, $\mathrm{M}_{\mathrm{r}}$, é calculado conforme a seção 13.5 da S16.1, Momento Fletor Resistente para Membros com Suporte Contínuo, já que não pode ocorrer flambagem lateral por torção.

(a) Para seções duplamente simétricas Classes 1 e 2, o momento resistente de cálculo é obtido conforme a Equação 6.39:

$$
M_{r}=Z_{x} \times f_{y}
$$

(b) Para seções duplamente simétricas Classes 3 e 4, o momento resistente de cálculo é obtido por meio da Equação 6.40:

$$
M_{r}=W_{x} \times f_{y}
$$

em que $Z_{x}$ é o módulo de resistência plástico, $W_{x} 0$ módulo de resistência elástico e $\mathrm{f}_{\mathrm{y}}$ a tensão limite de escoamento.

Além disso, quando a flexo-tração ocorre, após calcular as resistências à tração e ao momento fletor da seção do perfil, é necessário obedecer à equação de interação de flexotração, expostaa a seguir.

$$
\frac{T_{d}}{T_{r}}+\frac{M_{d}}{M_{r}} \leq 1,0
$$

\subsection{Resistências nominais dos modelos}

Nesta seção, serão expostos os resultados para as resistências nominais de cada elemento para os 14 modelos estudados. Para o cálculo destas resistências, o coeficiente $\phi$ é igual a 1, para que as resistências encontradas sejam as mesmas encontradas pelo ANSYS [11], sem considerar coeficientes de redução. A resistência da laje à compressão e ao momento fletor terá sempre o mesmo valor, haja vista que para todos os modelos sua espessura e sua largura efetiva, $100 \mathrm{~mm}$ e $1500 \mathrm{~mm}$ respectivamente, são mantidos constantes. Desta maneira, 
$M_{r c} \cong 46,75 \mathrm{kNm}$ e $C_{r} \cong 1390,46 \mathrm{kN}$ para todos os modelos. Estas informações são apresentadas nas Tabelas 6.1 a 6.14 .

Tabela 6.1. Resistências nominais dos elementos do modelo SGM-1

\begin{tabular}{ccccc}
\hline SGM-1 & \multicolumn{4}{c}{ Resistências Nominais } \\
\hline Viga Mista & $\mathrm{M}_{\mathrm{rc}}(\mathrm{kNm})$ & 166,2 & $\mathrm{~V}_{\mathrm{r}}(\mathrm{kN})$ & 274,3 \\
\hline Stub & - & - & $\mathrm{V}_{\mathrm{hr}}(\mathrm{kN})$ & 765,1 \\
\hline Banzo Inferior & $\mathrm{M}_{\mathrm{rc}}(\mathrm{kNm})$ & 55,8 & $\mathrm{~T}_{\mathrm{r}}(\mathrm{kN})$ & 1000,5 \\
\hline
\end{tabular}

Tabela 6.2. Resistências nominais dos elementos do modelo SGM-2

\begin{tabular}{ccccc}
\hline SGM-2 & \multicolumn{4}{c}{ Resistências Nominais } \\
\hline Viga Mista & $\mathrm{M}_{\mathrm{rc}}(\mathrm{kNm})$ & 205,2 & $\mathrm{~V}_{\mathrm{r}}(\mathrm{kN})$ & 335,4 \\
\hline Stub & - & - & $\mathrm{V}_{\mathrm{hr}}(\mathrm{kN})$ & 924,5 \\
\hline Banzo Inferior & $\mathrm{M}_{\mathrm{rc}}(\mathrm{kNm})$ & 55,8 & $\mathrm{~T}_{\mathrm{r}}(\mathrm{kN})$ & 1000,5
\end{tabular}

Tabela 6.3. Resistências nominais dos elementos do modelo SGM-3

\begin{tabular}{ccccc}
\hline SGM-3 & \multicolumn{4}{c}{ Resistências Nominais } \\
\hline Viga Mista & $\mathrm{M}_{\mathrm{rc}}(\mathrm{kNm})$ & 230,1 & $\mathrm{~V}_{\mathrm{r}}(\mathrm{kN})$ & 357,0 \\
\hline Stub & - & - & $\mathrm{V}_{\mathrm{hr}}(\mathrm{kN})$ & 972,3 \\
\hline Banzo Inferior & $\mathrm{M}_{\mathrm{rc}}(\mathrm{kNm})$ & 55,8 & $\mathrm{~T}_{\mathrm{r}}(\mathrm{kN})$ & 1000,5
\end{tabular}

Tabela 6.4. Resistências nominais dos elementos do modelo SGM-4

\begin{tabular}{ccccc}
\hline SGM-4 & \multicolumn{4}{c}{ Resistências Nominais } \\
\hline Viga Mista & $\mathrm{M}_{\mathrm{rc}}(\mathrm{kNm})$ & 256,6 & $\mathrm{~V}_{\mathrm{r}}(\mathrm{kN})$ & 378,9 \\
\hline Stub & - & - & $\mathrm{V}_{\mathrm{hr}}(\mathrm{kN})$ & 1020,1 \\
\hline Banzo Inferior & $\mathrm{M}_{\mathrm{rc}}(\mathrm{kNm})$ & 55,8 & $\mathrm{~T}_{\mathrm{r}}(\mathrm{kN})$ & 1000,5
\end{tabular}

Tabela 6.5. Resistências nominais dos elementos do modelo SGM-5

\begin{tabular}{ccccc}
\hline SGM-5 & \multicolumn{4}{c}{ Resistências Nominais } \\
\hline Viga Mista & $\mathrm{M}_{\mathrm{rc}}(\mathrm{kNm})$ & 287,8 & $\mathrm{~V}_{\mathrm{r}}(\mathrm{kN})$ & 358,4 \\
\hline Stub & - & - & $\mathrm{V}_{\mathrm{hr}}(\mathrm{kN})$ & 972,3 \\
\hline Banzo Inferior & $\mathrm{M}_{\mathrm{rc}}(\mathrm{kNm})$ & 55,8 & $\mathrm{~T}_{\mathrm{r}}(\mathrm{kN})$ & 1000,5 \\
\hline
\end{tabular}


Tabela 6.6. Resistências nominais dos elementos do modelo SGM-6

\begin{tabular}{ccccc}
\hline SGM-6 & \multicolumn{5}{c}{ Resistências Nominais } \\
\hline Viga Mista & $\mathrm{M}_{\mathrm{rc}}(\mathrm{kNm})$ & 333,1 & $\mathrm{~V}_{\mathrm{r}}(\mathrm{kN})$ & 393,7 \\
\hline Stub & - & - & $\mathrm{V}_{\mathrm{hr}}(\mathrm{kN})$ & 1052,0 \\
\hline Banzo Inferior & $\mathrm{M}_{\mathrm{rc}}(\mathrm{kNm})$ & 55,8 & $\mathrm{~T}_{\mathrm{r}}(\mathrm{kN})$ & 1000,5 \\
\hline
\end{tabular}

Tabela 6.7. Resistências nominais dos elementos do modelo SGM-7

\begin{tabular}{ccccc}
\hline SGM-7 & \multicolumn{5}{c}{ Resistências Nominais } \\
\hline Viga Mista & $\mathrm{M}_{\mathrm{rc}}(\mathrm{kNm})$ & 382,9 & $\mathrm{~V}_{\mathrm{r}}(\mathrm{kN})$ & 460,3 \\
\hline Stub & - & - & $\mathrm{V}_{\mathrm{hr}}(\mathrm{kN})$ & 1211,4 \\
\hline Banzo Inferior & $\mathrm{M}_{\mathrm{rc}}(\mathrm{kNm})$ & 55,8 & $\mathrm{~T}_{\mathrm{r}}(\mathrm{kN})$ & 1000,5
\end{tabular}

Tabela 6.8. Resistências nominais dos elementos do modelo SGM-8

\begin{tabular}{ccccc}
\hline SGM-8 & \multicolumn{4}{c}{ Resistências Nominais } \\
\hline Viga Mista & $\mathrm{M}_{\mathrm{rc}}(\mathrm{kNm})$ & 166,2 & $\mathrm{~V}_{\mathrm{r}}(\mathrm{kN})$ & 274,3 \\
\hline Stub & - & - & $\mathrm{V}_{\mathrm{hr}}(\mathrm{kN})$ & 765,1 \\
\hline Banzo Inferior & $\mathrm{M}_{\mathrm{rc}}(\mathrm{kNm})$ & 121,3 & $\mathrm{~T}_{\mathrm{r}}(\mathrm{kN})$ & 1649,1 \\
\hline
\end{tabular}

Tabela 6.9. Resistências nominais dos elementos do modelo SGM-9

\begin{tabular}{ccccc}
\hline SGM-9 & \multicolumn{4}{c}{ Resistências Nominais } \\
\hline Viga Mista & $\mathrm{M}_{\mathrm{rc}}(\mathrm{kNm})$ & 205,2 & $\mathrm{~V}_{\mathrm{r}}(\mathrm{kN})$ & 335,4 \\
\hline Stub & - & - & $\mathrm{V}_{\mathrm{hr}}(\mathrm{kN})$ & 924,5 \\
\hline Banzo Inferior & $\mathrm{M}_{\mathrm{rc}}(\mathrm{kNm})$ & 121,3 & $\mathrm{~T}_{\mathrm{r}}(\mathrm{kN})$ & 1649,1 \\
\hline
\end{tabular}

Tabela 6.10. Resistências nominais dos elementos do modelo SGM-10

\begin{tabular}{ccccc}
\hline SGM-10 & \multicolumn{4}{c}{ Resistências Nominais } \\
\hline Viga Mista & $\mathrm{M}_{\mathrm{rc}}(\mathrm{kNm})$ & 230,1 & $\mathrm{~V}_{\mathrm{r}}(\mathrm{kN})$ & 357,0 \\
\hline Stub & - & - & $\mathrm{V}_{\mathrm{hr}}(\mathrm{kN})$ & 972,3 \\
\hline Banzo Inferior & $\mathrm{M}_{\mathrm{rc}}(\mathrm{kNm})$ & 121,3 & $\mathrm{~T}_{\mathrm{r}}(\mathrm{kN})$ & 1649,1 \\
\hline
\end{tabular}


Tabela 6.11. Resistências nominais dos elementos do modelo SGM-11

\begin{tabular}{ccccc}
\hline SGM-11 & \multicolumn{4}{c}{ Resistências Nominais } \\
\hline Viga Mista & $\mathrm{M}_{\mathrm{rc}}(\mathrm{kNm})$ & 256,6 & $\mathrm{~V}_{\mathrm{r}}(\mathrm{kN})$ & 378,9 \\
\hline Stub & - & - & $\mathrm{V}_{\mathrm{hr}}(\mathrm{kN})$ & 1020,1 \\
\hline Banzo Inferior & $\mathrm{M}_{\mathrm{rc}}(\mathrm{kNm})$ & 121,3 & $\mathrm{~T}_{\mathrm{r}}(\mathrm{kN})$ & 1649,1 \\
\hline
\end{tabular}

Tabela 6.12. Resistências nominais dos elementos do modelo SGM-12

\begin{tabular}{ccccc}
\hline SGM-12 & \multicolumn{4}{c}{ Resistências Nominais } \\
\hline Viga Mista & $\mathrm{M}_{\mathrm{rc}}(\mathrm{kNm})$ & 287,8 & $\mathrm{~V}_{\mathrm{r}}(\mathrm{kN})$ & 358,4 \\
\hline Stub & - & - & $\mathrm{V}_{\mathrm{hr}}(\mathrm{kN})$ & 972,3 \\
\hline Banzo Inferior & $\mathrm{M}_{\mathrm{rc}}(\mathrm{kNm})$ & 121,3 & $\mathrm{~T}_{\mathrm{r}}(\mathrm{kN})$ & 1649,1 \\
\hline
\end{tabular}

Tabela 6.13. Resistências nominais dos elementos do modelo SGM-13

\begin{tabular}{ccccc}
\hline SGM-13 & \multicolumn{4}{c}{ Resistências Nominais } \\
\hline Viga Mista & $\mathrm{M}_{\mathrm{rc}}(\mathrm{kNm})$ & 333,1 & $\mathrm{~V}_{\mathrm{r}}(\mathrm{kN})$ & 393,7 \\
\hline Stub & - & - & $\mathrm{V}_{\mathrm{hr}}(\mathrm{kN})$ & 1052,0 \\
\hline Banzo Inferior & $\mathrm{M}_{\mathrm{rc}}(\mathrm{kNm})$ & 121,3 & $\mathrm{~T}_{\mathrm{r}}(\mathrm{kN})$ & 1649,1 \\
\hline
\end{tabular}

Tabela 6.14. Resistências nominais dos elementos do modelo SGM-14

\begin{tabular}{ccccc}
\hline SGM-14 & \multicolumn{5}{c}{ Resistências Nominais } \\
\hline Viga Mista & $\mathrm{M}_{\mathrm{rc}}(\mathrm{kNm})$ & 382,9 & $\mathrm{~V}_{\mathrm{r}}(\mathrm{kN})$ & 460,3 \\
\hline Stub & - & - & $\mathrm{V}_{\mathrm{hr}}(\mathrm{kN})$ & 1211,4 \\
\hline Banzo Inferior & $\mathrm{M}_{\mathrm{rc}}(\mathrm{kNm})$ & 121,3 & $\mathrm{~T}_{\mathrm{r}}(\mathrm{kN})$ & 1649,1 \\
\hline
\end{tabular}

Estas resistências são importantes, pois através de seus valores, foram descobertas as cargas máximas para cada modelo. Estas cargas foram comparadas com as cargas máximas obtidas no Capítulo 4 e estão expostas na Tabela 6.15. 
Tabela 6.15. Cargas máximas possíveis encontradas para os modelos

\begin{tabular}{ccc}
\hline Modelo & $\mathrm{F}_{\mathrm{w}-\text { ANSYS }(\mathrm{kN})}$ & $\begin{array}{c}\text { Carga máxima } \\
\text { FTOOL }(\mathrm{kN})\end{array}$ \\
\hline SGM-1 & 163,1 & 174,4 \\
\hline SGM-2 & 194,78 & 203,5 \\
\hline SGM-3 & 207,40 & 205,3 \\
\hline SGM-4 & 214,42 & 205,3 \\
\hline SGM-5 & 234,00 & 205,3 \\
\hline SGM-6 & 237,24 & 205,3 \\
\hline SGM-7 & 235,24 & 205,3 \\
\hline SGM-8 & 142,42 & 174,4 \\
\hline SGM-9 & 191,16 & 216,0 \\
\hline SGM-10 & 219,0 & 240,0 \\
\hline SGM-11 & 253,20 & 270,1 \\
\hline SGM-12 & 291,12 & 302,94 \\
\hline SGM-13 & 311,58 & 317,00 \\
\hline SGM-14 & 343,69 & 317,00 \\
\hline & & \\
\hline & & \\
\hline
\end{tabular}

As discrepâncias entre os resultados obtidos no ANSYS e no FTOOL são da ordem de $10 \%$ e podem ser consideradas aceitáveis. Ocorre que para o modelo tridimensional, realizado no ANSYS, pode ocorrer efeitos considerados fora do plano, enquanto no modelo simplificado, apenas efeitos no plano são considerados. Além disso, como observado na discussão ocorrida no Capítulo 5, no modelo simplificado os comprimentos do banzo inferior, banzo superior e viga mista são maiores que os apresentados no modelo tridimensional, o que afetará os resultados.

Ainda sob esse ponto de vista, a transmissão de esforços entre banzo inferior e banzo superior acontece de forma mais natural nos modelos executados no ANSYS, visto que o fluxo de tensões é mais próximo da realidade nestes modelos quando comparados aos modelos simplificados executados no software FTOOL. Ainda assim, os resultados são considerados satisfatórios e no próximo capítulo será analisado um pavimento tipo formado por vigas secundárias consideradas stubgirders modificados. 


\subsection{Projeto de um pavimento de edifício de múltiplos andares}

O procedimento de projeto apresentado na seção 6.1 será utilizado para uso em um pavimento de edifício de múltiplos andares, cuja planta baixa é mostrada na Figura 6.2 e tem área total de $80 \mathrm{~m}^{2}$. A espessura da laje maciça é igual a $120 \mathrm{~mm}$ para vãos de laje de $4.000 \mathrm{~mm}$ e posteriormente comparado a um pavimento de mesma área calculado apenas com vigas mistas tradicionais.

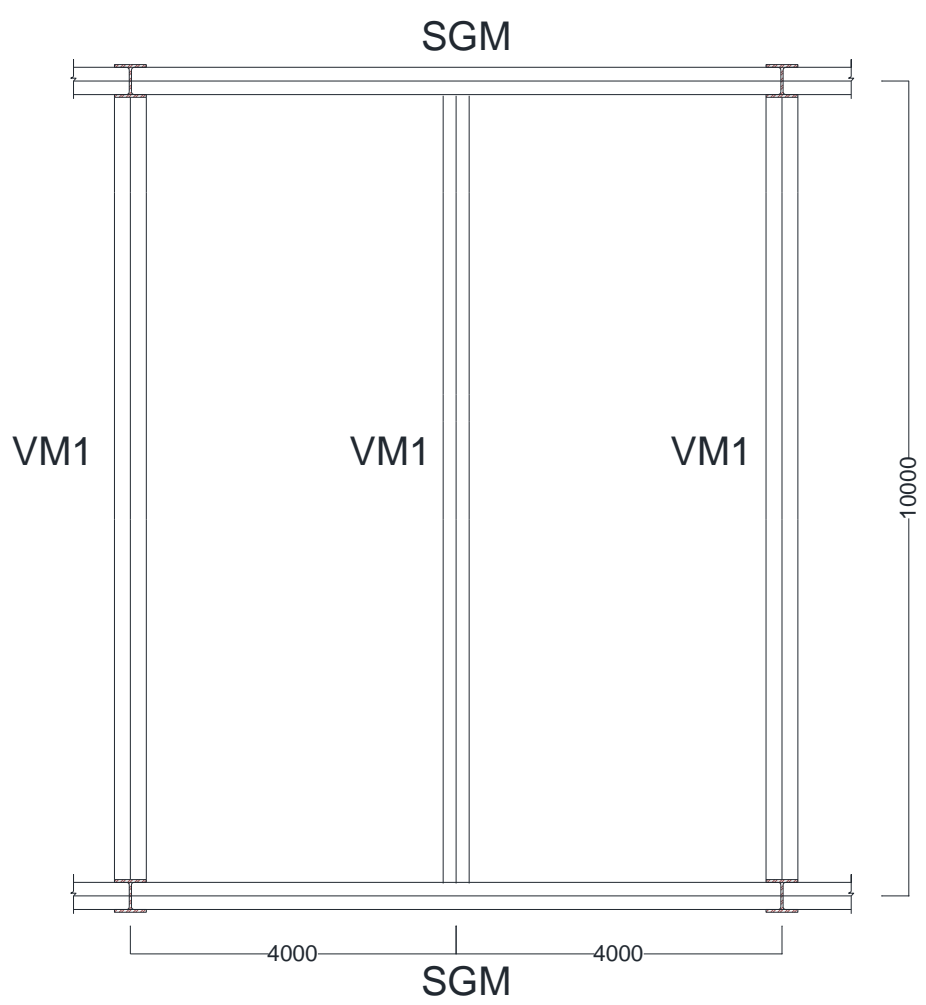

Figura 6.2. Planta baixa de um pavimento de edifício de múltiplos andares

Para este pavimento, serão estudados diversos carregamentos distribuídos e calculadas as seções dos perfis das vigas SGM e VM1. Os carregamentos são mostrados na Tabela 6.16. 
Tabela 6.16. Carregamentos distribuídos analisados

\begin{tabular}{cc}
\hline Configuração & $\begin{array}{c}\text { Carregamento fatorado } \\
\left(\mathrm{kN} / \mathrm{m}^{2}\right)\end{array}$ \\
\hline 1 & 9,0 \\
\hline 2 & 10,5 \\
\hline 3 & 12,0
\end{tabular}

\subsubsection{Stub-girder modificado (SGM)}

Primeiramente serão projetadas as vigas SGM, formadas pelo sistema modificado. A carga aplicada no centro da viga será igual à soma das reações de apoio das vigas mistas VM1, dada por $P=2 \times \frac{q_{d}}{2} \times L \times A_{i}$, onde L é o vão da viga VM1 e $A_{i}$ a sua área de influência (neste caso, igual a 4 metros). A viga tem vão total igual a 8 metros, largura da abertura de $1.280 \mathrm{~mm}$ e stubs com comprimento de $900 \mathrm{~mm}$.

Como primeiro passo, recomenda-se escolher a altura do perfil que compõe a viga mista. O momento fletor máximo nesta seção é dado por $M_{d}=L_{v m} \times \frac{P}{2}$.

Em que $\mathrm{M}_{\mathrm{d}}$ é o momento solicitante, $\mathrm{P}$ é a carga no centro da viga e $\mathrm{L}_{\mathrm{vm}}$ é o comprimento da viga mista, neste caso igual a 2,46 metros.

Tabela 6.17. Seções escolhidas para o stub misto

\begin{tabular}{ccccccc}
$\begin{array}{c}\text { Configu- } \\
\text { ração }\end{array}$ & $\begin{array}{c}\text { Carregamento } \\
\mathrm{q}_{\mathrm{d}}\left(\mathrm{kN} / \mathrm{m}^{2}\right)\end{array}$ & $\begin{array}{c}\text { Carga } \\
\text { aplicada } \\
(\mathrm{kN})\end{array}$ & $\begin{array}{c}\text { Momento } \\
\text { Solicitante } \\
(\mathrm{kN} . \mathrm{m})\end{array}$ & $\begin{array}{c}\text { Seção dos } \\
\text { stubs (viga } \\
\text { mista em } \\
\text { SGM) }\end{array}$ & $\begin{array}{c}\text { Momento } \\
\text { Resistente }\end{array}$ & $\begin{array}{c}\text { Taxa de } \\
\text { utilização }\end{array}$ \\
\hline 1 & 9,0 & 360,0 & 442,8 & W410x38,8 & 460,2 & 96,2 \\
\hline 2 & 10,5 & 420,0 & 516,6 & W410x46,1 & 537,2 & 96,2 \\
\hline 3 & 12,0 & 480,0 & 590,4 & W410x53,0 & 611,0 & 96,6
\end{tabular}

Com a conclusão desta etapa, pode-se montar o modelo plano dos sistemas no software Ftool [10], em que a altura da corda inferior será de 200 mm. A próxima 
etapa é a sua verificação, que está sujeita à flexo-tração. A Tabela 6.18 apresenta as seções selecionadas para cada configuração.

Tabela 6.18. Seções escolhidas para a corda inferior

\begin{tabular}{cccccc}
\hline $\begin{array}{c}\text { Configu- } \\
\text { ração }\end{array}$ & $\begin{array}{c}\text { Carregamento } \\
\mathrm{q}_{\mathrm{d}}\left(\mathrm{kN} / \mathrm{m}^{2}\right)\end{array}$ & $\begin{array}{c}\text { Tração } \\
\text { Solicitante } \\
(\mathrm{kN})\end{array}$ & $\begin{array}{c}\text { Momento } \\
\text { Solicitante } \\
(\mathrm{kN} . \mathrm{m})\end{array}$ & $\begin{array}{c}\text { Seção da } \\
\text { corda }\end{array}$ & $\begin{array}{c}\text { Taxa de } \\
\text { utilização } \\
(\%)\end{array}$ \\
\hline 1 & 9,0 & 1065,5 & 48,0 & W200x46,1 & 93,1 \\
\hline 2 & 10,5 & 1243,0 & 60,4 & W200x52,0 & 93,8 \\
\hline 3 & 12,0 & 1422,0 & 73,9 & W200x59,0 & 96,5 \\
\hline
\end{tabular}

A terceira etapa consiste na verificação da resistência da laje de concreto, que está sujeita à flexo-compressão. A Tabela 6.19 apresenta os resultados obtidos.

Tabela 6.19. Verificação da laje de concreto

\begin{tabular}{cccccc}
\hline $\begin{array}{c}\text { Configu- } \\
\text { ração }\end{array}$ & $\begin{array}{c}\text { Carregamento } \\
\mathrm{q}_{\mathrm{d}}\left(\mathrm{kN} / \mathrm{m}^{2}\right)\end{array}$ & $\begin{array}{c}\text { Compressão } \\
\text { Solicitante } \\
(\mathrm{kN})\end{array}$ & $\begin{array}{c}\text { Momento } \\
\text { Solicitante } \\
(\mathrm{kN} . \mathrm{m})\end{array}$ & $\begin{array}{c}\text { Seção da } \\
\text { laje de } \\
\text { concreto }\end{array}$ & $\begin{array}{c}\text { Taxa de } \\
\text { utilização } \\
(\%)\end{array}$ \\
\hline 1 & 9,0 & 1065,5 & 48,8 & $2000 \times 120$ & 65,0 \\
\hline 2 & 10,5 & 1243,0 & 51,8 & $2000 \times 120$ & 69,0 \\
\hline 3 & 12,0 & 1422,0 & 53,8 & $2000 \times 120$ & 72,0
\end{tabular}

Por fim, deve ser feita a verificação dos stubs aos esforços cortantes horizontais. Os resultados são apresentados na Tabela 6.20.

Tabela 6.20. Verificação da resistência dos stubs

\begin{tabular}{cccccc}
\hline $\begin{array}{c}\text { Configu } \\
\text {-ração }\end{array}$ & $\begin{array}{c}\text { Carregamento } \\
\mathrm{q}_{\mathrm{d}}\left(\mathrm{kN} / \mathrm{m}^{2}\right)\end{array}$ & $\begin{array}{c}\text { Cortante } \\
\text { horizontal } \\
\text { Solicitante } \\
(\mathrm{kN})\end{array}$ & $\begin{array}{c}\text { Seção dos } \\
\text { stubs }\end{array}$ & $\begin{array}{c}\text { Cortante } \\
\text { horizontal } \\
\text { resistente }\end{array}$ & $\begin{array}{c}\text { Taxa de } \\
\text { utilização } \\
(\%)\end{array}$ \\
\hline 1 & 9,0 & 1065,5 & W410x38,8 & 1108,6 & 96,1 \\
\hline 2 & 10,5 & 1243,0 & W410x46,1 & 1291,1 & 96,3 \\
\hline 3 & 12,0 & 1422,0 & W410x53,0 & 1495,0 & 95,1
\end{tabular}




\subsubsection{Vigas mistas VM1}

As vigas mistas VM1 são calculadas como vigas mistas biapoiadas, ocorrendo em seu centro o momento máximo, $M_{v s}=\frac{q \times L^{2}}{8}$, sendo $\mathrm{q}$ o carregamento linear em kN/m e L é o seu vão livre (10 metros). A Tabela 6.21 apresenta os momentos solicitantes, bem como os carregamentos utilizados e a resistência da seção do perfil escolhido, calculada conforme 6.2.1.

Tabela 6.21. Seção das vigas mistas VM1

\begin{tabular}{|c|c|c|c|c|c|}
\hline Configuração & $\begin{array}{c}\text { Seção do } \\
\text { perfil VM1 }\end{array}$ & $\begin{array}{c}\text { Carregamento } \\
\qquad(\mathrm{kN} / \mathrm{m})\end{array}$ & $\begin{array}{c}\text { Momento } \\
\text { Solicitante } \\
\text { (kN.m) }\end{array}$ & $\begin{array}{c}\text { Momento } \\
\text { Resistente } \\
\text { (kN.m) }\end{array}$ & $\begin{array}{l}\text { T.U. } \\
(\%)\end{array}$ \\
\hline 1 & W410x38,8 & 36,0 & 450,0 & 460,2 & 97,7 \\
\hline 2 & W410x46,1 & 42,0 & 525,0 & 537,2 & 97,7 \\
\hline 3 & W410x53,0 & 48,0 & 600,0 & 611,0 & 98,1 \\
\hline
\end{tabular}

\subsubsection{Vigas mistas tradicionais}

O mesmo pavimento foi projetado utilizando apenas vigas mistas. A Figura 6.3 apresenta o pavimento.

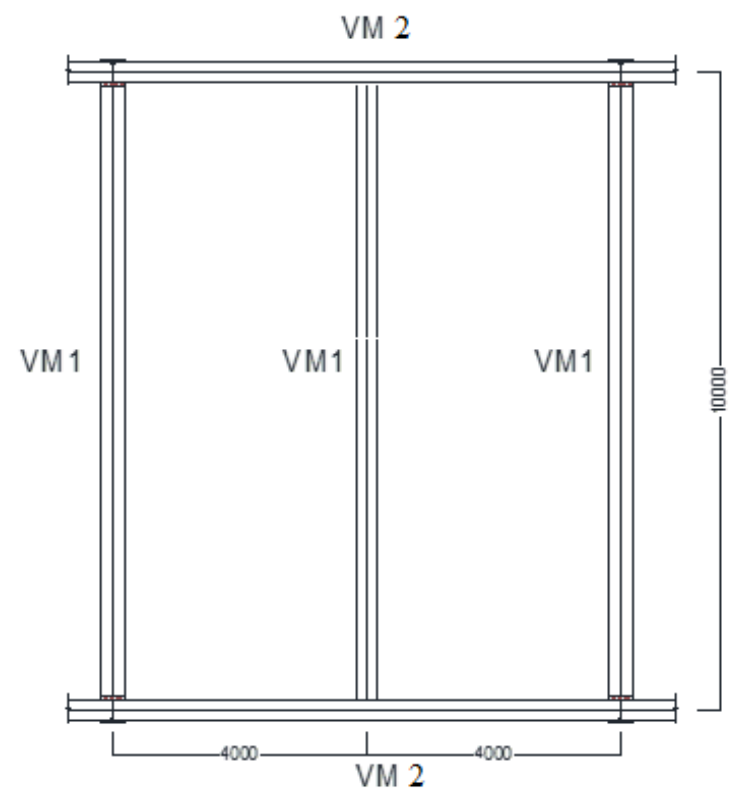

Figura 6.3. Pavimento calculado com uso de vigas mistas tradicionais 
As vigas VM1 são as mesmas para ambos os pavimentos. $\mathrm{O}$ material utilizado para ambas é o exposto na Tabela 6.21. As vigas VM2 recebem as reações de apoio das vigas VM1, que resultam nas mesmas cargas aplicadas no sistema modificado projetado no item anterior. O momento é dado por $M_{2}=\frac{2 \times R_{v m 1} \times L}{4}$. As resistências destas vigas são calculadas conforme 6.2.1 e os resultados apresentados na Tabela 6.22.

Tabela 6.22. Seção das vigas mistas VM2

\begin{tabular}{cccccc}
\hline Configuração & $\begin{array}{c}\text { Carga } \\
\text { aplicada } \\
(\mathrm{kN})\end{array}$ & $\begin{array}{c}\text { Seção do } \\
\text { perfil VM2 }\end{array}$ & $\begin{array}{c}\text { Momento } \\
\text { Solicitante } \\
(\mathrm{kN} . \mathrm{m})\end{array}$ & $\begin{array}{c}\text { Momento } \\
\text { Resistente } \\
(\mathrm{kN} . \mathrm{m})\end{array}$ & $\begin{array}{c}\text { T.U. } \\
(\%)\end{array}$ \\
\hline 1 & 360,0 & W460x60,0 & 720,0 & 733,0 & 98,2 \\
\hline 2 & 420,0 & W530x66 & 840,0 & 885,6 & 94,8 \\
\hline 3 & 480,0 & W530x74 & 960,0 & 996,5 & 96,3 \\
\hline \multirow{\delta}{\sigma}{} & & & &
\end{tabular}

\subsubsection{Discussão de resultados}

Foi calculado o consumo de aço para cada uma das configurações de carregamento fatorado aplicado no pavimento para os casos e a taxa de consumo de aço por metro quadrado sendo apresentada nas Tabelas 6.23 e 6.24 .

Tabela 6.23. Taxa de consumo de aço com uso do sistema modificado

\begin{tabular}{ccccc}
\hline & SGM & VM1 & $\begin{array}{r}\text { Peso } \\
\text { total } \\
\text { Configuração }\end{array}$ & $\begin{array}{c}\text { Taxa de Consumo de } \\
\text { aço }\left(\mathrm{kg} / \mathrm{m}^{2}\right)\end{array}$ \\
\cline { 2 - 4 } & \multicolumn{2}{c}{ Peso $(\mathrm{kg})$} & & \\
\hline 1 & 402,7 & 776,0 & 1178,7 & 14,73 \\
\hline 2 & 470,0 & 922,0 & 1392,0 & 17,40 \\
\hline 3 & 537,9 & 1060,0 & 1597,9 & 19,97 \\
\hline
\end{tabular}


Tabela 6.24. Taxa de consumo de aço com vigas mistas tradicionais

\begin{tabular}{|c|c|c|c|c|}
\hline \multirow[b]{2}{*}{ Configuração } & VM2 & VM1 & \multirow{2}{*}{$\begin{array}{l}\text { Peso } \\
\text { total } \\
(\mathrm{kg})\end{array}$} & \multirow{2}{*}{$\begin{array}{l}\text { Taxa de Consumo de } \\
\text { aço }\left(\mathrm{kg} / \mathrm{m}^{2}\right)\end{array}$} \\
\hline & \multicolumn{2}{|c|}{ Peso (kg) } & & \\
\hline 1 & 480,0 & 776,0 & 1256,0 & 15,70 \\
\hline 2 & 528,0 & 922,0 & 1450,0 & 18,12 \\
\hline 3 & 592,0 & 1060,0 & 1652,0 & 20,65 \\
\hline
\end{tabular}

Figura 6.4. Peso do pavimento em função do carregamento distribuído

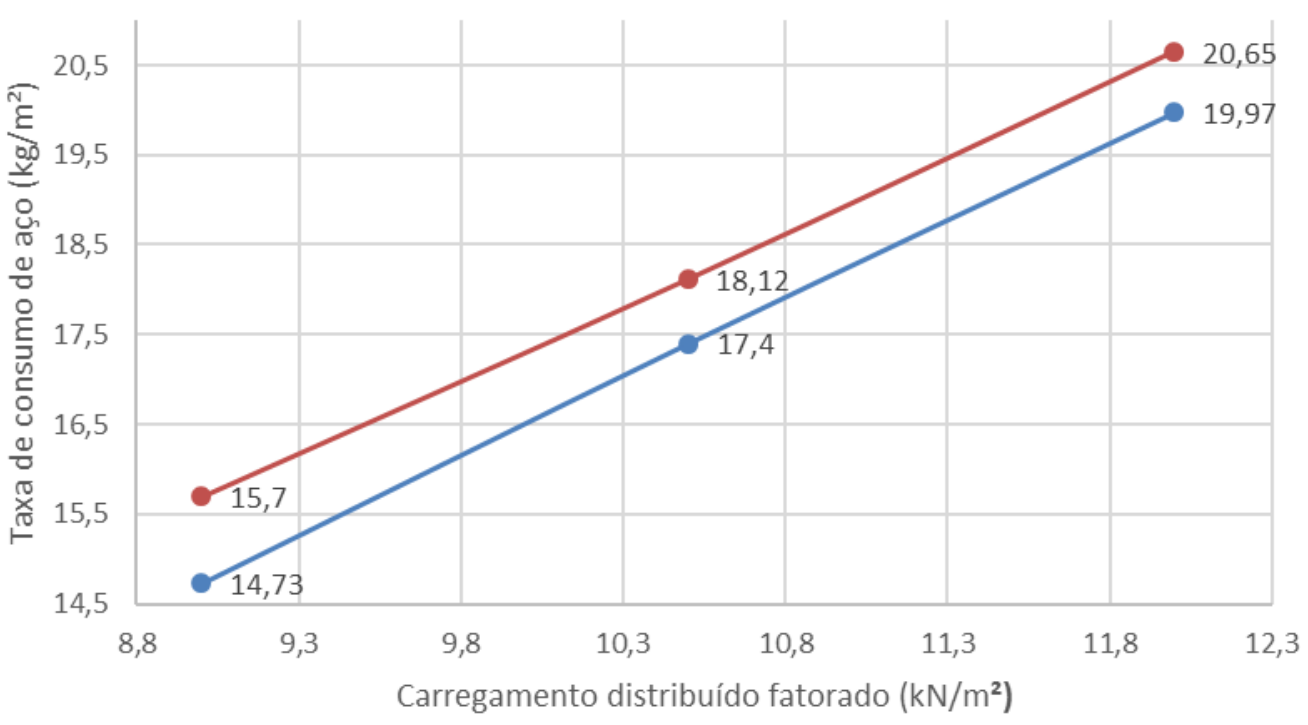

A solução com uso do stub-girder modificado mostrou-se ser mais econômica que a solução com uso de vigas mistas tradicionais. Apesar da diferença de altura entre ambas (de $150 \mathrm{~mm}$ no pior caso), o uso do sistema stub-girder modificado é justificado pela economia de material e a vantagem de possuir aberturas inerentes a si, facilitando a instalação de serviços como dutos e tubulações. 


\section{7 \\ Considerações finais}

\subsection{Conclusões}

No presente trabalho foi realizado um estudo sobre o comportamento estrutural do sistema de vigamento de piso tipo stub-girder de geometria modificada. Foi executada uma análise de tensões e deformações com uso do software ANSYS [11]. Inicialmente procurou-se entender o comportamento do sistema, incluindo controle de deformações e avaliação das seções de resistência críticas do mesmo, sendo a plastificação monitorada por meio do critério de Von Mises. Foram calculadas as cargas limite de serviço e máximas para os 14 modelos estudados.

Por meio do software FTOOL, foi criado um modelo plano unifilar, buscando assim, obter os resultados para deslocamentos e esforços solicitantes de maneira simplificada. Por meio de comparativos entre o modelo plano e o modelo sólido tridimensional executado no ANSYS, verificou-se que esforços e deslocamentos podem ser obtidos no regime linear-elástico por meio do FTOOL. As discrepâncias entre os dois modelos foram desprezíveis para a prática de projeto estrutural.

As recomendações de projeto do sistema foram feitas de acordo com a norma CAN S16-10, por meio do método dos estados limites e o resultado foi satisfatório, pois as discrepâncias entre as cargas de serviço obtidas pelo modelo plano e modelo sólido são muito pequenas e as seções críticas do sistema modificado são as mesmas para ambos os modelos. Um pavimento de edifício de múltiplos andares foi estudado com uso do sistema modificado e vigas mistas convencionais, tendo sido obtidos resultados satisfatórios quanto ao peso total da estrutura, mostrando assim a viabilidade do uso prático do sistema stub-girder modificado. É importante salientar que pelo fato de o sistema modificado ser formado por dois tipos diferentes de perfil, existe a possibilidade de emprego de diferentes configurações de estruturas as quais podem fornecer resistências satisfatórias e economia de material, bem como facilidade de instalação de serviços, tais como dutos e tubulações, que podem passar pelas aberturas da viga stub-girder. 
Além disso, o sistema tipo stub-girder modificado apresenta a vantagem de permitir a reutilização de pequenos comprimentos de perfis que sobram no processo normal de fabricação. A facilidade da montagem do sistema, que funciona a partir da variação do momento de inércia em sua extensão é outro ponto importante, já que tal montagem é mais rápida e mais barata quando comparada às vigas de inércia variável formadas por perfis $\mathrm{W}$.

Em virtude do que foi abordado, conclui-se que o sistema pode ser utilizado na prática de construção de edifícios de múltiplos andares em substituição às vigas mistas tradicionais. Contudo, são necessárias análises mais aprofundadas no que diz respeito à altura dos perfis, largura da abertura e da região de solda, espessura da laje e vão total para que sejam obtidas as especificações que farão com que o sistema seja o mais econômico possível e ofereça resistência e rigidez satisfatórias.

\subsection{Sugestões para trabalhos futuros}

A seguir são propostos temas para trabalhos futuros com o objetivo de dar continuidade à linha de estudo da presente pesquisa.

- Estudar o sistema stub-girder modificado de maneira que não seja necessária a interação total entre o aço e a laje de concreto;

- Estudar a ligação entre stubs e corda inferior, de maneira a encontrar o comprimento ideal dos filetes de solda necessários para tal ligação;

- Avaliar a relação entre a largura da abertura e as seções críticas do sistema, visando fazer com que todas as seções do sistema trabalhem de maneira a chegar às cargas críticas simultaneamente; 


\section{Referências bibliográficas}

1 Colaco, J. P., 1972, Stub-girder system for high-rise buildings. Engineering Journal-American Institute of Steel Construction Inc, Vol. 9, pp. 89-95.

2 Ritchie, J. K., Chien, E. Y. L., 2008, Design and Construction of Composite Floor Systems. CISC, 323 p.

3 Canadian Standard Association, 2010. S-16-10, Design of Steel Structures, $174 \mathrm{p}$.

4 Harbok, M. M., Hosain, M. U., 1978, Analysis of stub-girder using substructuring, Comput. Struct. 8 615-619.

5 Faria, M. J. R. S., 1992, Comportamento e projeto de sistemas de vigamento de piso tipo 'stub-girder', PUC-Rio.

6 Ritchie, J. K., Chien, E. Y. L., 1993, Composite floor systems - a mature option, Journal of Construction and research, 25 (1-2).

7 Wang, C. M., Padmanaban, K., Shnanmagon, N. E., 1995, Ultimate strength analisys of stub-girders, ASCE Journal of Structural Engineering, 121 (9).

8, 9 Ismail, R. E. S., El-katt, M. T., ZienEldin, H. A., Kasem, Y. M., 2007, Behavior of multi-layer composite stub-girder. 6th International Alexandria Conference on Structural and Geotechnical Engineering, Alexandria, Egypt.

10 Martha, L. F., 2002. Ftool - Two Dimensional Frame Analysis Tool.

11 ANSYS 15.0 ®, 2014. ANSYS - Inc. Theory Reference.

12 ABNT, 2008 - NBR-8800. Projeto de estruturas de aço e de estruturas mistas de aço e concreto em edifícios, 237 p.

13 Hill, R., 1983. The Mathematical Theory of Plasticity. New York: Oxford University Press. 355 p.

14 von Mises, R. (1913). Mechanik der festen Körper im plastisch deformablen Zustand. Göttin. Nachr. Math. Phys., vol. 1 p. 582-592.

15 Kennedy, D. J. Z., 2000, Notas de aula do curso de pós-graduação da PUCRio. 